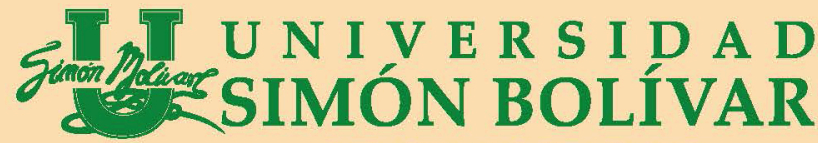

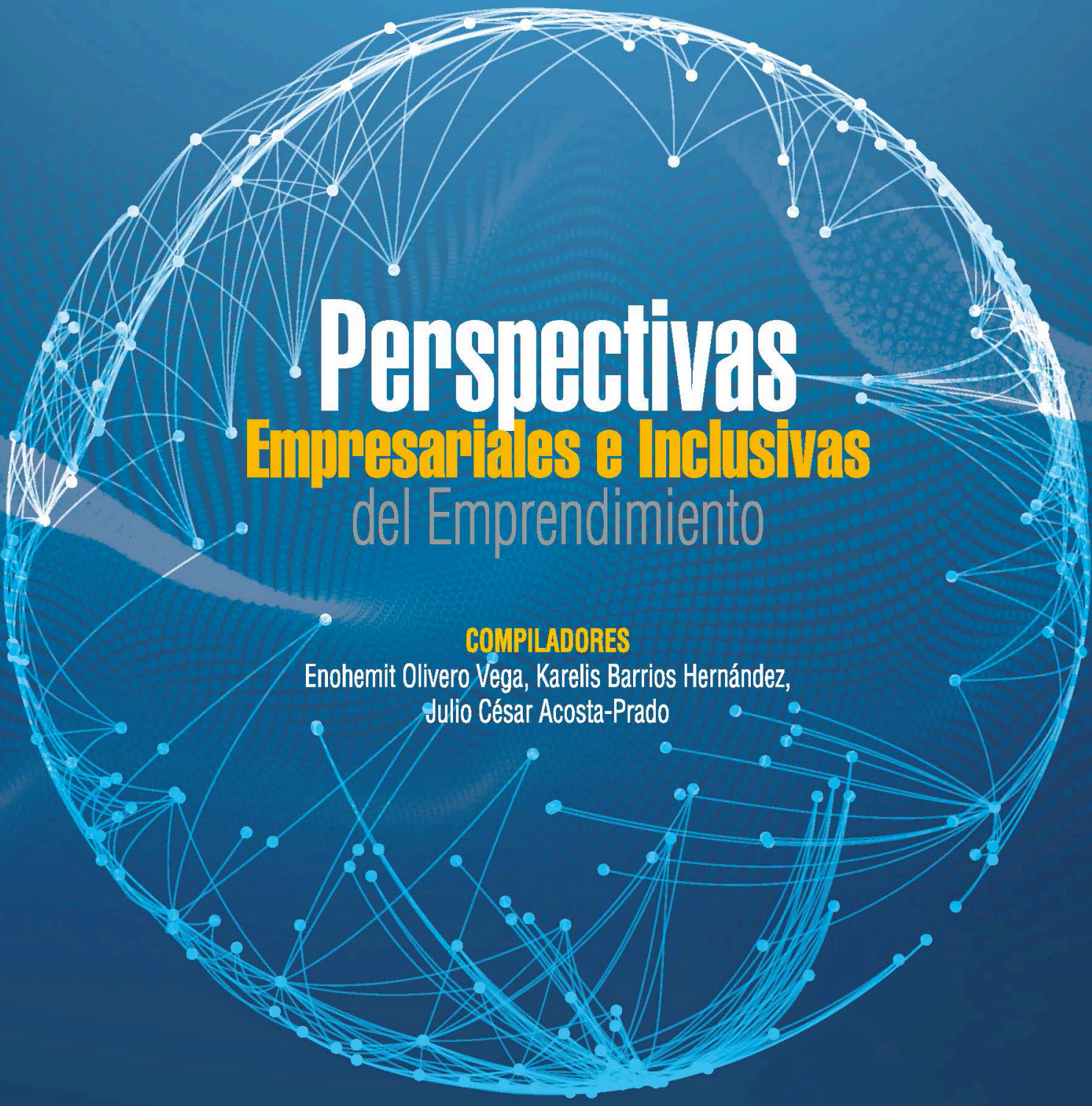

averifituse 


\section{Perspectivas \\ Empresarpiales e Inclusivas \\ del Emprendimiento}




\section{PERSPECTIVAS EMPRESARIALES E INCLUSIVAS DEL}

\section{EMPRENDIMIENTO}

(C) Enohemit Olivero Vega - Karelis Barrios Hernández - Julio César Acosta-Prado Narledis Núñez Bravo - Carlos Miranda Medina - Ricardo Prada Ospina - Duván Emilio Ramírez Ospina - José María Mendoza - Ronald Prieto Pulido - Carlos Osorio Torres - Lilibeth Sánchez Güette - Yarelis Lara Rodríguez - Carla Palacio Orozco - Doniphane Romain Amaury Meslier - Annherys Paz Marcano - Vanessa Sotelo Berrio - Félix Franco Segovia

Compiladores: Enohemit Olivero Vega - Karelis Barrios Hernández Julio César Acosta-Prado

Facultad Administración y Negocios

Grupo de Investigación Pensamiento Contable y Gestión Internacional

Director: Milena Isabel Zabaleta De Armas

Proceso de arbitraje doble ciego

Recepción: Mayo de 2016

Evaluación de propuesta de obra: Julio de 2016

Evaluación de contenidos: Septiembre de 2016

Correcciones de autor: Noviembre de 2016

Aprobación: Enero de 2017 


\section{Sinon PT: U N I V E R S I D A D SIMÓN BOLIVAR}

BARRANQUILLA Y CÚCUTA - COLOMBIA

Enohemit Olivero Vega, Karelis Barrios Hernández, Julio César Acosta-Prado, Narledis Núñez Bravo, Carlos Miranda Medina, Ricardo Prada Ospina, Duván Emilio Ramírez Ospina, José María

Mendoza, Ronald Prieto Pulido, Carlos Osorio Torres, Lilibeth Sánchez Güette, Yarelis Lara Rodríguez, Carla Palacio Orozco, Doniphane Romain Amaury Meslier, Annherys Paz Marcano, Vanessa Sotelo Berrío, Félix Franco Segovia.

\section{Penspertivas Empresarpiales e Inclusivas del Emprendimiento}

\section{COMPILADORES}

Enohemit Olivero Vega, Karelis Barrios Hernández, Julio César Acosta-Prado 
Perspectivas empresariales e inclusivas del emprendimiento / compiladores Enohemit Olivero Vega, Karelis Barrios Hernández, Julio César Acosta-Prado; Narledis Núñez Bravo [y otros 16] -Barranquilla: Ediciones Universidad Simón Bolívar, 2017.

177 páginas; ilustraciones; $17 \times 24 \mathrm{~cm}$

ISBN: 978-958-5430-12-9

1. Liderazgo 2. Cambio organizacional 3. Empresarios industriales 4. Formación profesiona 5. Planificación estratégica 6. Industrias - Innovaciones tecnológicas I. Olivero Vega, Enohemit, compilador-autor II. Barrios Hernández, Karelis, compilador-autor III. Acosta-Prado, Julio César, compilador-autor IV. Núñez Bravo, Narledis V. Miranda Medina, Carlos VI. Prada Ospina, Ricardo VII. Ramírez Ospina, Duván Emilio VIII. Mendoza, José María IX. Prieto Pulido, Ronald X. Osorio Torres, Carlos XI. Sánchez Güette, Lilibeth XII. Lara Rodríguez, Yarelis XIII. Palacio Orozco, Carla XIV. Amaury Meslier, Doniphane Romain XV. Paz Marcano, Annherys XVI. Sotelo Berrio, Vanessa XVII. Franco Segovia, Félix XVIII. Tít.

658.4 P467 2017 Sistema de Clasificación Decimal Dewey 22a edición Universidad Simón Bolívar - Sistema de Bibliotecas

Impreso en Barranquilla, Colombia. Depósito legal según el Decreto 460 de 1995. El Fondo Editorial Ediciones Universidad Simón Bolívar se adhiere a la filosofia del acceso abierto y permite libremente la consulta, descarga, reproducción o enlace para uso de sus contenidos, bajo una licencia Creative Commons Atribución 4.0 Internacional. https://creativecommons.org/licenses/by/4.0/

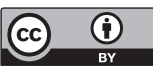

CEdiciones Universidad Simón Bolívar

Carrera 54 No. $59-102$

http://publicaciones.unisimonbolivar.edu.co/edicionesUSB/

dptopublicaciones@unisimonbolivar.edu.co

Barranquilla - Cúcuta

Producción Editorial

Editorial Mejoras

Calle 58 No. $70-30$

info@editorialmejoras.co

www.editorialmejoras.co

Marzo de 2017

Barranquilla

Made in Colombia

\section{Cómo citar este libro:}

Olivero Vega, E., Barrios Hernández, K., Acosta-Prado, C., Núñez Bravo, N., Miranda Medina, C., Prada Ospina, R., . . O Osorio Torres, C. (2017). En E. Olivero Vega, K. Barrios Hernández, C. Acosta-Prado, N. Núñez Bravo, C. Miranda Medina, R. Prada Ospina, ... C. Osorio Torres, E. Olivero Vega, K. Barrios Hernández, \& J. C. Acosta-Prado (Comp.), Perspectivas Empresariales e Inclusivas del Emprendimiento. Barranquilla: Ediciones Universidad Simón Bolívar. 


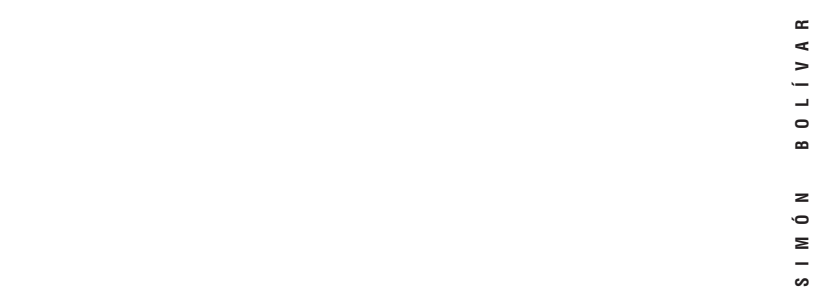

CONTENIDO

Introducción

Prólogo

El intraemprendimiento y su impacto en el desarrollo del sector de autopartes colombiano.

The intrapreneurship and its impact on the development of the colombian auto parts sector

Identificación del perfil emprendedor para el desarrollo del emprendimiento.

Identification of the entrepreneurial profile for the development of the entrepreneur

Influencia del liderazgo sobre el emprendimiento innovador en nuevas empresas de base tecnológica.

Un estudio de casos basado en el enfoque de gestión del conocimiento.

Influence of leadership on innovative entrepreneurship in new technology based firm. A case study based on the knowledge management approach

Emprender después de una discapacidad Undertake ofter a disability

Emprendimiento Social. Mecanismo Integrador de las empresas mixtas petroleras

Social enterprise. Integrated mechanism of mixed oil companies

Acerca de los autores 


\section{INTRODUCCIÓN}

El emprendimiento se concibe como una filosofía de vida, porque comprende una manera especial de pensar, de sentir y de actuar, orientada a crear valor tanto para el emprendedor, los empresarios, como también para la sociedad en general, incorporando las respuestas oportunas en las empresas de los diferentes sectores productivos con perfiles emprendedores idóneos que permitan aportar en la gestión de nuevas ideas innovadoras.

Así mismo, el sistema educativo ha desarrollado estrategias para garantizar una oferta educativa de calidad que incluya formación en emprendimiento, con el objetivo de fomentar en el individuo las competencias específicas que le permitan participar de manera eficiente y eficaz en el sector productivo, abarcando aspectos culturales, religiosos, políticos, académicos, sociales que generen competitividad y cambios significativos en la sociedad.

En este sentido, se impulsa el fomento al emprendimiento en todas las personas, empresarios, sin ningún criterio de exclusión, sin importar la condición humana, porque lo fundamental del emprededor con o sin discapacidad es lograr que alcance el máximo desarrollo, que sea mirado por sus grandes potencialidades, demostrando su cualidad de liderazgo y aporte al cambio cultural permitiendo valorar el aporte que hace a la sociedad, estimulando una mirada social inclusiva.

Por su parte, el emprendimiento es un proceso que parte de la identificación de oportunidades y la decisión de aprovecharlas 
mediante la realización de un conjunto de acciones estructuradas y organizadas que generen cambios desde diferentes perspectivas, con el fin de obtener bienestar social sostenible. Estas acciones se concretan en la constitución de nuevas organizaciones o en el desarrollo de las existentes, las cuales, a partir de constante y óptima combinación de los recursos y de las capacidades a su alcance, empiezan a innovar y asumir un liderazgo que les permita satisfacer las necesidades que surgen en el día a día, con sentido ético y responsabilidad social que impulsen nuevos negocios e ideas que generen bienestar, riqueza y competitividad.

El presente libro titulado Perspectivas Empresariales e Inclusivas del Emprendimiento está estructurado por cinco capítulos, basado en aportes investigativos, teóricos y metodólogicos por los autores abordando temáticas sobre el emprendimiento, Intraemprendimeinto, Perfil Emprendedor, Influencia del Liderazgo, Emprender después de una discapacidad y el emprendimiento Social. Cada una tiene su enfoque en el emprendimiento demostrando el desarrollo que tiene y la capacidad de ver oportunidades en las personas a través de la identificación e implementación de los factores como el liderazgo, la responsabilidad social, creatividad, innovación etc., elementos claves para adaptarse con mayor facilidad a las exigencias que surgen en su entorno. 


\section{PRÓLOGO}

Este libro es el resultado de una investigación de profesores de diferentes universidades del país, quienes han dado su aporte desde varias perspectivas del Emprendimiento con base en lo empresarial y la inclusión. El primer capítulo resalta el intraemprendimiento y su impacto en el desarrollo del sector de autopartes colombiano a través de una revisión literaria para definir las variables intraemprendimiento y emprendimiento corporativo y cómo se han desarrollo en las empresas. Por su parte, el segundo capítulo se centra en la identificación del perfil emprendedor para el desarrollo del emprendimiento de los estudiantes de una Institución de Educación Superior, relevante para evidenciar de qué manera estos aspectos del perfil les permiten desarrollar sus competencias para emprender en el mundo actual.

Seguidamente, el tercer capítulo en este estudio analiza la relación entre liderazgo y emprendimiento innovador, desde un enfoque de gestión de conocimiento. Por tanto los resultados muestran cómo las habilidades de los líderes emprendedores influyen positivamente en el reconocimiento y la explotación de oportunidades de negocio, que a su vez, permite guiar a los miembros de las empresas hacia una eficiente gestión del conocimiento que favorece el desarrollo de innovaciones. El cuarto capítulo hace referencia al desarrollo de un estudio de caso a través del cual las experiencias significativas de vida de un sujeto, pretenden describir los factores sociales e individuales que lo llevan a afrontar las dificultades y sobresalir en la sociedad en que se desenvuelve, venciendo barreras y obstáculos para lograr el emprendimiento y empresarismo. 
Finalmente, el quinto capítulo demuestra cómo el emprendimiento social genera un cambio en las comunidades, con acciones que crean valor al bienestar del colectivo, teniendo el emprendedor que explorar oportunidades que contribuyan a la calidad de vida. El propósito de esta investigación estuvo basado en el análisis del emprendimiento social como mecanismo integrador de las empresas mixtas petroleras al desarrollo de las comunidades venezolanas, que ejercen el emprendimiento social para integrar las comunidades en iniciativas sociales para apoyar las acciones destinadas al bienestar del colectivo desde las políticas públicas y una cultura responsable que garantice el valor agregado al desarrollo económico y productivo, con ayuda de los grupos de interés.

De forma especial, damos gracias por el apoyo infinito a Paola Amar, Vicerrectora de Investigación e Innovación de la Universidad Simón Bolívar; a Yaneth Herazo, Directora de Investigación y a los investigadores por la inmensa colaboración y valiosos aportes en el desarrollo de este proyecto editorial.

\section{Enohemit Olivero Vega}

Profesora Investigadora de la Facultad de Administración y Negocios 


\section{EL INTRAEMPRENDIMIENTO Y SU IMPACTO EN EL DESARROLLO DEL SECTOR DE AUTOPARTES COLOMBIANO}

The intrapreneurship and its impact on the development of the colombian auto parts sector

RICARDO PRADA OSPINA

JULIO CÉSAR ACOSTA-PRADO

\section{RESUMEN}

Como efecto de la aceleración del cambio tecnológico, así como por la creciente competencia mundial de los últimos años, los directivos y empresarios han encontrado necesario adoptar un estilo de comportamiento de tipo emprendedor en la formulación de sus estrategias. Este capítulo pretende analizar el intraemprendimiento y su impacto en el desarrollo del sector de autopartes colombiano. Se trata de un estudio cualitativo que se realiza en tres fases: análisis, diseño e implementación del proceso de caracterización del emprendimiento corporativo en una muestra del sector de autopartes. En ese sentido, se realizó una revisión de la literatura para definir las variables intraemprendimiento y emprendimiento corporativo, y cómo se han desarrollado en las empresas.

Palabras clave: autopartes, desarrollo empresarial, intraemprendimiento.

\section{ABSTRACT}

As a result of the acceleration of technological change and the increasing global competition in recent years, managers and entrepreneurs have found it necessary to adopt an entrepreneurial style of behavior in the formulation of their strategies. This chapter aims to analyze the intrapreneurship and its impact on the development of the Colombian auto parts sector. This is a qualitative study that is carried out in three phases: analysis, design and implementation of the characterization process of the corporate enterprise in a sample of the auto parts sector. In that sense, a review of the literature was made to define the variables intrapreneurship and corporate entrepreneurship and how they have developed in companies.

Key words: auto parts, business renewal, intrapreneurship. 


\section{INTRODUCCIÓN}

Como efecto de la aceleración del cambio tecnológico, así como por la creciente competencia mundial de los últimos años, los directivos y empresarios han encontrado necesario adoptar un estilo de comportamiento de tipo emprendedor en la formulación de sus estrategias. Covin \& Slevin (1991) argumentan que las tres posturas emprendedoras -asunción de riesgos, innovación y proactividad-, desarrolladas en unidades de negocio nuevas e independientes, se pueden aplicar también a procesos corporativos.

El presente capítulo pretende analizar el intraemprendimiento y su impacto en el desarrollo del sector autopartes colombiano. Se trata de un estudio cualitativo que se realiza en tres fases: análisis, diseño e implementación del proceso de caracterización del emprendimiento corporativo en una muestra del sector de autopartes. En ese sentido, se realizó una revisión de la literatura para definir las variables intraemprendimiento y emprendimiento corporativo, y cómo se han desarrollado en las empresas.

Los resultados muestran que, a pesar de ser considerados el intraemprendimiento y el emprendimiento corporativo dos escenarios estratégicos de renovación empresarial, las empresas autopartistas colombianas no promueven su desarrollo estratégico, ya que asumen, principalmente, modelos de negocio tradicionales, basados en una orientación económica impulsada por factores básicos de producción.

Este capítulo se estructura de la siguiente forma: posterior a la introducción, el segundo epígrafe aborda el marco teórico, en donde se describen los constructos emprendimiento corporativo e intraemprendimiento, y se relaciona con el sector automotor, específicamente con el subsector de autopartes. El tercer 
epígrafe presenta el problema de investigación. En el cuarto se descubren los resultados y principales hallazgos encontrados, y por último, se establecen las consideraciones finales.

\section{FUNDAMENTACIÓN TEÓRICA: EMPRENDIMIENTO E INTRAEMPRENDIMIENTO}

El concepto de emprendimiento surge inicialmente de la unión de los vocablos francés entreprendre, y alemán unternehmen, que significan emprender (Veeraraghavan, 2009). Este vocablo emprendedor se asume como de origen francés y se refiere a quien asume riesgos, es decir, aquel que persigue beneficios y trabaja en equipo o individualmente, innovando, creando oportunidades de negocio (Hisrich, 1990; Bruneau \& Machado, 2006).

Originalmente emprendimiento se relaciona con capacidad empresarial, aun cuando en realidad es un término mucho más amplio. Say (1803) afirma que el entrepreneur, es decir, la persona que inicia una pequeña empresa, hace el cambio de recursos desde una zona de bajo rendimiento a una de productividad alta y de rendimiento mayor.

De cualquier forma, son numerosos los términos para describir los esfuerzos emprendedores dentro de las organizaciones ya establecidas, lo que en cierta medida ha entorpecido el desarrollo de este campo de investigación (Sharma \& Chrisman, 1999). De acuerdo con Coduras, Guerrero y Peña (2011), al igual que sucede con la mayoría de conceptos derivados del emprendimiento, no hay hasta el momento presente una definición consensuada y única de emprendimiento corporativo. Así, diversos autores como Morris \& Kuratco (2002), Hornsby, Kuratko y Zahra (2002), Phan, Orlichenko, Boyd, Angstadt, Coccaro, Liberzon 
\& Arfanakis (2009) y Parker (2011) han señalado que no existe un consenso en la terminología, lo cual provoca que se utilicen como sinónimos las siguientes expresiones:

- Intraemprendimiento (Susbauer, 1973; Pinchot, 1985; Knight, 1987).

- Emprendimiento corporativo (Burgelman, 1983; Zahra, 1991; Covin \& Slevin, 1991; Sharma \& Chrisman, 1999; Ireland, Hitt \& Sirman 2003; Kuratko, 2007; Parker, 2011).

- Emprendimiento estratégico (Ireland \& Webb, 2007; Kuratko, 2007).

El intraemprendimiento y el emprendimiento corporativo son considerados como sinónimos por varios investigadores. No obstante, Trujillo \& Guzmán (2008) mencionando a Åmo \& Kolvereid (2005), argumentan una diferencia conceptual entre emprendimiento corporativo e intraemprendimiento cuando sostienen que, aun cuando ambos términos están relacionados y representan procesos incrementales de renovación en las organizaciones, a través de iniciativas de innovación llevadas a cabo por los empleados, dichos términos representan ligeramente diferentes fenómenos de renovación organizacional. Según estos autores, la diferencia fundamental radica en que el intraemprendimiento está focalizado en las iniciativas independientes, o por cuenta propia de los empleados, y el emprendimiento corporativo por iniciativas internas de la empresa o por cuenta ajena.

Adicionalmente, el emprendimiento corporativo está relacionado con los procesos utilizados por la empresa para fomentar actividades de innovación a través de la iniciativa de los empleados; de igual manera, el impacto que sobre el éxito de la empresa puede tener el comportamiento de los individuos (Åmo \& Kolvereid, 2005).

Por el contrario, Stopford \& Badem-Fuller (1990) argumentan que 
el emprendimiento corporativo solo tiene lugar en el interior de la organización cuando describe el proceso de renovación de una empresa existente, llevado a cabo solo por actores de la misma. Considerando asi, el emprendimiento corporativo e intraemprendimiento podrían ser utilizados como sinónimos (Seshadri \& Tripathy, 2006).

Los emprendedores innovan para sí mismos, mientras que los intraemprendedores o emprendedores corporativos innovan para las empresas en las que trabajan. No obstante, la problemática está en que el espíritu emprendedor corporativo es un término abstracto (Lumpkin \& Dess, 1996). Schumpeter (1911) sostiene que la introducción de innovaciones por parte de los emprendedores podía darse a través de la creación de una nueva empresa o dentro de los límites de una organización existente. Sin embargo, a lo largo del tiempo este constructo ha variado en su alcance y significado, confundiéndose en la actualidad dos fenómenos interrelacionados dentro del mismo término: intraemprendimiento y emprendimiento corporativo.

Las diferentes definiciones permiten desprender que los emprendedores corporativos son, habitualmente, personas muy motivadas dentro de las organizaciones, con alta orientación al logro, proactivos en extremo, y que actúan con comodidad para tomar iniciativas que permitan alcanzar la realización o desarrollo de nuevos productos dentro de sus empresas (Prada \& Ocampo, 2014).

Para Guth \& Ginsberg (1990) el intraemprendimiento involucra la innovación en la formación de nuevos negocios y las transformaciones mediante renovación estratégica. Al igual que sucede con el emprendimiento en general, el de tipo corporativo está viviendo un momento de expansión y es objeto del interés de 
\& diversos agentes relacionados con el desarrollo económico, así como del cuerpo de investigadores de la creación de empresas.

Por esto, el intraemprendedor puede impactar en la organización a través de diversos resultados relacionados con diversos ámbitos de la misma (Morris \& Kuratko, 2002). Según Coduras et al. (2011), el impacto más evidente de este tipo de actividad es el desarrollo de nuevas empresas, ya sean de carácter interno o externo, siendo también muy relevante el diseño de nuevos modelos de negocio, que suelen generar valor $\mathrm{y}$ beneficios adicionales, así como el acceso a otros mercados.

\subsection{La industria automotriz}

El continuo proceso de cambio en el entorno económico, donde la aceleración de la globalización y el desarrollo de la economía del conocimiento vienen actuando como motores, dinamiza a las empresas de forma sistemática. Por ello, en la actualidad la prioridad de las empresas debería ser evaluar la posición competitiva y participación de sus productos, a fin de aprovechar las oportunidades del mercado que les permita fortalecerse frente a los retos de los nuevos competidores (Escolano \& Belso, 2003).

La industria automotriz no ha sido ajena a esta situación, lo que se evidencia con el cambio constante de los gustos y tendencias de los clientes, al igual que el comportamiento del mercado automotor. Machorro et al, (2009), argumentan que al contar con mayores opciones de compra los clientes se han vuelto más selectivos y naturalmente buscan obtener el mejor producto, en las mejores condiciones, y con el mejor trato. Por esto, a nivel mundial el sector automotor es muy competitivo y ha evolucionado paralelamente a la tecnología del producto, del proceso y de los materiales con los que se fabrican los automóviles. En Colombia, la globalización también ha generado cambios funda- 
mentales, no sólo en la economía, sino además en el comportamiento de los mercados y gustos de los clientes, específicamente en el sector automotor.

El sector automotor a nivel mundial, en las últimas décadas, se ha caracterizado por presentar un constante proceso de reestructuración, convirtiéndose en una de las industrias más dinámicas de la era moderna, generadora de efectos importantes en las distintas economías en términos de productividad, desarrollo tecnológico y competitividad.

La importancia del sector automotor en el desarrollo de un país radica en su capacidad de generar innovación en la adquisición y el desarrollo de tecnología, la gran generación de empleo, debido a las diferentes cadenas productivas de diversos sectores que lo integran, y el desarrollo que representa para la sociedad donde se desarrolla esta actividad (Calderón, Engle, Mora, Styner, Gómez, Zhu, 2011).

Con la finalidad de ocupar los primeros lugares en producción y ventas en los mercados mundiales, las empresas integrantes del sector han estado siempre en busca de innovaciones que les permitan fortalecer y hacer más competitivos sus procesos productivos (Carvajal, 2010). Este sector, siendo como es, dinámico, integra diferentes subsectores y componentes relacionados con el transporte terrestre motorizado, tales como, ensambladoras, autopartes, comercializadoras, talleres de servicio, motocicletas, centros de diagnóstico, entre otros.

Cuando se plantea identificar el estado actual del sector en Colombia, se propone conocer su importancia para el país. Según estudios del Sector Automotor Colombiano, realizados por la Superintendencia de Industria y Comercio en el año 2012, 
$\approx$ desde el punto de vista económico, se encontró que existe una correlación entre la venta de vehículos y la variación porcentual del Producto Interno Bruto real del país.

Esta correlación puede sustentarse en el consumo de vehículos nacionales. Según los datos suministrados por el Departamento Administrativo Nacional de Estadística (DANE, 2014), el 47,7\% de las unidades de vehículos comercializados fueron de producción nacional, el 52,3\% restante fueron de origen extranjero, es decir, en el mercado interno de vehículos se presenta una participación casi equitativa entre la cantidad de automotores importados y los fabricados en el país. Sin embargo, medido en pesos colombianos, las ventas de vehículos importados tienden a aumentar, mientras que las ventas de vehículos nacionales parecen permanecer constantes. Este incremento se explica por la reducción de las barreras de entrada y la generación de competencia basada en precio de venta unitario de automotores.

\subsection{Descripción del mercado automotriz en Colombia}

La industria automotriz en Colombia se centra principalmente en cuatro grandes actividades: ensamble de vehículos, producción de autopartes, comercialización de autos y ensamble de motocicletas; entre otros.

En Colombia, la cadena productiva del sector automotor se entiende como un conjunto de eslabones vinculados entre sí por relaciones de tipo proveedor-cliente-proveedor (Departamento Nacional de Planeación - DNP, 2004). 


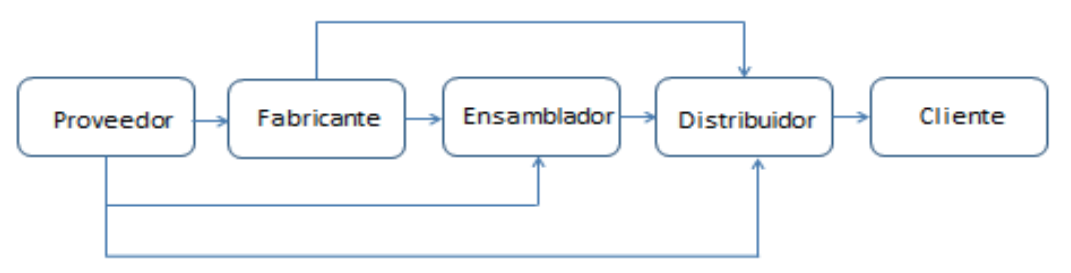

Figura 1. Cadena de valor del sector automotor

Fuente: Adaptado de Arango (2013)

De igual forma el Ministerio de Industria, Comercio y Turismo (2009), identificó que la cadena de valor del sector automotor en Colombia está integrada por proveedor, ensamblador, distribuidor, prestador de servicios post-venta o agente financiero (Zapata, Menendez, Prieto \& Romero 2013).

Por tanto, el proceso productivo del sector automotor comprende las actividades de ensamble de vehículos como la producción de partes, piezas y repuestos, las cuales también pueden ser utilizadas en el proceso de ensamble; es decir, comprende desde la fabricación de partes y piezas utilizadas en el ensamblaje hasta el ensamblaje de vehículos (vehículos ligeros, camiones, buses y motocicletas).

En Colombia se identifican siete empresas ensambladoras, dos de ellas de alta trayectoria, las cuales controlan el $54 \%$ del mercado nacional, distribuidas de la siguiente manera: GM Colmotores: $33,6 \%$ y Renault Sofasa: $15,0 \%$. Hasta agosto de 2014 existió además la Compañía Colombiana Automotriz (Mazda CCA), que controlaba el 5,4 \% del mercado nacional, pero dejó de operar definitivamente en cuanto a manufactura se refiere, dejando solo la operación de comercialización y venta.

Las restantes ensambladoras son: Hino Motors Manufacturing S.A., Carrocerías Non Plus Ultra, Compañía de Autoensamble Nissan, Navitrans S.A. y Daimler. Se debe señalar que las cuatro 
primeras empresas representan el $99 \%$ de la producción en términos de unidades (Calderón, Engle, Mora, Styner, Gómez \& Zhu, 2011; ANDI, 2013).

También hay que hacer notar que en la cadena automotriz en Colombia participan proveedores de insumos de otras industrias como la metalmecánica, la petroquímica (plásticos y cauchos) y la de textiles (BBVA, 2012; 2013) (Zapata et al, 2013).

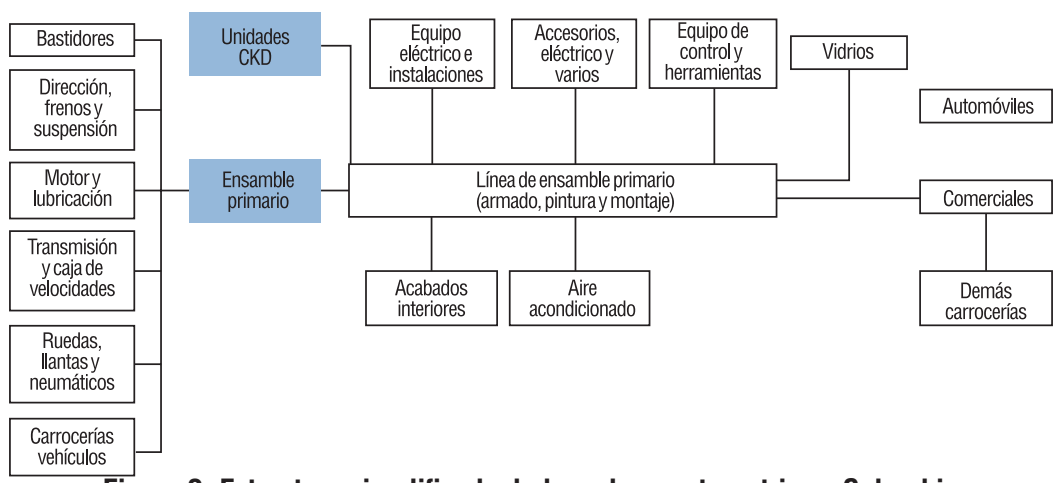

Figura 2. Estructura simplificada de la cadena automotriz en Colombia

Fuente: Dirección Nacional de Planeación - DNP (2007)

\subsection{El subsector de Autopartes}

En Bogotá se encuentra el parque automotor más grande de Colombia. Para 2013 alrededor de 1,8 millones de automóviles circulaban en la ciudad, esto representa el $39 \%$ del parque vehicular del país. Es un sector en expansión, ya que entre 2001 y 2010 el número de vehículos privados se incrementó en un $180 \%$ en la ciudad; además, Bogotá es sede de 6 de las 7 ensambladoras que tiene Colombia y el sector de autopartes, se concentra principalmente en tres ciudades: Bogotá, Cali y Medellín, empresas que, en su gran mayoría, están localizadas en Bogotá con cerca de 100 EMSA, que generan el $70 \%$ de la producción de autopartes del país (Invest in Bogotá, 2014). 
El sector de autopartes es el segundo eslabón de la cadena productiva que compone la industria automotriz colombiana. Sin embargo, aunque su participación se estima en menos del $20 \%$ de la producción total de este frente económico, detrás de él existen varios grupos que ejercen actividades de fabricación, comercialización y logística de estos productos, según lo concluido por el estudio "Caracterización integral de los procesos logísticos en el sector autopartes" (Zapata, Menendez, Prieto \& Romero, 2013).

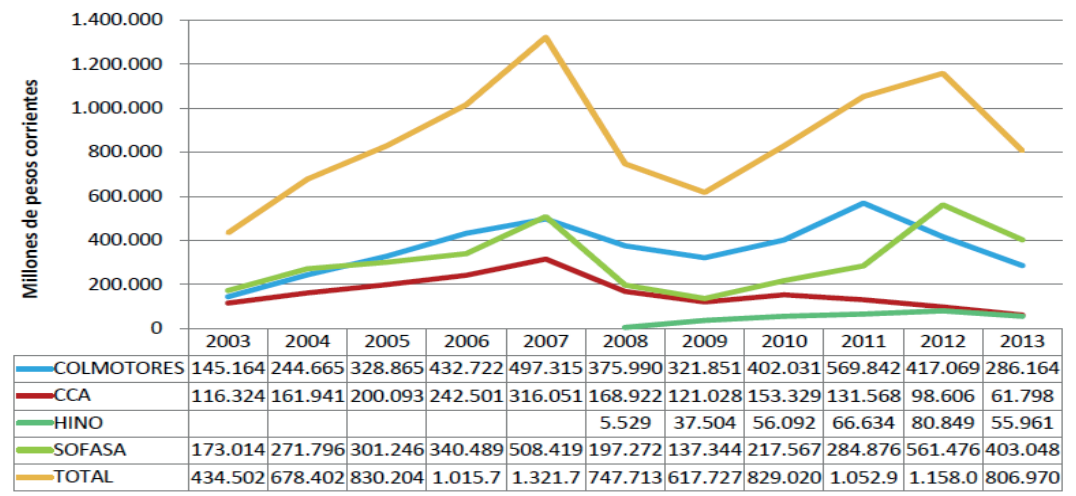

Figura 3. Compras de partes nacionales para ensamble

Fuente: ACOLFA (2014)

El sector de las piezas y partes para vehículos está compuesto por:

- $\quad$ Proveedores nacionales e internacionales que abastecen de piezas a fabricantes, ensambladores y distribuidores.

- Empresas fabricantes de piezas que suministran tanto a ensambladores como distribuidores.

- Empresas ensambladoras de vehículos ligeros, camiones, buses y motocicletas.

- Las sociedades distribuidoras, cuyo objeto social es la comercialización de autopartes.

También se incluyen las transportadoras de mercancías, que 
movilizan las piezas entre cada uno de los grupos anteriormente señalados. En cuanto a los subsectores por tipo de componente, según datos revelados por la Superintendencia de Industria y Comercio, para el año 2009 el 28 \% de la producción nacional de autopartes correspondió a equipos eléctricos e instalaciones; el $18 \%$ a sistemas de dirección, frenos y suspensión; y el $16 \%$ al de demás carrocerías, siendo estos los tres principales segmentos en la cadena productiva del sector de autopartes en Colombia.

Según Aguilar (2009) la baja sofisticación de las empresas conduce a improductividades de variada naturaleza. Es cuando se presenta poca incorporación de generación de valor por estrategias empresariales deficientes, así como por la presencia de desperdicios y la generación de costos innecesarios.

Con base en lo anterior, el objetivo principal de la presente investigación es caracterizar el intraemprendimiento y su impacto en el desarrollo del sector autopartes colombiano. Para ello, fueron consideradas las variables: innovación empresarial, capital humano, prácticas, procesos, implementación y resultados del intraemprendimiento, desde el nivel básico hasta el más alto. En consecuencia, se busca entender si las empresas medianas y grandes del sector de autopartes en la actualidad realizan o no actividades de intraemprendimiento, o son muy incipientes.

\section{METODOLOGÍA}

Autores como Katz (2010) han conceptuado en varios trabajos de investigación sobre la forma como el cambio estructural y las brechas tecnológicas destacan la importancia de los sectores difusores de conocimiento (SDC) en la dinámica económica como fuente de innovación del tejido productivo. Precisamente dentro de este SDC se encuentra el subsector metalmecánico, 
definiéndolo como aquel que genera bienes de capital y está relacionado con la creación de nuevas tecnologías, maquinaria y equipos para la industria y la transformación. Con base en esto, surge el interés de identificar si existen actividades de emprendimiento corporativo en este sector, aunque de manera informal.

Se trata de un estudio cualitativo que se realiza en tres fases: análisis, diseño e implementación del proceso de caracterización del emprendimiento corporativo en una muestra del sector de autopartes. La fase de análisis comprende el conocimiento teórico del emprendimiento corporativo y de sus variables intervinientes, así como del sector y su contexto. La fase de diseño implicó la construcción del instrumento a través del cual se reveló información sobre el emprendimiento corporativo, en una muestra de empresas del sector que accedieron a proporcionarnos sus datos. El instrumento fue diseñado para recopilar información productiva y económica de la empresa, innovación empresarial, capital humano, como variables contexto de la empresa para luego profundizar en el ciclo de desarrollo del emprendimiento corporativo: prácticas, procesos, implementación y resultados.

La muestra se obtuvo a partir del número de empresas legalmente constituidas en el sector de autopartes a 2015 en tres instituciones diferentes: Cámara de Comercio de Bogotá (CCB), Superintendencia de Sociedades (Supersociedades) y la Asociación Colombiana de Fabricantes de Autopartes (ACOLFA). En la CCB, bajo el código CIIU C2930, se registran 15 grandes empresas y 40 medianas, las cuales conforman el $70 \%$ del país (Araque, 2012).

La Supersociedades clasifica a las fabricantes de partes y repuestos para automotores mediante el código CIIU D3430, y las contabiliza en 115 empresas registradas; mientras que para ACOLFA son 38 las afiliadas. Al reunir los registros se encon- 
traron nombres de empresas coincidentes, las cuales se filtran para dar un total de 110 empresas legalmente registradas en las tres instituciones que conforman el marco muestral de la presente investigación. Se realizó un muestreo aleatorio, al enviar la encuesta a todas las empresas de marco muestral, de las cuales respondieron veinte con información completa (80 \%).

\section{RESULTADOS}

La Encuesta de Desarrollo e Innovación Tecnológica 2013-2014 que realiza el Departamento Administrativo Nacional de Estadística (DANE, 2014) ofrece información pertinente sobre las empresas que se dedican a la fabricación de vehículos automotores y sus partes. De allí se concluye que el $25 \%$ son innovadoras en sentido amplio y estricto, el 6,3\% potencialmente innovadoras y el $68,8 \%$ no innovadoras.

Del total de estas empresas, tan solo el $12,5 \%$ realizan innovaciones en el mercado nacional e internacional, y el resto innovaciones para la empresa. Es decir, a nivel nacional se encuentra que en el sector, aproximadamente el $40 \%$ realizan actividades innovadoras, por tanto, es probable que realicen procesos de emprendimiento corporativo.

En este capítulo se describe cómo de un total de 20 empresas del sector de autopartes que respondieron a la encuesta sobre intraemprendimiento, el $55 \%$ cuenta en nómina entre 10 y 49 empleados (empresas pequeñas, de acuerdo a la Ley 590 de 2000), el $30 \%$ entre 50 y 199 (empresas medianas), y sólo el $15 \%$, cuenta con más de 200 empleados (empresas grandes). No obstante, en la Tabla 1 se observa que el $55 \%$ de las empresas encuestadas declara ventas por más de 300 millones de pesos colombianos, el $60 \%$ tiene entre 5 y 10 años de antigüedad, y se extrae que el $70 \%$ forma parte de la industria manufacturera. Solamente el $10 \%$ de las empresas exporta. 
Tabla 1. Características de la muestra de empresas en el sector de autopartes

\begin{tabular}{|c|c|c|}
\hline \multicolumn{2}{|c|}{ COMPOSICIÓN DE LA MUESTRA } & SECTOR AUTOPARTES \\
\hline \multicolumn{2}{|c|}{ Tamaño de la muestra } & 20 \\
\hline \multicolumn{3}{|c|}{ Distribución de empresas por tamaño } \\
\hline & Muestra & \\
\hline & 10 y 49 & $55 \%$ \\
\hline & 50 y 199 & $30 \%$ \\
\hline & 200 o más & $15 \%$ \\
\hline \multicolumn{3}{|l|}{ Total ventas } \\
\hline & 51 y 100 millones & $30 \%$ \\
\hline & 101 y 300 millones & $15 \%$ \\
\hline & 301 millones o más & $55 \%$ \\
\hline \multicolumn{3}{|l|}{ Edad } \\
\hline & $<5$ años & $15 \%$ \\
\hline & 5 y 10 años & $60 \%$ \\
\hline & 10 o más años & $25 \%$ \\
\hline \multicolumn{3}{|l|}{ Industrial principal } \\
\hline & Manufactura & $70 \%$ \\
\hline & Servicios & $5 \%$ \\
\hline & Comercio & $25 \%$ \\
\hline
\end{tabular}

Fuente: Elaboración propia

\subsection{Características de las empresas}

Al preguntar sobre el uso de nuevas tecnologías, el $30 \%$ de las empresas encuestadas responde que no usa ninguna tecnología, el $55 \%$ que usa tecnología dura y el $15 \%$ tecnología blanda. El $45 \%$ indica que sí ha realizado procesos de innovación que han generado ingresos o disminución de costos, y de estos, mientras que el $70 \%$ son innovaciones de procesos, el $30 \%$ es innovación del servicio, como doblaje de láminas, en la producción en línea, en el almacenamiento múltiple de vehículos, y mercadeo y ventas. El $45 \%$ invierte menos del $25 \%$ de sus ingresos en nuevas tecnologías e innovación, el $35 \%$ entre 25 y $50 \%$, y el resto no reinvierte nada. 
\& Con relación a la distribución por género del talento humano que labora en las empresas analizadas, el $65 \%$ contrata en su mayoría más hombres (75\%) que mujeres (25\%). Al indagar por el nivel de formación educativa que contratan, se encuentra, en promedio, que el $46 \%$ de los empleados son trabajadores sin formación, pero con experiencia; el $27 \%$ cuenta con nivel técnico o tecnólogo; y el restante $27 \%$, lo conforma profesionales. Aproximadamente el $70 \%$ de los empleados en el sector de autopartes están contratados a término indefinido.

\subsection{Prácticas de intraemprendimiento}

Una vez que los gerentes de las empresas encuestadas fueron informados de lo que significa el emprendimiento corporativo, al preguntarles si creían que la empresa realizaba algún tipo de emprendimiento corporativo, el $45 \%$ responde que sí, el $45 \%$ que no y el restante $15 \%$ no sabe o no contesta.

Tabla 2. Empresas que realizan algún tipo de emprendimiento corporativo según el número de empleados en el sector de autopartes

\begin{tabular}{|c|c|c|c|}
\hline \multirow{2}{*}{ NÚMERO DE EMPLEADOS } & \multicolumn{3}{|c|}{$\begin{array}{c}\text { ¿SU EMPRESA REALIZA ALGÚN TIPO DE } \\
\text { ACTIVIDAD RELACIONADA CON EC? }\end{array}$} \\
\cline { 2 - 4 } & Sí & No & NS/NC \\
\hline Entre 10 y 49 empleados & 33,3 & 75,0 & 100 \\
\hline Entre 59 y 199 empleados & 44,4 & 12,5 & 0 \\
\hline Más de 200 empleados & 22,2 & 12,5 & 0 \\
\hline Total & 100 & 100 & 100 \\
\hline
\end{tabular}

Fuente: Elaboración propia

En la Tabla 2 se puede observar que del $100 \%$ de los encuestados que responden que su empresa realiza algún tipo de actividad relacionada con emprendimiento corporativo, el $33 \%$ son empresas pequeñas, el $45 \%$ medianas y el $22 \%$ grandes. 
Tabla 3. Razones por las que las empresas realizan o no actividades de emprendimiento corporativo

\begin{tabular}{|c|c|c|}
\hline \multirow[t]{2}{*}{ ¿POR QUÉ? } & \multicolumn{2}{|c|}{$\begin{array}{l}\text { ¿CREE USTED QUE SU EMPRESA } \\
\text { REALIZA ALGÚN TIPO DE ACTIVIDAD } \\
\text { RELACIONADA CON EC? }\end{array}$} \\
\hline & Sí & No \\
\hline Así como está funciona bien & 0 & 1 \\
\hline Así se comporta bien el negocio & 0 & 1 \\
\hline Creamos nuevas estrategias de ventas & 1 & 0 \\
\hline El tipo de negocio no permite incluir cambios & 0 & 1 \\
\hline Es un mercado específico ya establecido & 0 & 1 \\
\hline Investigación en tecnología de punta & 1 & 0 \\
\hline La actividad principal ya está establecida & 0 & 1 \\
\hline La empresa cree en el aporte de los trabajadores & 1 & 0 \\
\hline La labor es muy común & 0 & 1 \\
\hline $\begin{array}{l}\text { La línea de motos cambia constantemente en el mer- } \\
\qquad \text { cado }\end{array}$ & 1 & 0 \\
\hline Mejora en la venta y servicio oportuno & 1 & 0 \\
\hline Nuevas líneas de negocios con la dobladora & 1 & 0 \\
\hline Objeto social representación de una marca & 0 & 1 \\
\hline $\begin{array}{l}\text { Pensando en el crecimiento de la empresa y el incre- } \\
\text { mento de las utilidades }\end{array}$ & 1 & 0 \\
\hline Se cuenta con un departamento de innovación & 1 & 0 \\
\hline Se trata en mantener y atraer nuevos clientes & 1 & 0 \\
\hline Tiempo y negocio limitado & 0 & 1 \\
\hline
\end{tabular}

Fuente: Elaboración propia

Al preguntar a los gerentes de las empresas de autopartes, según la definición expuesta en el instrumento, si realizan algún tipo de actividad relacionada al emprendimiento corporativo, el $47 \%$ responde que sí la hace, a diferencia del $42 \%$ quienes responden que no, mientras el resto no contesta. Las que dicen que sí lo hacen aluden a su interés por mantener a los clientes, incrementar las ventas y mantenerse competitivos en el mercado; las que no lo hacen es porque perciben que el negocio es estático, se encuentran en su zona de confort, entre otras respuestas que se pueden observar en la Tabla 3. 
Al detallar el tipo de prácticas que las empresas están realizando en el marco del emprendimiento corporativo, como pregunta que confirme la respuesta si realizan prácticas de EC, se encuentra que a pesar que aproximadamente un $40 \%$ afirma que no realizan ninguna actividad, el $25 \%$ aproximadamente realiza trabajo colaborativo entre las diferentes áreas de la compañía; un $40 \%$ de manera frecuente realiza actividades orientadas al incremento de las ventas; el $15 \%$ actúa en grupos de trabajo para la generación de nuevas líneas de negocio (véase Tabla 4).

Tabla 4. Prácticas de Emprendimiento Corporativo

\begin{tabular}{|c|c|}
\hline $\begin{array}{l}\text { PRÁCTICAS PARA INVOLUCRAR A LOS EMPLEADOS EN EL FORTALECIMIENTO } \\
\text { DE LA EMPRESA }\end{array}$ & PORCENTAJE \\
\hline Generación de proyectos por equipos de trabajo & 10 \\
\hline Trabajo colaborativo entre diferentes áreas de la empresa & 25 \\
\hline Monitoreo y evaluación de oportunidades de negocio & 10 \\
\hline Ninguno & 55 \\
\hline Total & 100 \\
\hline PRÁCTICAS DE EMPRENDIMIENTO CORPORATIVO REALIZADAS DE MANERA FRECUENTE & PORCENTAJE \\
\hline Innovación de proceso, producto o servicio & 10 \\
\hline Creación o generación de nuevos productos & 10 \\
\hline Creación o generación de nuevas utilidades de negocio dentro de la empresa & 5 \\
\hline Búsqueda de nuevas oportunidades de negocio en el mercado & 35 \\
\hline Actividades orientadas al incremento de las ventas & 40 \\
\hline Total & 100 \\
\hline MECANISMOS PARA QUE LOS EMPLEADOS PROPONGAN NUEVAS LÍNEAS DE NEGOCIO & PORCENTAJE \\
\hline Incentivos a los empleados que proponen proyectos & 10 \\
\hline Grupos de trabajo para la generación de nuevas líneas de negocio & 15 \\
\hline Ninguno & 75 \\
\hline Total & 100 \\
\hline $\begin{array}{l}\text { RAZONES PARA NO REALIZAR NINGUNA PRÁCTICA DE APOYO } \\
\text { AL EMPLEADO EMPRENDEDOR }\end{array}$ & PORCENTAJE \\
\hline La empresa no lo requiere & 15 \\
\hline El clima organizacional no se adapta & 10 \\
\hline La estructura organizacional de la empresa no lo ha permitido & 25 \\
\hline Escasez de financiamiento & 15 \\
\hline Escasez de tiempo & 30 \\
\hline
\end{tabular}




\begin{tabular}{|c|c|}
\hline No le encuentra valor agregado a este tipo de prácticas & 5 \\
\hline Total & 100 \\
\hline RAZONES QUE HAN IMPEDIDO LA ADOPCIÓN DE PRÁCTICAS DE EMPRENDIMIENTO \\
CORPORATIVO & PORCENTAJE \\
\hline Riesgo corporativo & 25 \\
\hline Falta de recursos & 35 \\
\hline Bajo interés de las directivas & 35 \\
\hline Otro & 5 \\
\hline Total & 100 \\
\hline
\end{tabular}

Fuente: Elaboración propia

De acuerdo a la Tabla 4, se observa que los factores que más pesan para no realizar prácticas de emprendimiento corporativo son el bajo interés de las directivas y la falta de recursos específicos. Otros factores que se extraen de la Tabla son la escasez de tiempo para estas actividades y porque se cree que la estructura organizacional no lo permite.

\subsection{Procesos de emprendimiento corporativo}

A un nivel mayor de profundidad se cuenta con un grupo de preguntas que indagan sobre los procesos relacionados con el emprendimiento corporativo. En este campo el escenario es más precario que en el anterior. A la hora de profundizar en el trabajo en equipo y las propuestas de los empleados, el $55 \%$ afirma que no hace ningún proceso específico al respecto, y el $40 \%$ realiza reuniones para generación de ideas y propuestas de nuevas unidades de negocios, aunque $75 \%$ afirma que el gerente no se reúne con mandos medios y bajos a escuchar ideas de nuevos negocios, un $65 \%$ de las empresas indica que no se reflejan productos de estas actividades, y un $10 \%$ dice que se plasma en lluvia de ideas y en nuevos proyectos.

De las empresas que afirman realizar procesos de emprendimiento corporativo se indaga sobre el impacto en el mapa de procesos o la estructura organizacional, y el $90 \%$ afirma que no se ha observado un impacto a este nivel (véase Tabla 5). 
Tabla 5. Procesos de emprendimiento corporativo

\begin{tabular}{|c|c|}
\hline $\begin{array}{c}\text { ACTIVIDADES ESPECIFICAS QUE REALIZA LA EMPRESA CON RELACIÓN AL TRABAJO EN } \\
\text { EQUIPO Y A LAS PROPUESTAS DE SUS EMPLEADOS }\end{array}$ & PORCENTAJE \\
\hline Reuniones específicas para generación de ideas & 20 \\
\hline Generación de propuestas de nuevas unidades de negocio & 20 \\
\hline Otra & 5 \\
\hline Ninguna & 55 \\
\hline Total & 100 \\
\hline ¿EL GERENTE SE REÚNE CON MANDOS MEDIOS Y BAJOS PARA ESCUCHAR & PORCENTAJE \\
IDEAS DE NUEVOS NEEOCIOS? & 25 \\
\hline Sí & 75 \\
\hline No & 100 \\
\hline Total & PORCENTAJE \\
\hline LOS PRODUCTOS DE LAS ACTIVIDADES QUE GENERAN NUEVAS IDEAS & 10 \\
\hline Y PROYECTOS SE PLASMAN EN & 10 \\
\hline Lluvia de ideas & 10 \\
\hline Nuevos proyectos & 5 \\
\hline Nuevas unidades de negocio & 65 \\
\hline Otro & 100 \\
\hline Ninguna & \\
\hline Total & \\
\hline
\end{tabular}

Fuente: Elaboración propia

\subsection{Implementación del emprendimiento corporativo}

Otra fase de evaluación del emprendimiento corporativo es la implementación que se refiere a las actividades, indicadores relacionados a: la creación de nuevas unidades de negocio, la postura de las directivas en la fase de ejecución de nuevos proyectos, y el impacto que estos procesos de ejecución le han representado a la empresa. 
Tabla 6. Implementación del emprendimiento corporativo

\begin{tabular}{|c|c|}
\hline $\begin{array}{c}\text { ¿EN LOS ÚLTIMOS AÑOS CUÁNTAS LÍNEAS DE NEGOCIO, UNIDADES DE NEGOCIO O } \\
\text { NUEVOS PRODUCTOS SE HAN GENERADO? }\end{array}$ & PORCENTAJE \\
\hline Uno & 10 \\
\hline Menos de cinco & 25 \\
\hline Más de cinco & 5 \\
\hline Ninguno & 60 \\
\hline Total & 100 \\
\hline ¿CUÁL ES LA POSTURA DE LAS DIRECTIVAS ANTE LOS PROYECTOS? & PORCENTAJE \\
\hline Se quedan estancadas & 10 \\
\hline Las leen y evalúan su factibilidad & 30 \\
\hline Se implementan & 10 \\
\hline Otro & 50 \\
\hline Total & 100 \\
\hline $\begin{array}{l}\text { EN LA EMPRESA ¿SE HAN GENERADO NUEVOS PROCESOS, PRODUCTOS O } \\
\text { SERVICIOS EN LOS ÚLTIMOS AÑOS? }\end{array}$ & PORCENTAJE \\
\hline Sí & 30 \\
\hline No & 70 \\
\hline Total & 100 \\
\hline ¿CUÁL ES EL TIPO DE NOVEDAD? & PORCENTAJE \\
\hline Nuevos procesos & 20 \\
\hline Nuevos productos & 10 \\
\hline $\mathrm{NS} / \mathrm{NC}$ & 70 \\
\hline Total & 100 \\
\hline ¿CUÁNTAS UNIDADES DE NEGOCIO SE HAN IMPLEMENTADO EN SU EMPRESA? & PORCENTAJE \\
\hline Una & 20 \\
\hline Dos & 5 \\
\hline $\mathrm{NS} / \mathrm{NC}$ & 75 \\
\hline Total & 100 \\
\hline ¿QUÉ TIPO DE IMPACTO LE HA GENERADO EN SU EMPRESA? & PORCENTAJE \\
\hline Incremento en la productividad & 10 \\
\hline Incremento en los ingresos & 15 \\
\hline Reducción de costos & 10 \\
\hline Otro & 25 \\
\hline NS/NC & 40 \\
\hline Total & 100 \\
\hline
\end{tabular}

Fuente: Elaboración propia 
Es importante contar con una mirada integral del proceso de emprendimiento corporativo que da cuenta del tipo y la fase en el que se encuentra la empresa, es decir, si bien se encuentra que en el sector de autopartes se realizan prácticas y procesos de emprendimiento corporativo, en aproximadamente el $50 \%$ de ellas, reflejan cierta dinámica a la hora de verificar la implementación de esta apertura, nuevas ideas y su ejecución a través de la creación de nuevas unidades de negocio, se encuentra que aproximadamente el $40 \%$ ha generado alguna nueva unidad de negocio, línea de negocio o nuevos productos $10 \%$ uno, $25 \%$ menos de cinco y $5 \%$ más de cinco (véase Tabla 6 ).

A la hora de evaluar la postura de las directivas ante los proyectos o nuevas propuestas formuladas, el $50 \%$ de las empresas de autopartes indica que hay desinterés e indiferencia, $10 \%$ comenta que se quedan estancadas, el $30 \%$ indica que se leen y se evalúa su factibilidad y tan solo el $10 \%$ afirma que se implementan.

En el último año, el $30 \%$ de las empresas afirma que ha generado nuevo procesos, productos o servicios; de este porcentaje el $20 \%$ habla de una innovación de proceso y el $10 \%$ de producto. El impacto que ha representado la implementación del emprendimiento corporativo en aproximadamente el $40 \%$ de las empresas de autopartes se da en tres ámbitos: incremento en la productividad $(10 \%)$, incremento de los ingresos (15\%) y reducción de costos (10\%).

Todo esfuerzo de capital humano y recursos se debe evidenciar en resultados concretos que representen beneficios tangibles, como mayores ingresos, o intangibles, como el aprendizaje de la empresa. En este sentido, el apartado de medición de los resultados del emprendimiento corporativo tiene el objetivo de evidenciar los resultados de la ejecución de actividades del emprendimiento corporativo visto como impacto en el corto, mediano y largo plazo. 
Como se puede evidenciar en la Tabla 7, en la cual se incorporan las respuestas de las empresas del sector autopartes en cuanto a indicadores de emprendimiento corporativo a nivel organizacional, aproximadamente el $5 \%$ afirma contar con un equipo reconocido como emprendedores dentro la empresa, con una estrategia organizacional para la gestión de nuevas ideas, con bases de datos sobre ideas innovadoras, y con manuales de procedimiento para la gestión de ideas innovadoras.

El $95 \%$ de las empresas encuestadas no cuenta con indicadores de resultado del emprendimiento corporativo.

Tabla 7. Resultados del emprendimiento corporativo: organizacional

\begin{tabular}{|c|c|}
\hline $\begin{array}{c}\text { ¿EXISTE UN GRUPO IDENTIFICADO DE EMPRENDEDORES DENTRO DE SU } \\
\text { EMPRESA? }\end{array}$ & PORCENTAJE \\
\hline Sí & 5 \\
\hline No & 95 \\
\hline Total & 100 \\
\hline $\begin{array}{c}\text { ¿LA EMPRESA CUENTA CON UNA ESTRATEGIA ORGANIZACIONAL PARA LA } \\
\text { GESTIÓN DE NUEVAS IDEAS? }\end{array}$ & PORCENTAJE \\
\hline Si & 5 \\
\hline No & 95 \\
\hline Total & 100 \\
\hline ¿EXISTE UNA BASE DE DATOS PARA EL REGISTRO Y SEGUIMIENTO DE NUEVIAS \\
IDEAS O INNOVACIONES? & PORCENTAJE \\
\hline Sí & 10 \\
\hline No & 85 \\
\hline NS/NC & 5 \\
\hline Total & 100 \\
\hline ¿EXISTEN PROCESOS Y MANUALES DE PROCEDIMIENTOS DEFINIDOS PARA LA & PORCENTAJE \\
\hline CREACIÓN DE NUEVAS UNIDADES DE NEGOCIO? & 5 \\
\hline Sí & 90 \\
\hline No & 5 \\
\hline NS/NC & 100 \\
\hline TOtal & \\
\hline
\end{tabular}

Fuente: Elaboración propia 
En cuanto a la ejecución de recursos y financiamiento de los intraemprendimientos, se encuentra que el $65 \%$ no ofrece ningún incentivo, el $15 \%$ da incentivos verbales y $15 \%$ bonos. Al parecer, si la empresa cuenta con políticas e implementa nuevas unidades de negocio a partir de las ideas de sus emprendedores, estos se financian con recursos propios de la empresa en un $15 \%$, a través de convocatorias externas en un $5 \%$, endeudamiento $10 \%$ y el resto no contesta o no responde. A pesar del financiamiento que brinda el gobierno, el sector de autopartes lo considera solo en un $5 \%$ (véase Tabla 8).

Tabla 8. Resultados del intraemprendimiento: financiamiento

\begin{tabular}{|c|c|}
\hline $\begin{array}{c}\text { ¿CUÁLES SON LOS INCENTIVOS QUE OFRECE LA EMPRESA A SUS } \\
\text { INTRAEMPRENDEDORES? }\end{array}$ & PORCENTAJE \\
\hline Ninguno & 65 \\
\hline Incentivos verbales & 15 \\
\hline Bonos & 15 \\
\hline Otro & 5 \\
\hline Total & 100 \\
\hline ¿CUÁL ES EL TIPO DE FINANCIAMIENTO DE LAS NUEVAS UNIDADES DE & PORCENTAJE \\
\hline NEGOCIO GENERADAS POR SUS EMPLEADOS? & 15 \\
\hline Financiamiento propio de la empresa & 5 \\
\hline Convocatorias externas & 10 \\
\hline Endeudamiento & 60 \\
\hline Otro & 10 \\
\hline NS/NC & 100 \\
\hline Total &
\end{tabular}

¿CUÁL ES EL TIEMPO PROMEDIO TRASCURRIDO DESDE LA GENERACIÓN DE UNA IDEA HASTA SU IMPLEMENTACIÓN COMO BENEFICIO ECONÓMICO DE LA EMPRESA?

\begin{tabular}{|c|c|}
\hline Menos de 6 meses & 55 \\
\hline Entre 6 meses y 1 año & 20 \\
\hline Más de 1 año & 20 \\
\hline NS/NC & 5 \\
\hline Total & 100 \\
\hline $\begin{array}{c}\text { ¿QUÉ PORCENTAJE DE INCREMENTO TUVO LA EMPRESA EN SUS GANANCIAS } \\
\text { ATRIBUIDAS A LAS NUEVAS UNIDADES DE NEGOCIO CREADAS EN LOS } \\
\text { UULTIMOS 3 AÑNOS? }\end{array}$ & PORCENTAJE \\
\hline
\end{tabular}




\begin{tabular}{|c|c|}
\hline Ningún incremento & 65 \\
\hline Menos del $10 \%$ de incremento & 15 \\
\hline Entre el $11 \%$ y $20 \%$ & 15 \\
\hline Más del $20 \%$ & 5 \\
\hline Total & 100 \\
\hline $\begin{array}{c}\text { ¿QUÉ POSIBILIDADES DE SOSTENIBLIDAD A LARGO PLAZO TIENEN } \\
\text { ACTUALMENTE LAS NUEVAS UNIDADES DE NEGOCIO? }\end{array}$ & PORCENTAJE \\
\hline Baja & 75 \\
\hline Media & 15 \\
\hline Alta & 10 \\
\hline Total & 100 \\
\hline ¿LA EMPRESA SEGUIRÁ PROMOVIENDO NUEVAS UNIDADES DE NEGOCIO, & PORCENTAJE \\
\hline GENERADAS POR SUS EMPLEADOS, A LARGO PLAZO? & 35 \\
\hline Sí & 65 \\
\hline No & 100 \\
\hline Total & \\
\hline
\end{tabular}

Fuente: Elaboración propia

Tabla 9. Resultados del emprendimiento corporativo: eficiencia

¿CUÁL ES EL TIEMPO PROMEDIO TRASCURRIDO DESDE LA GENERACIÓN DE UNA IDEA HASTA SU IMPLEMENTACIÓN COMO BENEFICIO ECONÓMICO DE LA EMPRESA?

\begin{tabular}{|c|c|}
\hline Menos de 6 meses & 55 \\
\hline Entre 6 meses y 1 año & 20 \\
\hline Más de 1 año & 20 \\
\hline NS/NC & 5 \\
\hline Total & 100 \\
\hline
\end{tabular}

¿QUÉ PORCENTAJE DE INCREMENTO TUVO LA EMPRESA EN SUS GANANCIAS ATRIBUIDAS A LAS NUEVAS UNIDADES DE NEGOCIO CREADAS EN LOS ÚLTIMOS 3 AÑOS?

\begin{tabular}{|c|c|}
\hline Ningún incremento & 65 \\
\hline Menos del $10 \%$ de incremento & 15 \\
\hline Entre el $11 \%$ y $20 \%$ & 15 \\
\hline Más del $20 \%$ & 5 \\
\hline Total & 100 \\
\hline
\end{tabular}




\begin{tabular}{|c|c|}
\hline Baja & 75 \\
\hline Media & 15 \\
\hline Alta & 10 \\
\hline Total & 100 \\
\hline ¿LA EMPRESA SEGUIRÁ PROMOVIENDO NUEVAS UNIDADES DE NEGOCIO, \\
GENERADAS POR SUS EMPLEADOS, A LARGO PLAZO? & PORCENTAJE \\
\hline Sí & 35 \\
\hline No & 65 \\
\hline Total & 100 \\
\hline
\end{tabular}

Fuente: Elaboración propia

\section{CONCLUSIONES}

Los estudios de mercado muestran que la respuesta a las necesidades del cambio de deseos del cliente debe ser rápida. No obstante, con base en lo observado, se concluye que es bajo el porcentaje de empresas de autopartes que practican el emprendimiento corporativo. La respuesta a los tiempos que toma el desarrollo de un proyecto, desde la idea hasta su implementación, indica que el $55 \%$ de las empresas da respuesta en menos de 6 meses, el $20 \%$ en menos de un año y el $20 \%$ en más de un año (véase Tabla 9).

Las ganancias, atribuidas a nuevos proyectos, en los últimos tres años son aproximadamente menos del $10 \%$ de las utilidades para el $80 \%$ de las empresas de autopartes. Tan solo para el $5 \%$ representó más del $20 \%$.

En este escenario acelerado, al indagar sobre la sostenibilidad de las nuevas unidades de negocio, el $75 \%$ cree que son bajas, el $15 \%$ media y el $10 \%$ alta. Y, de acuerdo a todo lo anterior, tan solo el $35 \%$ de las empresas afirma que seguirán promoviendo el emprendimiento corporativo a largo plazo, mientras que el $65 \%$ afirma que no. 


\section{REFERENCIAS BIBLIOGRÁFICAS}

Acolfa (17 de septiembre de 2014). Desarrollo y prospectiva de la industria automotriz en Colombia. Obtenido de Desarrollo y Prospectiva de la Industria Automotriz en Colombia: http:// www.acolfa.org.co/index.php/acolfa/19-acolfa-2014/file.

Aguilar, C. (2009). Los subalternos como limitantes del poder. Hegemonía, legitimidad y dominación, en Contribuciones a las Ciencias Sociales. www.eumed.net/rev/cccss/04/craa. htm.

Åmo, B. \& Kolvereid, L. (2005). Estrategia organizativa, personalidad individual e innovación. Cultura Emprendedora (JEC), World Scientific Publishing Co. Pte. Ltd., 13(01), 7-19.

Antoncic, B. \& Hisrich, R. D. (2003). Clarifying the intrapreneurship concept. Journal of Small Business and Enterprise Development, 10(1), 7-24.

Arango, M. D. (2013). Caracterización integral de los procesos logísticos en el sector autopartes - automotores en Colombia - Propuesta Metodológica. Medellín.

Araque, N. (2012). Clasificación industrial uniforme de todas las actividades económicas. Bogotá: DANE. Obtenido de Informe de Coyuntura Económica Regional: http://www.dane.gov.co/ files/icer/2012/ICER_Bogota_Cundinamarca_2012.pdf.

Asociación Nacional de Empresarios de Colombia (2013). Automotriz y La ANDI. Disponible en: http://inflacion.com.co/ automotriz-y-la-andi-2013.html.

Banco Bilbao Vizcaya Argentaria (2012). Los ingresos de BBVA han crecido un 12,1\% en 2012 gracias a un modelo de negocio bien diversificado y equilibrado. Disponible en: https://accionistaseinversores.bbva.com/microsites/bbva2012/ es/index.html.

Banco Bilbao Vizcaya Argentaria (2013). BBVA Solidos Fundamentales. Disponible en:https://accionistaseinversores.bbva. com/microsites/bbvain2013/es/index.html.

Bruneau, J., Machado, H. (2006). Emprendedorismo en los países de América Latina, basado en los indicadores del Global Entrepreneurship Monitor (GEM). En: Panorama socioeconómico, 18-25.

Burgelman, R. (1983). A process Model of Internal CorporateVenturing in Diversified MajorFirm. Administrative ScienceQuarterly, 28, 223-244. 
Calderón, L., Engle, R., Mora, A., Styner, M., Gómez, G. \& Zhu, H. (2011). La exposición a la contaminación atmosférica urbana grave influye en los resultados cognitivos, el volumen cerebral y la inflamación sistémica en niños clínicamente sanos. Cerebro y Cognición, 77, 345-55.

Carvajal, J. (2010). Relaciones dirigentes-dirigidos: Un acercamiento desde los Derechos Humanos. Paipa, Colombia: II Congreso de Investigación en Administración.

Corduras, A., Guerrero, M. \& Peña, I. (2011). Emprendimiento Corporativo en España. GEM España-Fundacion Xavier De Salas para la dirección General de Política de la pyme.

Covin, J. G. \& Slevin, O. P. (1991). A conceptual model of entrepreneurship as firm behavior. Entrepreneurship Theory, and Practice, 16(1), 7-25.

Departamento Administrativo Nacional de Estadística (2014). Indicadores coyunturales. Disponible en: https://www. dane.gov.co/files/ses/ses_2014/Indicadores_Coyunturales_19_08_14.pdf

Departamento Nacional de Planeación (2007). Plan Nacional de Desarrollo 2006-2010. Estado Comunitario: desarrollo para todos. Bogotá: DNP.

Departamento Nacional de Planeación-FONADE (2004). Metodología para la Evaluación de la Formulación de los Planes de Desarrollo Municipales.

Departamento Nacional de Planeación (2004). Dirección de Estudios Económicos Programación Seminarios. Disponible en: https://colaboracion.dnp.gov.co/CDT/Estudios\%20 Econmicos/2004_Programaci\%C3\%B3n\%20a\%C3\%B1o.pdf

Drucker, P. F. (1985). Innovation and Entrepreneurship. USA: Harper \& Row.

Escolano, C. \& J. Belso (2003). Internacionalización y pymes: conclusiones para la actuación pública a partir de un análisis multivariante. Revista Asturiana de Economía, 27, 169-195.

Galán, J. L. \& Pizarro, I. (2005). El comportamiento emprendedor de las empresas: negocios internos y externos. Recuperado de http://catedradiversificacion.unizar.es/contenidos/publicaciones/ELCOMPORTAMIENTOEMPRENDEDOR.pdf

Gálvez E. J. (2011). Cultura intraemprendedora e innovación: un estudio empírico en las mipyme turísticas colombianas. Cuadernos de Administración, 27(46), 103-114. 
Gálvez, E. \& García, D. (2011). Cultura, innovación, intraemprendimiento y rendimiento en las mipyme de Colombia (Tesis doctoral). Universidad Politécnica de Cartagena.

Gálvez, E. J. \& García, D. (2011). Impacto de la Cultura Intraemprendedora en el rendimiento de las mipyme del sector turístico colombiano. Un estudio empírico. Universidad y Ciencia, 52, 27-36.

Garzón, M. (2008). Propuesta de modelo de emprendimiento corporativo o intraemprendimiento para la innovación. Revista Ciencias Administrativas. Universidad del Norte.

Guth, W. \& Ginsberg, A. (1990). Guest editor's introduction: Corporate entrepreneurship. Strategic Management Journal, 12, 5-15.

Hamel, G. (2009). El futuro de la administración. USA: Harvard Business School Press.

Hisrich, R. D. (1990). Entrepreneurship/Intrapreneurship. American Psychologist, 45(2), 209-229.

Hornsby, J. S., Kuratko, D. F. \& Montagno, R. V. (1999). Perception of internal factors for corporate entrepreneurship: A comparison of Canadian and U.S. managers. Entrepreneurship Theory and Practice, 24(2), 9-24.

Hornsby, J. S., Kuratko, D. F. \& Zahra, S. A. (2002). Middle managers' perception of the internal environment for corporate entrepreneurship: assessing a measurement scale. Journal of Business Venturing, 17(3), 253-274.

Invest in Bogotá (2014). Informe Anual: Promoción de Inversión. Disponible en: https://es.investinbogota.org/sites/default/ files/2017-11/informe-anual-2014_0.pdf

Ireland, D. R. \& Webb, J. W. (2007). Strategic entrepreneurship: Creating competitive advantage through streams of innovation. Business Horizons, 50(1).

Ireland, R., Hitt, M. \& Sirman, D. (2003). A model of strategic entrepreneurship: the construct and its dimensions. Journal of Management, 29(6), 963-989.

Jericó, P. (2013). ¡Necesitamos intraemprendedores! Expansión. com. Recuperado de: http://www.expansion.com/2013/01/18/ emprendedores-empleo/opinion/1358537150.html

Kantis, H. \& Drucaroff, S. (2011). Emprendimiento corporativo en América Latina, Conceptos, lecciones de la experiencia coreana y plataforma estratégica para su desarrollo en la región. Washington, D.C.: Fondo Multilateral de Inversiones (FOMIN). 
Kantis, H., Ishida, M. \& Komori, M. (2002). Empresarialidad en economías emergentes: Creación y desarrollo de nuevas empresas en América Latina y el Este de Asia. Inter-American Development Bank.

Katz, J. y Bernat, G. (2010) Micro to Macro interactions in the context of Argentine manufacturing activities: exit and entry of firms, productivity growth, structural change and innovative behavior in response to changes in the macroeconomic policy regime", paper presentado en Globelics 2010, $8^{\circ}$. Kuala Lumpur, Malaysia: International Conference, University of Malaya.

Knight, J. (1987). Foodservice Dictionary. New York: Van Nostrand Reinhold.

Kuratko, D. (2007). Corporate Entrepreneurship. Foundations and Trends in Entrepreneurship, 3(2), 1-51.

Kuratko, D. (2009). Entreprenuership Theory, Process, Practice. South-Wenster: Cenage Learning.

Kuz, D. (2010). Exploration of Intrapreneurship and Innovation in Advanced Technology Organizations in the Western United States. Recuperado de: http://gradworks.umi.com/3425617.pdf

Lessem, R. (1990). Gestión de la cultura corporativa. Madrid: Ediciones Díaz de Santos, S.A.

Ley (1803). Congreso de Colombia. Disponible en: http://www. secretariasenado.gov.co/senado/basedoc/ley_1803_2016.html.

Lombriser, R. (1994). Grandes intraempresarios: Desarrollo de nuevos negocios dentro de las organizaciones. Barcelona: Folio. S.A.

Lumpkin, G. T. \& Dess, G. G. (1996). Clarifying the entrepreneurial orientation construct and linking it to performance. Academy of Management Review, 21(1), 135-172.

Lumpkin, G. T. (2007). Intrapreneurship and Innovation, En J. R. Baum, M. Frese y R. A. Baron (Eds.), The Psychology of Entrepreneurship (237-263). New Jersey: Lawrence Erlbaum.

Lyon, D. W., Lumpkin, G. T. \& Dess, G. G. (2000). Enhancing entrepreneurial orientation research: operationalizing and measuring a key strategic decision making process. Journal of Management, 26(5), 1055-1085.

Machorro, A., Venegas, A., Resenos, E., et al. (2009). La calidad en el servicio como ventaja competitiva en una empresa automotriz. Academia Journals, Revista de Ingeniería Industrial, 3(1), 1-16. 
Manimala, M. J. (2006). Organizational Constraints on Innovation and Intrapreneurship: Insights from Public Sector. Vikalpa, 31, 49-60.

McDaniel, B. A. (2000). A Survey on entrepreneurship and innovation. The Social Science Journal, 37(2), 277-284.

Medina, C. \& Espinosa, M. (2000). La innovación en las organizaciones modernas. Revista Gestión y Estrategia, 5. Universidad Autónoma de México.

Ministerio de Comercio, Industria y Turismo (2009). DesarroIlando Sectores de Clase Mundial. Informe final Sector Textil, Confección, Diseño y Moda. Bogotá, D.C.

Morris, M. H. \& Kuratko, D. F. (2002). Corporate entrepreneurship. Orlando: Harcourt College Publishers.

Novoa, F. (2008). Intra-emprender... ¿Y qué es eso?. Revista de la Asociación de egresados del Inalde, 3, 17-23.

Parker, S. C. (2011). ¿Intrapreneurship or entrepreneurship? Journal of Business Venturing, 26(1), 19-34.

Phan, K. Orlichenko, A., Boyd, E., Angstadt, M., Coccaro, E., Liberzon, I., Arfanakis, K. (2009). Preliminary evidence of white matterab normality in the uncinate fasciculus in generalized social anxiety disorder. Biol Psychiatry, 66, 691-694.

Pinchot, G. (1985). Intrapreneuring (el empresario dentro de la empresa), cómo hacerse empresario sin salirse de la empresa. Bogotá: Norma.

Pinchot, G., Pellma, R. (1999). Intrapreneuring in action: a handbook for bussines innovation. San Francisco: Berrett-Koehler Publishers, inc.

Porter, M. (2007). Estrategia competitiva: técnicas para el análisis de los sectores industriales y de la competencia (1 ${ }^{\text {a }}$ ed.). México: Grupo Editorial Patria.

Prada, R. Ocampo, P. (2014). La productividad y la calidad y en su relación con el crecimiento en ventas. Caso de estudio: Compañía de Autoensamble en Colombia. Scientific Journal, 10(19), 1-10.

Prodem (2010). Programa de desarrollo emprendedor. Recuperado de http://www.prodem.ungs.edu.ar/blog/2010/12/ emprendimiento-corporativo/

Rothaermel, F. T., Agung, S. D. \& Jiang, L. (2007). University Entrepreneuship: a taxonomy of the literatura. Industrial and Corporate Change, 16(4), 691-791. 
Say, J. B. (1803). Tratado de Política Económica. México: Fondo de Cultura Económica.

Schumpeter, J. A. (1911). Theory of Economic Development. Oxford University Press. New York, 1961.

Seshadri, D. \& Tripathy, A. (2006). Innovation through intrapreneurship: The road less travelled. Vikalpa: The Journal for Decision Makers, 31(1), 17-29.

Sharma, P. \& Chrisman, J. J. (1999). Toward a reconciliation of the specific issues in the field of corporate entrepreneurship. Entrepreneurship Theory and Practice, 23, 3-11.

Stopford, J. \& Badem-Fuller, C. (1990). Creating corporate entrepreneurship. Strategic Management Journal, 15(7), 521-536.

Susbauer, J. (1973). Programa de emprendedurismo intra corporativo en la industria estadounidense. Universidad Estatal de Cleveland.

Trujillo, M. \& Guzmán, A. (2008). Intraemprendimiento: una revisión al constructo teórico, sus implicaciones y agenda de investigación futura. Cuadernos de Administración, 21(35), 37-63.

Veeraraghavan, V. (2009). Entrepreneurship and innovation. Asia-Pacific Business Review.

Vesga, R. (2007). Emprendimiento e innovación en Colombia: ¿Qué nos está haciendo falta? Recuperado el 20 de Noviembre de: http://web.unillanos.edu.co/docus/Emprendimiento\%20e\%20innovacion.pdf

Zahra, S. A. (1991). Predictors and financialoutcomes of corporate entrepreneurship: Anexploratory study. Journal of Business Venturing, 6(4), 259-285.

Zapata, A., Menendez, V. Prieto, M. \& Romero, C. (2013). A framework for recommendation in learning object repositories: An Example of application in Civil Engineering. Advances in Engineering Software, 56, 1-14. Available http://www.sciencedirect.com/science/article/pii/S0965997812001433. Lastaccessed April 09, 2016. 


\section{BIBLIOGRAFÍA CONSULTADA}

Antoncic, B. \& Hisrich, R. D. (2003). Clarifying the intrapreneurship concept. Journal of Small Business and Enterprise Development, 10(1), 7-24.

Departamento Nacional de Planeación - FONADE (2004). Metodología para la evaluación de la formulación de los Planes de Desarrollo Municipales.

Drucker, P. F. (1985). Innovation and Entrepreneurship. Harper \& Row.

Galán, J. L. \& Pizarro, I. (2005). El comportamiento emprendedor de las empresas: negocios internos y externos. Recuperado de http://catedradiversificacion.unizar.es/contenidos/publicaciones/ELCOMPORTAMIENTOEMPRENDEDOR.pdf

Gálvez E. J. (2011). Cultura intraemprendedora e innovación: un estudio empírico en las mipyme turísticas colombianas. Cuadernos de Administración, 27(46), 103-114.

Gálvez, E. \& García, D. (2011). Cultura, innovación, intraemprendimiento y rendimiento en las mipyme de Colombia (Tesis doctoral). Universidad Politécnica de Cartagena.

Gálvez, E. J. \& García, D. (2011). Impacto de la Cultura Intraemprendedora en el rendimiento de las mipyme del sector turístico colombiano. Un estudio empírico. Universidad y Ciencia, 52, 27-36.

Garzón, M. (2008). Propuesta de modelo de emprendimiento corporativo o intraemprendimiento para la innovación. Revista Ciencias Administrativas. Universidad del Norte.

Hamel, G. (2009). El futuro de la administración. Harvard Business School Press.

Jericó, P. (2013). Necesitamos intraemprendedores. Expansión. Com. Recuperado de: http://www.expansion.com/2013/01/18/ emprendedores-empleo/opinion/1358537150.html

Kantis, H. \& Drucaroff, S. (2011). Emprendimiento corporativo en América Latina, Conceptos, lecciones de la experiencia coreana y plataforma estratégica para su desarrollo en la región. Washington, D.C.: Fondo Multilateral de Inversiones (FOMIN).

Kantis, H., Ishida, M. \& Komori, M. (2002). Empresarialidad en economías emergentes: Creación y desarrollo de nuevas 
empresas en América Latina y el Este de Asia. Inter-American Development Bank.

Kuratko, D. (2009). Entreprenuership Theory, Process, Practice. South-Wenster: Cenage Learning.

Kuz, D. (2010). Exploration of Intrapreneurship and Innovation in Advanced Technology Organizations in the Western United States. Recuperado de: http://gradworks.umi.com/3425617. pdf

Lessem, R. (1990). Gestión de la cultura corporativa. Madrid: Ediciones Díaz de Santos, S.A.

Ley (1803). Congreso de Colombia. Disponible en: http://www. secretariasenado.gov.co/senado/basedoc/ley_1803_2016. html.

Lombriser, R. (1994). Grandes intraempresarios: Desarrollo de nuevos negocios dentro de las organizaciones. Barcelona: Folio. S.A.

Lumpkin, G. T. \& Dess, G. G. (1996). Clarifying the entrepreneurial orientation construct and linking it to performance. Academy of Management Review, 21(1), 135-172.

Lumpkin, G. T. (2007). Intrapreneurship and Innovation, En J. R. Baum, M. Frese y R. A. Baron (Eds.), The Psychology of Entrepreneurship (237-263). New Jersey: Lawrence Erlbaum.

Lyon, D. W., Lumpkin, G. T. \& Dess, G. G. (2000). Enhancing entrepreneurial orientation research: operationalizing and measuring a key strategic decision making process. Journal of Management, 26(5), 1055-1085.

Manimala, M. J. (2006). Organizational Constraints on Innovation and Intrapreneurship: Insights from Public Sector. Vikalpa, 31 , 49-60.

McDaniel, B. A. (2000). A Survey on entrepreneurship and innovation. The Social Science Journal, 37(2), 277-284.

Medina, C. \& Espinosa, M. (2000). La innovación en las organizaciones modernas. Revista Gestión y Estrategia, 5. Universidad Autónoma de México.

Pinchot, G., Pellma, R. (1999). Intrapreneuring in action: a handbook for bussines innovation. San Francisco: Berrett-Koehler Publishers, inc. 
Porter, M. (2007). Estrategia competitiva: técnicas para el análisis de los sectores industriales y de la competencia. ( $1^{\underline{a}}$ ed.). México: Grupo Editorial Patria.

Prodem (2010). Programa de desarrollo emprendedor. Recuperado de http://www.prodem.ungs.edu.ar/blog/2010/12/ emprendimiento-corporativo/

Rothaermel, F. T., Agung, S. D. \& Jiang, L. (2007). University Entrepreneuship: a taxonomy of the literatura. Industrial and Corporate Change, 16(4), 691-791. 


\title{
IDENTIFICACIÓN DEL PERFIL EMPRENDEDOR PARA EL DESARROLLO DEL EMPRENDIMIENTO
}

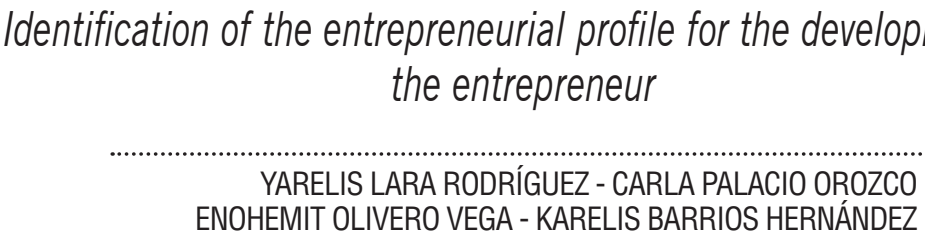 \\ JOSÉ MARÍA MENDOZA
}

\section{RESUMEN}

Este capítulo se centra en la identificación del perfil emprendedor para el desarrollo del emprendimiento de los estudiantes de la Institución de Educación Superior en la ciudad de Barranquilla que están cursando la cátedra de formación empresarial. Se realizó una revisión de la literatura que resultaba relevante para el desarrollo de cada uno de los aspectos relacionados con el proyecto: emprendimiento, emprendedor, creatividad, innovación, liderazgo, trabajo en equipo, la enseñanza del emprendimiento, los postulados del modelo pedagógico horizonte sociocrítico, entre muchos otros. Para conocer de qué manera estos aspectos del perfil se encuentran presentes en los estudiantes de primer y tercer módulo de la cátedra, se aplicó un instrumento con 35 afirmaciones. De la revisión realizada alrededor del significado del emprendimiento se concluyó que se trata de un concepto amplio, que se asocia a la cultura y se materializa en bienestar y desarrollo social. Estos desarrollos, consecuencia de la actividad emprendedora, pueden darse en distintos ámbitos, el empresarial, industrial, político, cultural, religioso, entre otros.

Palabras clave: cátedra, emprendimiento, formación empresarial, perfil emprendedor.

\section{ABSTRACT}

This chapter focuses on the identification of the entrepreneurial profile for the development of the entrepreneurship of the students of Institution of Higher Education e who are taking the business training course. A review of the literature that was relevant to the development of each of the aspects related to the project was undertaken: entrepreneurship, entrepreneurship, creativity, innovation, leadership, teamwork, entrepreneurship teaching, postu- 


\begin{abstract}
lates of the sociocritical horizon pedagogical model, among many others. In order to know how these aspects of the profile are present in the students of the first and third module of the chair, an instrument with 35 statements was applied. From the review carried out around the meaning of entrepreneurship, it was concluded that this is a broad concept, which is associated with culture and materialized in welfare and social development. These developments, as a result of the entrepreneurial activity, can take place in different areas, business, industrial, political, cultural, religious, etc.
\end{abstract}

Key words: professorship, entrepreneurship, business training, entrepreneurial profile.

\title{
1. INTRODUCCIÓN
}

El éxito de los proyectos empresariales está relacionado con las capacidades y competencias con las que cuente el emprendedor. La Institución de Educación Superior, ubicada en la ciudad de Barranquilla, Colombia, consciente del contexto económico-social que vive actualmente el país, y atendiendo a los requerimientos de la Ley 1014 de 2006, a través de la Resolución Rectoral 030 de 2009, crea la cátedra de formación empresarial con el objetivo de brindar al estudiante las herramientas necesarias para la creación y puesta en marcha de su proyecto empresarial.

Para evaluar si la cátedra de formación empresarial desarrolla las competencias, se realizarán encuestas de tipo Likert a los estudiantes de primer y tercer módulo. Este estudio permitirá evidenciar que los estudiantes tenían falencias en la generación de ideas de negocios creativas e innovadoras, y en la solución de problemas, aunque la cátedra de formación empresarial contempla en uno de sus módulos esta temática.

Partiendo de esta problemática, se investigarán son los aspectos principales que definen a un emprendedor, según diferentes autores de gran reconocimiento en el tema, con el objetivo de identificar el perfil emprendedor para el desarrollo del emprendimiento en los estudiantes. 
Con la publicación de la Ley 1014 de 2006, el Estado colombiano le dio piso jurídico y definió mecanismos para la promoción del emprendimiento y la creación de empresas. Uno de los mecanismos estipulados por el artículo 13 de la citada ley, se refiere a la enseñanza obligatoria del Emprendimiento en las instituciones de educación, desde el nivel preescolar hasta el superior, mediante la definición de un área de formación para el emprendimiento, la innovación, la creatividad y las competencias para la generación de empresas, la cual debe incorporarse al currículo y cursarse a través de todo el plan de estudios. Para cumplir con este mecanismo, las instituciones de educación diseñan e imparten módulos específicos sobre temas empresariales en el contexto de la "Cátedra Empresarial".

Otro de los mecanismos que contempla la Ley en el artículo 5 para el fomento del emprendimiento, es la creación de la Red Nacional para el Emprendimiento adscrita al Ministerio de Comercio, Industria y Turismo, encargada de definir las políticas y formular el plan estratégico nacional de emprendimiento, entre otras. Esta Ley también le da vida a las redes regionales de emprendimiento, adscritas a las Gobernaciones Departamentales (art. 6). REMA, es la Red Regional de Emprendimiento del Atlántico, a la cual está vinculada como miembro activo, la Institución de Educación Superior.

\section{FUNDAMENTACIÓN TEÓRICA}

Según Dolabela (2008), citado por Anzola y Farías (2011), para definir emprendimiento existen dos corrientes principales desde el punto de vista de los economistas que asocian al emprendedor con la innovación, y desde un enfoque de los comportamentalistas que enfatizan aspectos actitudinales como la creatividad y la intuición. 
$\approx$ Schumpeter (1936) reconoce el emprendimiento como una combinación de recursos, o más exactamente de servicios, que pueden ser derivados de dichos recursos (como se citó en Toca, 2010). Pero para Shumpeter (1936), los emprendedores (internos -dentro de la empresa- y externos) generan innovaciones que rompen los equilibrios económicos precedentes, generando nuevos equilibrios. Las innovaciones generan oleadas de destrucción creativa, que acaban con antiguos paradigmas y dan lugar a nuevos órdenes más robustos (Shumpeter, 1942 citado en Ferrás, 2010).

Por su parte, la Comisión Europea define el emprendimiento centrado en el contexto empresarial como una actitud en la que se manifiesta la motivación y la capacidad del individuo, independientemente o dentro de una organización, a la hora de identificar una oportunidad y luchar por ella para producir nuevo valor o éxito económico (Comisión Europea, 2003).

Bratnicki (2005), al referirse al emprendimiento, plantea que no se limita a oportunidades, sino que se extiende al plano de las acciones, es decir, conductas que buscan cambiar la forma como vive o trabaja la gente, movilizar recursos y desplegar iniciativas. Se concibe como una red de relaciones, interacciones e influencias de multicausalidad entre gente, oportunidades y acciones (Bratnicki, 2005 citado en Toca, 2010).

El emprendimiento es entendido como un proceso en el cual se involucran los individuos, y se inicia mucho antes de que las propias empresas se hayan creado. Así, el GEM toma información sobre todas estas etapas en el desarrollo Global Entrepreneurship Monitor (GEM, 2008). Es importante señalar que este organismo internacional analiza el fenómeno en el marco del proceso de creación de empresas y la actitud del sujeto que desarrolla la actividad emprendedora.

Como se puede observar, cada autor explica el fenómeno del emprendimiento desde perspectivas diferentes: una actividad en 
la cual la innovación es el eje central, un proceso de gestión de cambio radical, búsqueda de oportunidades, una actitud, un problema asociado a la cultura, la acción de iniciar una nueva empresa, desarrollar o reorientar organizaciones existentes, por citar algunos ejemplos. Los aportes realizados por los autores demuestran en sí que el emprendimiento juega un papel clave en el desarrollo de la sociedad.

En correspondencia con esto, Toca (2010) afirma que actualmente la actividad emprendedora es un tema importante, por lo que los gobiernos intentan promoverlo, los individuos aspiran practicarlo, las organizaciones buscan desesperadamente recapturarlo y la academia aspira estudiarlo.

En ausencia de una definición universal de emprendimiento y retomando los aspectos que los diferentes investigadores resaltan alrededor del fenómeno, los autores del presente trabajo de investigación proponen la siguiente definición:

El emprendimiento es un proceso que parte de la identificación de oportunidades y la decisión de aprovecharlas mediante la realización de un conjunto de acciones sistemáticas que generan cambios de diverso orden, en procura de obtener recompensas que se reflejen en un bienestar social sostenible. Estas acciones se concretan en la constitución de nuevas organizaciones o en el desarrollo de las existentes, las cuales, a partir de la permanente y óptima combinación de los recursos y de las capacidades a su alcance, se reinventan (innovadoras) para satisfacer necesidades, con sentido ético y responsabilidad social.

\subsection{Emprendedor-Entrepreneur}

El concepto de emprendedor se vincula al ámbito empresarial porque es en el contexto económico en el cual nace. Sin embargo, hoy es común encontrar en la literatura diferentes tipos 
de emprendedores: empresarial, social, político, cívico, corporativo, solidario, académico, religioso, entre otros.

Varela (2008) afirma que la diferenciación entre los tipos de emprendedores está más en el tema de la naturaleza de la actividad que realizan y el tipo de riquezas generadas, que en la que se pueda denominar "características básicas" de la acción dinámica del emprendedor.

Pereira (2007), por su parte, sostiene que lo que realmente diferencia al emprendedor es un proceso de desarrollo caracterizado por la innovación constante, centrándose en el proceso de desarrollo y no en los resultados de la acción. Lo que permite caracterizarlo como tal, no es el resultado de la acción del emprendedor, concretada en la creación de una empresa o en una gran acumulación de capital.

En concordancia con lo antes expuesto, Ferrás (2010), en su libro Innovación 6.0 relaciona los conceptos de innovación, emprendimiento y emprendedor, al afirmar que efectivamente ahora más que nunca, la innovación es la fuerza que mueve la economía.Y, si el proyecto (el emprendimiento o actividad emprendedora), es la unidad de innovación, el emprendedor es el agente específico que la hace posible.

Este mismo autor asigna a la innovación dos condiciones: Ser sistémica y sistemática. Si el emprendedor es el sujeto que desarrolla la innovación, la primera condición exige del individuo capacidad para observar y entender el sistema en el cual se desarrolla, los sistemas con los cuales interactúa, las partes que conforman dichos sistemas, su funcionamiento, el tipo de relaciones existentes entre estos, las posibilidades de establecer nuevas relaciones y sus significados. La segunda condición, ser 
sistemática, exige por parte del emprendedor la capacidad para ordenar las ideas y concretarlas en acciones con miras a lograr el efecto que se desea o se espera (Ferrás, 2010).

Al igual que con la definición de emprendimiento, no existe consenso alrededor de la definición de emprendedor. Cada autor asocia el término a aspectos relacionados con la actitud, capacidades, la innovación, la creación de empresas, entre otros. Con base en las mencionadas definiciones, y en coherencia con la que se presentó de emprendimiento, se propone la siguiente:

Emprendedor: Individuo (o grupo de individuos) que posee pensamiento sistémico, capaz de identificar oportunidades y aprovecharlas mediante la formulación de un plan que se pone en escena de manera creativa, innovadora, responsable e inclusive arriesgando su propio prestigio. El emprendedor impulsa una sucesión de cambios de diversa índole, que producen recompensas, para él y para la sociedad, bienestar sostenible.

\subsection{Perfil del estudiante emprendedor}

Como ya se ha mencionado, el emprendimiento se ha estudiado desde distintas disciplinas y paradigmas, razón por la cual las definiciones que se encuentran alrededor del fenómeno, difieren unas de otras. De igual manera, se encuentra un sinnúmero de investigaciones sobre el perfil del emprendedor, en las cuales se han identificado diversos tipos que se presentan en listas de características, habilidades, competencias, actividades, entre otras. Como resultado de una amplia revisión Louis Jacques Filion identificó los elementos mencionados con mayor frecuencia en las definiciones de "emprendedor", como se muestra en las Tabla No. 1 y 2 . En ellas se registran las actividades que comúnmente se le asocian a la actividad que realiza el emprendedor. 
Tabla 1. Elementos del empresario

\begin{tabular}{|c|c|}
\hline $\begin{array}{l}\text { ELEMENTOS QUE DEFINEN } \\
\text { AL EMPRESARIO } \\
\text { (EMPRENDEDOR) }\end{array}$ & AUTORES \\
\hline 1. Innovación & $\begin{array}{c}\text { Schumpeter (1947), Cochran (1968), Drucker (1985), } \\
\text { Julien (1989, 1998). }\end{array}$ \\
\hline 2. Riesgo & $\begin{array}{c}\text { Cantillon (1755), Knight (1921), Palmer (1971) } \\
\text { Reuters (1982), Rosenberg (1983). }\end{array}$ \\
\hline $\begin{array}{l}\text { 3. Coordinación de los recursos } \\
\text { para la producción; factor orga- } \\
\text { nizacional de producción o de la } \\
\text { administración de recursos }\end{array}$ & $\begin{array}{l}\text { Ely \& Hess (1893), Cole (1942), Aitken (1965), } \\
\text { Belshaw (1955), Chandler (1962), Leibenstein (1968), } \\
\text { Wilken (1979), Pearce (1981), Casson (1982). }\end{array}$ \\
\hline 4. Creación de valor & $\begin{array}{c}\text { Say }(1815,1996), \text { Bruyat \& Julien (2001), } \\
\text { Fayolle (2008) }\end{array}$ \\
\hline $\begin{array}{l}\text { 5. Pensamiento proyectivo y } \\
\text { visionario }\end{array}$ & Longenecker \& Schoen(1975), Filion (1991, 2004). \\
\hline 6. Foco en la acción & Baty (1981). \\
\hline 7. Liderazgo & Hornaday \& Aboud (1971) \\
\hline 8. Motor del sistema económico & $\begin{array}{l}\text { Weber (1947), Baumol (1968), } \\
\text { Storey (1982), Moffat (1983) }\end{array}$ \\
\hline 9. Creación de empresas & $\begin{array}{l}\text { Collins, Moore \& Unwalla (1964), Smith (1967), } \\
\text { Collins \& Moore (1970), Brereton (1974), } \\
\text { Komives (1974); Mancuso (1979), Schwartz (1982), } \\
\text { Carland, Hoy, Boulton \& Carland (1984), Vesper (1990) }\end{array}$ \\
\hline $\begin{array}{l}\text { 10. Reconocimiento de la } \\
\text { oportunidad }\end{array}$ & $\begin{array}{c}\text { Smith (1967), Meredith, Nelson \& Neck (1982), } \\
\text { Kirzner (1983), Stevenson \& Gumpert (1985), } \\
\text { Timmons (1989), Dana (1995), } \\
\text { Shane \& Venkataraman (2000), } \\
\text { Bygrave \& Zacharakis (2004), Timmons \& Spinelli } \\
\text { (2004). }\end{array}$ \\
\hline 11. Creatividad & Zaleznik \& Kets de Vries (1976), Pinchot (1985) \\
\hline 12. Ansiedad & Lynn (1969), Kets de Vries $(1977,1985)$ \\
\hline 13. Control & McClelland (1961) \\
\hline 14. Introducción de los cambios & Mintzberg (1973), Shapiro (1975) \\
\hline 15. Rebelión/Delincuencia & Hagen (1960) \\
\hline
\end{tabular}

Fuente: Filion, J. L. (2011) 
Tabla 2. Actividades y características comunes que se le atribuyen al emprendedor

\begin{tabular}{|c|c|}
\hline ACTIVIDADES & CARACTERÍSTICAS \\
\hline 1. Aprender & $\begin{array}{l}\text { Experiencia en el sector; memoriza la información; uso de } \\
\text { la retroalimentación. }\end{array}$ \\
\hline 2. Escoger un sector & $\begin{array}{l}\text { Interés; motivación; evaluación de potencial del valor añadi- } \\
\text { do para el futuro. }\end{array}$ \\
\hline 3. Identificar nichos & Cuidado; capacidades analíticas; precisión; meta. \\
\hline $\begin{array}{l}\text { 4. Reconocer y desarrollar } \\
\text { oportunidad empresarial }\end{array}$ & $\begin{array}{l}\text { Originalidad; diferenciación; creatividad; intuición; iniciati- } \\
\text { va; cultura de la innovación del valor. }\end{array}$ \\
\hline 5. Visualización proyectiva & $\begin{array}{l}\text { Habilidad para soñar realísticamente; Habilidades concep- } \\
\text { tuales; Pensamiento sistémico; anticipación; precaución; } \\
\text { habilidad para establecer metas y objetivos; visionario. }\end{array}$ \\
\hline 6. Manejar el riesgo & $\begin{array}{c}\text { Ahorro; seguridad; conservador; moderación al tomar } \\
\text { riesgos; habilidad para tolerar la incertidumbre y la ambi- } \\
\text { güedad; independencia. }\end{array}$ \\
\hline $\begin{array}{l}\text { 7. Diseñar (productos, } \\
\text { servicios, organizaciones) }\end{array}$ & Imaginación; habilidades para resolver problemas. \\
\hline 8. Comprometerse a la acción & $\begin{array}{l}\text { La auto-confianza relacionada con la identidad claramente } \\
\text { definida; compromiso a largo plazo; trabajo duro; energía; } \\
\text { orientación al resultado; toma de decisiones; pasión; centro } \\
\text { de control interno; determinación; perseverancia; tenacidad. }\end{array}$ \\
\hline 9. Usar recursos & Ingenio en el manejo de los recursos; coordinación; control. \\
\hline $\begin{array}{l}\text { 10. Construir redes } \\
\text { sociales }\end{array}$ & $\begin{array}{c}\text { Habilidades de interacción con otros; flexibilidad; empatía; } \\
\text { habilidades de comunicación y escucha; uso de mentores; } \\
\text { visión. }\end{array}$ \\
\hline $\begin{array}{l}\text { 11. Gerenciar: ventas, negocia- } \\
\text { ciones, personas }\end{array}$ & $\begin{array}{c}\text { Delegar; versatilidad; adaptabilidad; capacidad de diseñar } \\
\text { tareas; capacidad de delegar. }\end{array}$ \\
\hline 12. Desarrollo & م7an huch \\
\hline
\end{tabular}

Fuente: Filion, J. L. (2011)

Filion (2011) sostiene que no es posible definir un perfil en función de las características del individuo emprendedor, pues si bien identificarlas ayuda a precisar aspectos alrededor del concepto, no son el núcleo. La misma postura tiene frente a las actividades que se le asocian y afirma que estas son útiles al definir un tema de investigación, ya que son fácilmente identificables; pueden ser delimitadas e incluso algunas de ellas pueden medirse. 
Sin embargo, advierte que es necesario diferenciar cuáles son realmente las relacionadas con el emprendimiento (la iniciativa empresarial) y cuáles son simplemente actividades relacionadas con la gestión, que complementan a las primeras y caen en la categoría de actividades puramente gerenciales. En ese orden de ideas, sugiere identificar los elementos que el sujeto muestra cuando actúa como emprendedor y diferenciarlos de aquellos que son de naturaleza gerencial. Enfatiza la necesidad de concentrarse en el acto de reconocimiento y desarrollo de oportunidades como esencia de la actividad emprendedora que, según su juicio, determinan el perfil.

Por lo anterior, sostiene que en la definición de emprendedor deben estar presentes al menos los siguientes componentes:

1) Un emprendedor es un actor que innova; 2) mediante el reconocimiento de oportunidades; 3) toma moderadamente decisiones arriesgadas; 4) que conducen a acciones; 5) que requieren el uso eficiente de los recursos; y 6) aportan un valor añadido. (Filion, 2011, p.124).

En este mismo sentido, otros autores diferencian el rol del emprendedor del rol del administrador, al afirmar que:

el espiritu emprendedor permite advertir una oportunidad para satisfacer la necesidad de un cliente y después decidir cómo encontrar y usar recursos para elaborar un producto o un servicio que satisfaga esa necesidad. Una vez que un emprendedor logra producir algo que los clientes quieren, el espíritu emprendedor debe ceder su lugar a la administración, porque la necesidad apremiante se transforma en la de proveer el producto con eficiencia y eficacia. (Jones \& George, 2010, p.251)

Varela (2008) por su parte, presenta el perfil emprendedor asociándolo a competencias. Define un conjunto de 13 comportamientos observables y medibles vinculados en forma causal con un desempeño superior en la actividad emprendedora; estos son Ver Tabla 3. 
Tabla 3. Competencias y sus definiciones para el desarrollo de empresarios

\begin{tabular}{|c|c|}
\hline COMPETENCIA & DEFINICIONES \\
\hline $\begin{array}{l}\text { 1. Visión de la carrera } \\
\text { empresarial }\end{array}$ & $\begin{array}{l}\text { Formulación de un plan de acción con metas de largo plazo para } \\
\text { poner en marcha la empresa usando la imaginación. }\end{array}$ \\
\hline 2. Sensibilidad social & $\begin{array}{l}\text { Comprensión y aplicación de la idea de que el progreso y el bie- } \\
\text { nestar se deben construir respetando al ser humano y a la natura- } \\
\text { leza que debe beneficiar a todos los actores sociales, y que todos } \\
\text { debemos cumplir nuestra labor dentro de un marco ético y de un } \\
\text { proceso de consciencia social. }\end{array}$ \\
\hline 3. Orientación al logro & $\begin{array}{l}\text { Preocupación por alcanzar estándares de excelencia superiores a } \\
\text { los existentes. }\end{array}$ \\
\hline 4. Autoconfianza & $\begin{array}{l}\text { Optimismo para salir adelante en sus actividades, ya que asume } \\
\text { tener los conocimientos, la capacidad humana y profesional, la } \\
\text { actitud y la energía para lograr sus metas. }\end{array}$ \\
\hline 5. Amplitud perceptiva & $\begin{array}{l}\text { Exploración más allá de su círculo de experiencia y referencia para } \\
\text { poder encontrar nuevas oportunidades. }\end{array}$ \\
\hline 6. Flexibilidad & $\begin{array}{c}\text { Disposición a cambiar de enfoque o de manera de concebir la } \\
\text { realidad para dar lugar a otras opciones que permitan hacer bien } \\
\text { las cosas. }\end{array}$ \\
\hline 7. Empatía & $\begin{array}{l}\text { Comprensión de las emociones, necesidades e intereses de otros, } \\
\text { procurando su apropiada conciliación con las nuestras. }\end{array}$ \\
\hline $\begin{array}{l}\text { 8. Pensamiento } \\
\text { Conceptual }\end{array}$ & $\begin{array}{c}\text { Identificación de las relaciones existentes entre los diferentes } \\
\text { componentes de situaciones complejas, que no están directamen- } \\
\text { te relacionadas, y construcción de conceptos o modelos de fácil } \\
\text { aplicación. }\end{array}$ \\
\hline $\begin{array}{l}\text { 9. Orientación al } \\
\text { mercado }\end{array}$ & $\begin{array}{l}\text { Consideración permanente de las condiciones del mercado en to- } \\
\text { das las decisiones que se toman en las actividades empresariales. }\end{array}$ \\
\hline 10. Gestión de empresa & $\begin{array}{l}\text { Reunión e integración de manera creativa de los recursos requeri- } \\
\text { dos para iniciar, mantener y acrecentar la actividad empresarial. }\end{array}$ \\
\hline $\begin{array}{l}\text { 11. Construcción de } \\
\text { redes empresariales }\end{array}$ & $\begin{array}{l}\text { Es establecer, mantener y aprovechar relaciones con personas y } \\
\text { entidades para alcanzar los objetivos empresariales. }\end{array}$ \\
\hline 12. Toma de decisiones & $\begin{array}{c}\text { Análisis de las diversas alternativas para determinar los mejores } \\
\text { caminos a seguir, asumiendo la responsabilidad de los resultados } \\
\text { logrados. }\end{array}$ \\
\hline $\begin{array}{l}\text { 13. Orientación a la } \\
\text { acción }\end{array}$ & $\begin{array}{l}\text { Energía, fuerza, coraje y dedicación para llevar a cabo, por inicia- } \\
\text { tiva propia, las acciones necesarias para hacer realidad las ideas, } \\
\text { propuesta, oportunidades y proyectos empresariales. }\end{array}$ \\
\hline
\end{tabular}

Fuente: Varela, R. Bedoya, 0. (2006). 
A partir de la definición establecida por los autores de la presente investigación, se entiende el emprendimiento como un proceso que parte de la identificación de oportunidades y la decisión de aprovecharlas, mediante la realización de un conjunto de acciones sistemáticas, que generan cambios de diverso orden, en procura de obtener recompensas que se reflejen en un bienestar social sostenible.

Estas acciones se concretan en la constitución de nuevas organizaciones o en el desarrollo de las existentes, las cuales, a partir de la permanente y óptima combinación de los recursos y de las capacidades a su alcance, se reinventan (innovadoras) para satisfacer necesidades, con sentido ético y responsabilidad social. De esta definición se puede inferir que el emprendedor es el agente que impulsa una sucesión de cambios de diversa índole, que producen recompensas para él, y para la sociedad, bienestar sostenible, los elementos claves constitutivos de su perfil, son, el poseer: pensamiento sistémico, capacidad para identificar y aprovechar oportunidades emprendedoras, autoeficacia, ser creativo e innovador, ser responsable consigo mismo y con la sociedad.

\subsection{Pensamiento sistémico}

El pensamiento sistémico es una facultad inherente al ser humano que se fundamenta en su capacidad para percibir el mundo real en términos de totalidades para el análisis, comprensión de los sistemas en los cuales está inmerso y sus conexiones, con el propósito de resolver los problemas que surjan de las propiedades emergentes de dichos sistemas.

El pensamiento sistémico es una forma de pensamiento, es una concepción práctica que parte de la idea de cómo individuos somos un sistema y estamos rodeados de un sinnúmero de 
sistemas. O'Connor \& McDermontt (1998) lo definen como un método para identificar algunas series de patrones y sucesos, para prepararnos de cara al futuro e influir sobre él en alguna medida. Nos aporta cierto control.

Actualmente el enfoque sistémico se aplica al estudio de las organizaciones, ya que plantea una visión integradora (interdisciplinaria, multidisciplinaria y transdisciplinaria) para comprender la dinámica organizacional con mayor claridad y profundidad. Desde esta perspectiva, se entiende a la organización como un sistema, constituido por partes que se interrelacionan entre sí a través de una estructura organizativa, mediante la cual establece relaciones al interior y con el contexto en el cual se desenvuelve. En esta perspectiva holística e integradora, las organizaciones están en capacidad de identificar los problemas a los cuales se enfrentan, las necesidades de cambio y los procesos que deben emprender para implementarlos de manera integral. Es decir, considerando todos los ámbitos y sus repercusiones en las personas, los recursos, el medioambiente y la sociedad en general, desarrollando aprendizaje y crecimiento sostenible.

\subsection{Identifica y aprovecha oportunidades}

En la revisión de la literatura es claro que los académicos coinciden en que un aspecto característico del emprendedor es su capacidad para identificar oportunidades. Hitt, Ireland \& Hoskisson (2008), afirman que no se trata de cualquier oportunidad, sino de oportunidades emprendedoras, y las definen como aquellas condiciones en las que los nuevos bienes o servicios podrán satisfacer una necesidad que existe en el mercado, las cuales se presentan como resultado de las imperfecciones de la competencia en los mercados, y de los factores de producción que se utilizan para producirlos, y cuando la información acerca de estas imperfecciones está distribuida de forma asimétrica entre las personas. 
Según Mendoza (2006), una oportunidad es un valor de una variable o un comportamiento de un actor del entorno que tendría un impacto positivo en los resultados de la empresa, si se gestiona su aprovechamiento.

\subsection{Autoeficacia}

En la definición de emprendedor, en el proceso de aprovechar una oportunidad emprendedora, este individuo realiza una serie de acciones que generan una sucesión de cambios de diversa índole, que producen beneficios. Anteriormente se afirmó que el emprendedor, a diferencia del común de las personas, es capaz de identificar la oportunidad emprendedora, la que a su vez se distingue de una simple oportunidad, porque el resultado de su aprovechamiento es un nuevo bien o servicio (innovación). Varela (2008) define la autoconfianza como la seguridad de poseer el conocimiento y la capacidad humana para asumir con éxito situaciones que implican riesgos, estrés e incertidumbre.

\subsection{Creatividad e innovación}

Al revisar las definiciones de innovación, encontramos que existe una estrecha relación entre dos conceptos, innovación y creatividad. Uno de los autores que muestra de manera amplia y sencilla dicha relación es Mendoza (2006), al exponer que la innovación es el resultado de combinar la creatividad y la acción. La creatividad se refleja en la obtención de algo nuevo, pero ese algo se puede quedar en una simple idea o cuando más en una intención, en este caso no habría innovación porque falta la realización práctica de esa idea. A la inversa, la innovación no exige la presencia de una idea totalmente novedosa, se puede ser innovador cuando se toma una idea (nueva) de otro, reconociendo su paternidad, incluso haciéndole ajustes, y se pone en ejecución por parte de uno mismo. De esta forma se puede ser 
creativo sin ser innovador y se puede ser innovador sin ser tan creativo.

A partir de todo lo anterior podríamos concluir, de manera general, que los innovadores son aquellas personas capaces de poner en escena soluciones originales exitosas.

Por su parte, Peter Drucker, uno de los padres de la filosofía del management del siglo XX, afirma que "las innovaciones, especialmente aquellas de más éxito, son fruto de una búsqueda consciente y deliberada de oportunidades" (citado por Ponti \& Ferrás, 2008, p.166).

Ferrás (2010), al referirse al líder innovador, lo califica como la fuerza motriz del cambio, librepensador, transgresor, creativo, capaz de fluir en condiciones de cambio, y de influir decisivamente en la estrategia global de la empresa.

\subsection{Responsabilidad social}

Algunos autores, con el propósito de incorporar al fenómeno del emprendimiento el tema de la responsabilidad social, han empezado a calificarlo como emprendimiento social. Vale la pena señalar que en la comunidad académica existen relativamente pocos acuerdos al respecto, incluso entre aquellos que lo han tratado de definir. De manera muy general se puede identificar en las diferentes definiciones, el deseo de fondo de producir cambios sostenibles en lo social. Por ello, es común encontrar que en el marco de este "tipo" de emprendimiento se pretenda dar soluciones a problemas sociales, tales como el analfabetismo, la drogadicción o la contaminación ambiental, entre otros. Al referirse al emprendedor social, le asignan la característica de actuar como agente de cambio, como ocurre con el emprendedor en un sentido general. 
\& Guzmán \& Trujillo (2009) proponen una definición ecléctica, en la cual el emprendimiento social se entiende como un tipo específico de emprendimiento que busca soluciones para problemas sociales a través de la construcción, evaluación y persecución de oportunidades que permitan la generación de valor social sostenible, alcanzando equilibrios nuevos y estables en relación con las condiciones sociales, a través de la acción directa llevada a cabo por organizaciones sin ánimo de lucro, empresas u organismos gubernamentales.

Como ya se anotó, en la presente investigación se aborda el fenómeno del emprendimiento desde una perspectiva general y amplia, independientemente del contexto en el cual se desarrolle. Sin embargo, la anterior definición, pese a que se refiere a un tipo de emprendimiento social reconoce, por una parte, que ella se puede desarrollar en cualquier sector (organizaciones sin ánimo de lucro, empresas u organismos gubernamentales), y del individuo emprendedor, la disposición para sentir, pensar y dirigir las acciones como estrategia para alcanzar objetivos y metas que generen valor social sostenible, a lo cual se agrega: ponderando y armonizando las implicaciones de las acciones que desarrolle para sí mismo, para la comunidad con la cual interactúa y para el planeta.

\subsection{Enseñanza del emprendimiento}

La importancia del sistema educativo en su rol de generador de conocimiento y formador del talento humano idóneo debe servir para el desarrollo sostenible de la sociedad. Dicho de otra manera, el sistema debe garantizar una oferta educativa de calidad que incluya formación en emprendimiento, es decir, que fomente en el individuo las competencias específicas que le permitan participar de manera innovadora en el sector productivo 
(público o privado), como en los ámbitos cultural, religioso, político, académico, social... que generen competitividad social.

Teniendo en cuenta la relación existente entre el emprendimiento y la administración, de manera específica en lo relacionado con el aprendizaje de esta última, Charles Handy (1995), uno de los pensadores de la gerencia más reconocidos en Europa, sostiene que el aprendizaje es un proceso que incluye cuatro fases, lo que él denominó la rueda del aprendizaje. Las fases son: hacerse preguntas, elaborar teorías a manera de respuesta a las cuestiones planteadas en la fase uno, comprobación de dichas teorías, y reflexión, para ver por qué la teoría dio o no dio resultado.

En la misma vía, Senge (1990) sostiene que los elementos centrales del aprendizaje de las organizaciones son: la maestría personal, el trabajo en equipo, la visión compartida, los modelos mentales y el enfoque sistémico, dándole prioridad a este último. Mitzberg (1998) por su parte, en lo relacionado con el aprendizaje se centra en los métodos de aprendizaje, que van desde los juegos gerenciales, de roles, proyectos de aplicación en las empresas y estudios de caso, siendo estos en la actualidad los métodos más utilizados para potenciar las competencias del emprendedor citado por (Mendoza, 2013).

De manera general, otros aspectos que hay que mencionar y que dificultan el proceso de formación en emprendimiento son, por una parte, un entorno turbulento con nuevos y complejos problemas por resolver, y por otra, que la pedagogía no cambia con la misma velocidad con la que cambia el entorno. Esta realidad exige que las Universidades revisen permanentemente los contenidos, las metodologías, estrategias y recursos pedagógicos que utiliza para garantizar que estén alineados con 
× las exigencias del mundo moderno y cumplan con la intención de formar individuos emprendedores. Por lo tanto, el sistema educativo debe enfatizar en enseñar al estudiante cómo pensar, para lo que existen unas metodologías recomendadas y relacionadas con la solución de problemas.

Estas acciones se concretan en la constitución de nuevas organizaciones o en el desarrollo de las existentes, las cuales, a partir de la permanente y óptima combinación de los recursos y de las capacidades a su alcance, se reinventan (innovadoras) para satisfacer necesidades, con sentido ético y responsabilidad social. $Y$ al sujeto que desarrolla el proceso, es decir, el emprendedor lo define como Individuo (o grupo de individuos) que posee pensamiento sistémico, capaz de identificar oportunidades y aprovecharlas mediante la formulación de un plan que se pone en escena de manera creativa, innovadora, responsable e inclusive arriesgando su propio prestigio. El emprendedor impulsa una sucesión de cambios de diversa índole, que producen recompensas para él y para la sociedad, bienestar sostenible.

En consonancia con lo antes expuesto, y teniendo en cuenta la definición propuesta por los autores de emprendimiento y emprendedor, en las que se identifica el perfil que se desea formar en el estudiante, para la enseñanza se propone una metodología activa en la que el estudiante construya conocimiento sobre el qué, por qué, para qué y cómo del emprendimiento. Para lograrlo desarrollarán a lo largo de los cinco módulos que componen la cátedra, cuatro grandes estrategias didácticas, cuyo propósito general es el de potenciar en el estudiante su capacidad para identificar los problemas presentes en su entorno, entenderse como parte de ellos y como gestor de soluciones innovadoras que se caractericen por ser éticas y responsables, las cuales se describen con detalle en la propuesta de rediseño de la cátedra. 


\section{METODOLOGÍA}

En esta sección se presentan los aspectos relevantes de la metodología utilizada para el desarrollo de la presente investigación: tipo de investigación, diseño, tamaño de la muestra, el instrumento de recolección de la información y su análisis. Con el objetivo de identificar el perfil emprendedor de los estudiantes de una Institución de Educación Superior para el desarrollo del emprendimiento.

El presente proyecto es un estudio descriptivo de corte cuantitativo; estos estudios buscan especificar las propiedades, características y los perfiles de personas, grupos, comunidades, procesos, objetos o cualquier otro fenómeno que se someta a un análisis (Danhke, 1989 en Hernández Sampieri, 2008).

En esta clase de estudios el investigador debe ser capaz de especificar quién o quiénes tienen que incluirse en la medición. La descripción puede ser más o menos profunda, pero en cualquier caso se basa en la medición de uno o más atributos del fenómeno descrito (Sampieri, 2008).

Para la recolección de datos primarios se aplicó una encuesta cerrada con escala tipo Likert, a estudiantes de primer y tercer modulo de la cátedra de formación empresarial de los programas académicos de pregrado (profesionales) de Administración de Empresas, Comercio y Negocios Internacionales, Contaduría Pública, Derecho, Enfermería, Fisioterapia, Ingeniería de Sistemas, Ingeniería Industrial, Psicología y Trabajo Social. Es importante aclarar que no se tienen en cuenta a los estudiantes de las Licenciaturas en Educación y Medicina, porque el plan de estudios de estos programas no obliga a cursar ninguno de los módulos que conforman la Cátedra. Tampoco se incluyó a los estudiantes de Ingeniería de Mercados y Microbiología, debido a que estos programas tienen un número de estudiantes poco representativo para el presente estudio. 
× Para identificar a los estudiantes fue necesario consultar el sistema de información académico administrativo (SIAA, base de datos de estudiante) de la Universidad, lo cual arrojó los siguientes resultados; (Ver Tabla 4 y 5).

Tabla 4. Estudiantes de primer módulo (2012-2 período)

\begin{tabular}{|c|c|}
\hline PROGRAMAS PROFESIONALES & $\begin{array}{c}\text { No. DE ESTUDIANTES DE PRIMER MÓDULO DE } \\
\text { LA CÁTEDRA DE FORMACIÓN EMPRESARIAL }\end{array}$ \\
\hline Administración de Empresas & 133 \\
\hline Comercio y Negocios Internacionales & 34 \\
\hline Contaduría Pública & 159 \\
\hline Derecho & 281 \\
\hline Enfermería & 102 \\
\hline Fisioterapia & 77 \\
\hline Ingeniería de Sistemas & 59 \\
\hline Ingenieria Industrial & 35 \\
\hline Psicología & 224 \\
\hline Trabajo Social & 46 \\
\hline Total estudiantes de primer módulo & 1.150 \\
\hline
\end{tabular}

Fuente: Elaboración propia

Tabla 5. Estudiantes que cursan el tercer módulo de la cátedra de formación empresarial $\left(2012-2^{\circ}\right.$ periodo).

\begin{tabular}{|c|c|}
\hline PROGRAMAS PROFESIONALES & $\begin{array}{c}\text { No. DE ESTUDIANTES QUE CURSAN EL TERCER } \\
\text { MÓDULO DE LA CÁTEDRA DE FORMACIÓN } \\
\text { EMPRESARIAL }\end{array}$ \\
\hline Administración de Empresas & 120 \\
\hline Comercio y Negocios Internacionales & 19 \\
\hline Contaduría Pública & 76 \\
\hline Derecho & 144 \\
\hline Enfermería & 177 \\
\hline Fisioterapia & 42 \\
\hline Ingeniería de Sistemas & 34 \\
\hline Ingenieria Industrial & 78 \\
\hline Psicología & 89 \\
\hline Trabajo Social & 28 \\
\hline Total estudiantes que cursan el tercer módulo \\
de la cátedra de formación empresarial
\end{tabular}

Fuente: SIAA 
Para definir el tamaño de la muestra se utilizó el muestreo aleatorio simple, porque la población objeto de estudio es identificable y de fácil acceso, debido a que se encuentra en el SIAA, por lo cual, los miembros de la muestra han sido elegidos al azar, de forma que cada miembro de la población tuvo igual oportunidad de ser elegido.

Cabe mencionar que la toma de la muestra se realizó utilizando números aleatorios del listado que arroja SIAA, el que contiene el nombre del estudiante, el programa académico al que pertenece y el módulo que cursa, primero o tercero, de la cátedra de Formación Empresarial. De este ejercicio el instrumento se aplicó a 548 estudiantes de los distintos programas académicos que tienen en su currículo la obligatoriedad de cursar la cátedra.

La validación del instrumento se realizó de la siguiente manera, en un primer momento se sometió este a un juicio de expertos, en el que participaron tres docentes versados en el tema de emprendimiento. Se presentaron las afirmaciones que correspondían a cada aspecto y se les pidió, entre otras cosas, que conceptuaran sobre la claridad con que se expresaba y la coherencia con el elemento del perfil. Los expertos realizaron una serie de valiosas observaciones que fueron tomadas en cuenta.

En un segundo momento, con el propósito de revalidar el instrumento, se les presentó a otros tres expertos los aspectos del perfil y la relación completa de las afirmaciones, pidiéndoles que asociaran cada afirmación con el aspecto del perfil que a su juicio tenía mayor relación. Como resultado de este ejercicio se confirmó que el instrumento es válido para recoger la información que se solicita en el estudio.

Luego se realizó una prueba piloto a 10 estudiantes inscritos en la cátedra de formación empresarial adscritos a los diferentes programas académicos, donde se analizó la confiabilidad de la 


\section{RESULTADOS}

A continuación se presentan los resultados de la aplicación del instrumento, por aspecto identificado en el perfil del emprendedor, a los estudiantes que cursan el primer módulo de la cátedra. La encuesta se aplicó a una muestra de 288 estudiantes de los programas académicos de pregrado (profesionales) de Administración de Empresas, Comercio y Negocios Internacionales, Contaduría Pública, Derecho, Enfermería, Fisioterapia, Ingeniería de Sistemas, Ingeniería Industrial, Psicología y Trabajo Social.

\subsection{Evaluación de las competencias emprendedoras de los estudiantes del primer módulo de la cátedra de formación empresarial}

Tabla 6. Resumen del procesamiento de los casos: Estudiantes que cursan el primer módulo de la cátedra

\begin{tabular}{|c|c|c|c|c|c|c|}
\hline \multirow{2}{*}{ AFIRMACIONES } & \multicolumn{5}{|c|}{ CASOS } \\
\cline { 2 - 8 } & \multicolumn{2}{|c|}{ Válidos } & \multicolumn{2}{c|}{ Perdidos } & \multicolumn{2}{|c|}{ Total } \\
\cline { 2 - 8 } & $\mathrm{N}$ & $\%$ & $\mathrm{~N}$ & $\%$ & $\mathrm{~N}$ & $\%$ \\
\hline $\begin{array}{c}\text { Considero en las actividades que realizo el im- } \\
\text { pacto de estas sobre el medioambiente y las } \\
\text { personas. }\end{array}$ & 288 & 100 & 0 & 0 & 288 & 100 \\
\hline $\begin{array}{c}\text { Al desarrollar una actividad o proyecto soy de los } \\
\text { que pienso "El fin justifica los medios". }\end{array}$ & 288 & 100 & 0 & 0 & 288 & 100 \\
\hline
\end{tabular}




\begin{tabular}{|c|c|c|c|c|c|c|}
\hline \multirow{3}{*}{ AFIRMACIONES } & \multicolumn{6}{|c|}{ CASOS } \\
\hline & \multicolumn{2}{|c|}{ Válidos } & \multicolumn{2}{|c|}{ Perdidos } & \multicolumn{2}{|c|}{ Total } \\
\hline & N & $\%$ & N & $\%$ & N & $\%$ \\
\hline Asumo mis errores con responsabilidad. & 288 & 100 & 0 & 0 & 288 & 100 \\
\hline $\begin{array}{l}\text { Asumo retos y los veo como escenario propicio } \\
\text { para desarrollar mi potencial. }\end{array}$ & 288 & 100 & 0 & 0 & 288 & 100 \\
\hline $\begin{array}{l}\text { Brindo el apoyo necesario a mi equipo de trabajo } \\
\text { en la ejecución de sus responsabilidades. }\end{array}$ & 288 & 100 & 0 & 0 & 288 & 100 \\
\hline $\begin{array}{c}\text { Considero al momento de plantear la solución a } \\
\text { un problema las variables internas y externas del } \\
\text { contexto que inciden en ella. }\end{array}$ & 288 & 100 & 0 & 0 & 288 & 100 \\
\hline $\begin{array}{l}\text { Cuando empiezo algo lo termino sin importar los } \\
\text { obstáculos que se interpongan. }\end{array}$ & 288 & 100 & 0 & 0 & 288 & 100 \\
\hline $\begin{array}{l}\text { Cuando me enfrento a un problema conocido, me } \\
\text { gusta encontrar nuevas formas para resolverlo. }\end{array}$ & 288 & 100 & 0 & 0 & 288 & 100 \\
\hline $\begin{array}{l}\text { Cuando pienso en mi futuro, alguna vez me imagi- } \\
\text { no al frente de mi propio negocio. }\end{array}$ & 288 & 100 & 0 & 0 & 288 & 100 \\
\hline $\begin{array}{l}\text { Cuando trabajo en equipo, no tengo miedo de } \\
\text { expresar mis opiniones, aunque otros miembros } \\
\text { del grupo no estén de acuerdo conmigo. }\end{array}$ & 288 & 100 & 0 & 0 & 288 & 100 \\
\hline $\begin{array}{l}\text { Desarrollo ideas nuevas en la cotidianidad para } \\
\text { demostrar mi capacidad. }\end{array}$ & 288 & 100 & 0 & 0 & 288 & 100 \\
\hline $\begin{array}{c}\text { Disfruto del triunfo que he alcanzado por mis } \\
\text { propios medios. }\end{array}$ & 287 & 100 & 1 & 0 & 288 & 100 \\
\hline Disfruto trabajar en varios proyectos a la vez. & 288 & 100 & 0 & 0 & 288 & 100 \\
\hline $\begin{array}{l}\text { Donde otros ven problemas, yo veo oportunida- } \\
\text { des. }\end{array}$ & 288 & 100 & 0 & 0 & 288 & 100 \\
\hline $\begin{array}{l}\text { Encuentro formas únicas para resolver circunstan- } \\
\text { cias impredecibles e inesperadas. }\end{array}$ & 288 & 100 & 0 & 0 & 288 & 100 \\
\hline $\begin{array}{c}\text { Encuentro necesario el cumplimiento de la nor- } \\
\text { matividad relacionada en el desarrollo de un } \\
\text { proyecto. }\end{array}$ & 288 & 100 & 0 & 0 & 288 & 100 \\
\hline $\begin{array}{l}\text { Identifico rápidamente los aspectos claves que se } \\
\text { deben considerar e intervenir para la solución de } \\
\text { un problema. }\end{array}$ & 288 & 100 & 0 & 0 & 288 & 100 \\
\hline $\begin{array}{l}\text { Indago sobre el nivel de satisfacción de las per- } \\
\text { sonas con las que me relaciono, bien sea a nivel } \\
\text { personal o laboral. }\end{array}$ & 288 & 100 & 0 & 0 & 288 & 100 \\
\hline $\begin{array}{l}\text { Influyo positivamente en el desempeño de las } \\
\text { demás personas. }\end{array}$ & 288 & 100 & 0 & 0 & 288 & 100 \\
\hline
\end{tabular}




\begin{tabular}{|c|c|c|c|c|c|c|}
\hline \multirow{3}{*}{ AFIRMACIONES } & \multicolumn{6}{|c|}{ CASOS } \\
\hline & \multicolumn{2}{|c|}{ Válidos } & \multicolumn{2}{|c|}{ Perdidos } & \multicolumn{2}{|c|}{ Total } \\
\hline & $\mathrm{N}$ & $\%$ & $\mathrm{~N}$ & $\%$ & $\mathrm{~N}$ & $\%$ \\
\hline $\begin{array}{l}\text { Investigo sobre las posibles causas que afectan } \\
\text { un problema. }\end{array}$ & 288 & 100 & 0 & 0 & 288 & 100 \\
\hline $\begin{array}{l}\text { Las oportunidades que he identificado derivan } \\
\text { en la creación de nuevos productos, servicios o } \\
\text { formas de realizar una actividad. }\end{array}$ & 288 & 100 & 0 & 0 & 288 & 100 \\
\hline $\begin{array}{l}\text { Las reuniones sociales son una oportunidad para } \\
\text { establecer contactos que me pueden ser útiles. }\end{array}$ & 288 & 100 & 0 & 0 & 288 & 100 \\
\hline $\begin{array}{l}\text { Los productos y servicios deben responder a } \\
\text { criterios de sostenibilidad, seguridad, salubridad y } \\
\text { accesibilidad. }\end{array}$ & 288 & 100 & 0 & $0 \%$ & 288 & $100 \%$ \\
\hline Me adapto con facilidad a situaciones de cambio. & 288 & 100 & 0 & $0 \%$ & 288 & $100 \%$ \\
\hline Me gusta poder tomar mis propias decisiones. & 288 & 100 & 0 & $0 \%$ & 288 & $100 \%$ \\
\hline $\begin{array}{l}\text { Mi conocimiento, experiencia y habilidad personal } \\
\text { me ayudan a llevar a cabo con éxito los proyectos } \\
\text { que emprendo. }\end{array}$ & 288 & 100 & 0 & $0 \%$ & 288 & $100 \%$ \\
\hline $\begin{array}{l}\text { Organizo y priorizo fácilmente las actividades que } \\
\text { debo realizar, según su importancia, para cumplir } \\
\text { con éxito los objetivos. }\end{array}$ & 288 & 100 & 0 & $0 \%$ & 288 & $100 \%$ \\
\hline $\begin{array}{l}\text { Permito que se desarrollen las ideas de otros } \\
\text { en proyectos o actividades en las que participo, } \\
\text { incluso en aquellas que lidero. }\end{array}$ & 288 & 100 & 0 & 0 & 288 & 100 \\
\hline $\begin{array}{l}\text { Planteo más de un escenario posible en la solu- } \\
\text { ción de un problema. }\end{array}$ & 288 & 100 & 0 & 0 & 288 & 100 \\
\hline $\begin{array}{l}\text { Reconozco mis fortalezas y debilidades y cómo } \\
\text { estas pueden afectar el desarrollo de un proyecto. }\end{array}$ & 288 & 100 & 0 & 0 & 288 & 100 \\
\hline $\begin{array}{c}\text { Relaciono aspectos de diversa naturaleza cuando } \\
\text { busco la solución de un problema. }\end{array}$ & 288 & 100 & 0 & 0 & 288 & 100 \\
\hline $\begin{array}{l}\text { Relaciono fácilmente el nuevo conocimiento que } \\
\text { adquiero con aspectos conocidos, para tener una } \\
\text { mayor visión de lo que me rodea. }\end{array}$ & 288 & 100 & 0 & 0 & 288 & 100 \\
\hline $\begin{array}{l}\text { Resuelvo con facilidad circunstancias impre- } \\
\text { decibles, por ejemplo, la llegada repentina de } \\
\text { huéspedes, un cambio en los planes de un viaje, } \\
\text { situaciones en el estudio o trabajo. }\end{array}$ & 288 & 100 & 0 & 0 & 288 & 100 \\
\hline $\begin{array}{l}\text { Resuelvo rápidamente los problemas, incluso } \\
\text { cuando me encuentro bajo presión. }\end{array}$ & 288 & 100 & 0 & 0 & 288 & 100 \\
\hline Tomo iniciativas de negocios por cuenta propia. & 288 & 100 & 0 & 0 & 288 & 100 \\
\hline
\end{tabular}

Fuente: Elaboración propia 
4.1.1. Resultados por aspecto del perfil

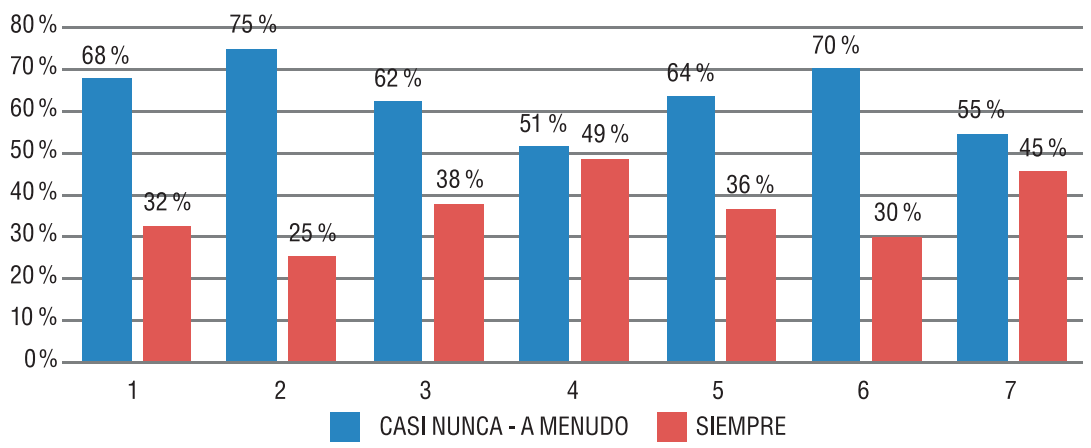

Figura 1. Aspecto del perfil emprendedor: Pensamiento Sistémico (estudiantes de primer módulo)

Fuente: Elaboración propia

De manera general el aspecto del perfil, Pensamiento Sistémico, alcanzó un bajo nivel. En promedio solo el $37 \%$ de los estudiantes valoraron correctamente este aspecto. En la lista de afirmaciones que se relacionan con esta competencia, las que mayor dificultad representaron para los estudiantes se relacionan con la capacidad para identificar las diferentes causas de un problema, relacionarlas y plantear escenarios para su resolución en un $75 \%$ y relacionar los aspectos de diversa naturaleza cuando busca la solución de un problema con un $70 \%$.

Lo anterior evidencia que los estudiantes encuestados presentan dificultades en la competencia de pensamiento sistémico, con muy poca capacidad de observación y análisis de los contextos para identificar las verdaderas causas de una situación-problema específico y plantear soluciones efectivas. 


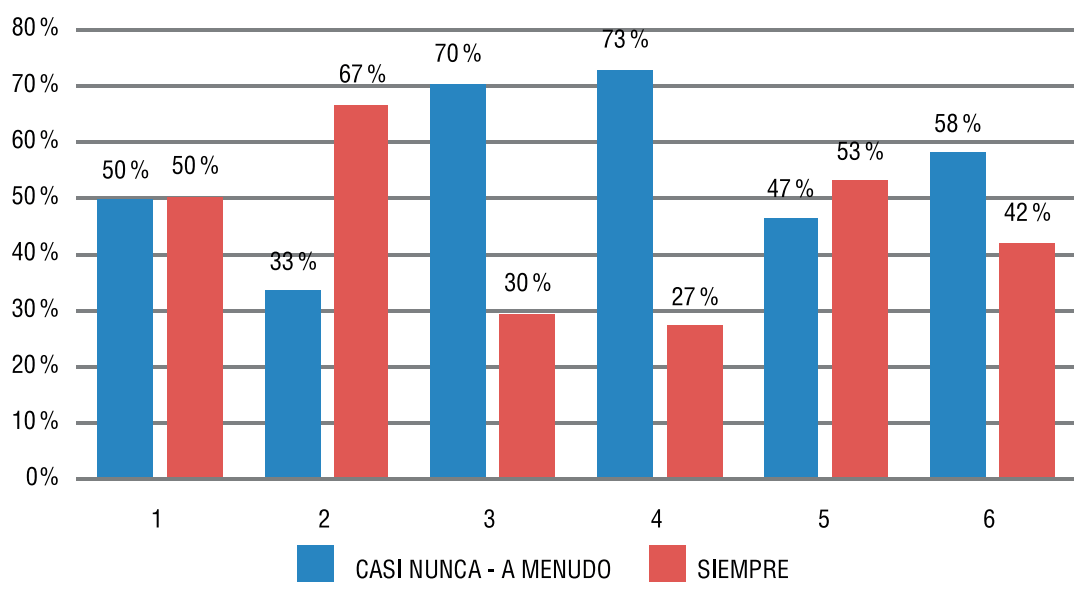

Figura 2. Aspecto del perfil emprendedor: Identifica y aprovecha oportunidades (estudiantes de primer módulo de cátedra)

Fuente: Elaboración propia

De manera general, el aspecto del perfil, Identifica y aprovecha oportunidades, alcanzó un nivel por debajo del 50 \%. En promedio el $45 \%$ de los estudiantes valoraron correctamente esta competencia. De acuerdo con los resultados por afirmación, las que mayor dificultad representaron para los estudiantes se relacionan con la actitud y capacidad para llevar al plano de la realidad las oportunidades de negocio que han identificado; esto implica que, las oportunidades emprendedoras, no las derivan en la realización de nuevos productos y servicios en nuevas formas o métodos de realizarlos. Por lo anterior se puede observar que los estudiantes presentan debilidades en la competencia de Identifica y aprovecha oportunidades, posiblemente por la falta de experiencias en el campo laboral y la poca capacidad para identificarlas y aprovecharlas en un contexto determinado (social o económico). 


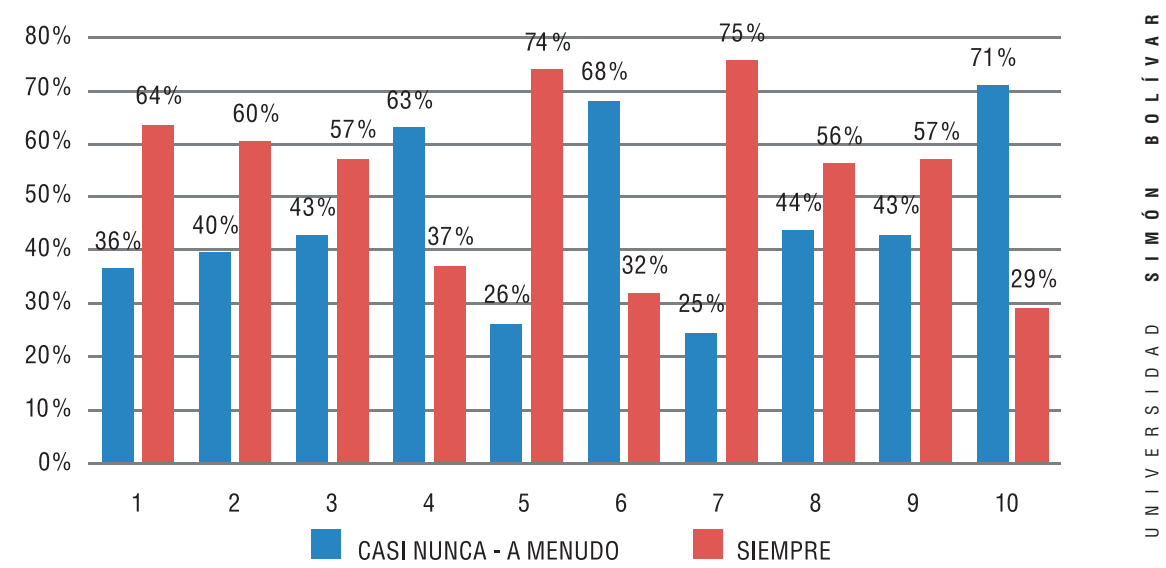

Figura 3. Aspecto del perfil del emprendedor: Autoeficacia (estudiantes de primer módulo de cátedra)

Fuente: Elaboración propia

De manera general el Aspecto del perfil, Autoeficacia, alcanzó un nivel por encima de $50 \%$. En promedio, el $54 \%$ de los estudiantes valoraron correctamente esta competencia. De acuerdo con los resultados obtenidos, los estudiantes tienen un concepto positivo sobre sí mismos, ya que se ven como personas que toman sus propias decisiones, asumen las consecuencias y disfrutan de sus triunfos. Asumen retos, reconocen sus fortalezas y debilidades, expresan lo que piensan y creen que el conocimiento, experiencia y habilidad personal ayuda a llevar a cabo con éxito los proyectos.

Del listado de las afirmaciones que componen el aspecto del perfil las que se observan débiles se relacionan con la generación de ideas nuevas en la cotidianidad para demostrar la capacidad personal y la actitud frente a los problemas y al trabajo bajo presión.

También se observa que un $15 \%$ no disfruta trabajar en varios proyectos a la vez, con esto podemos inferir el poco coraje que evidencia el individuo para realizar las acciones que ha identificado y que le conducen a hacer realidad su visión proyectiva. 


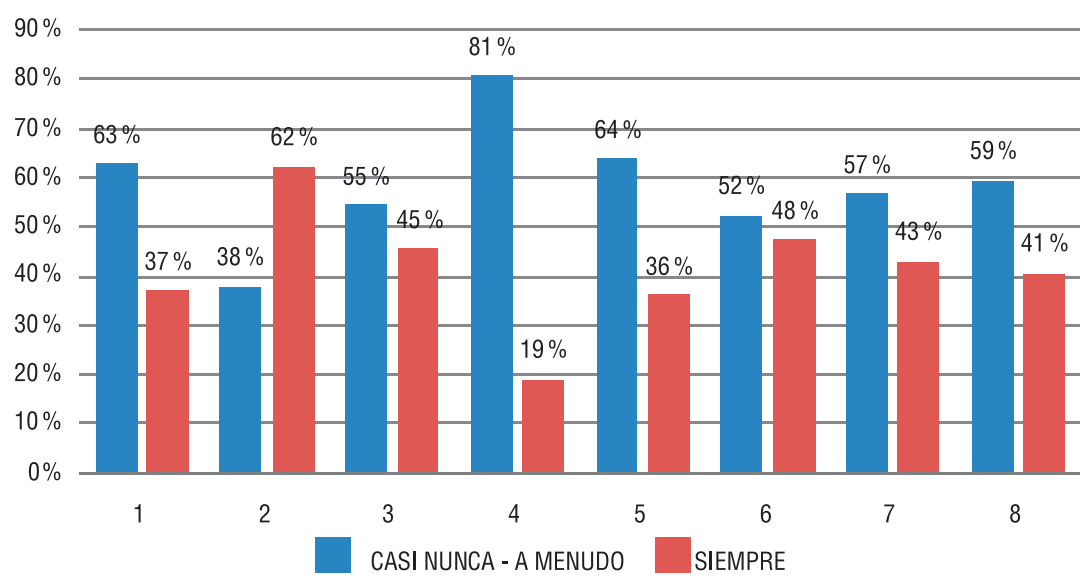

Figura 4. Aspecto del perfil del emprendedor: Creatividad e Innovación (estudiantes de primer módulo de cátedra) Fuente: Elaboración propia

En lo relativo a Creatividad e Innovación, el $41 \%$ de los estudiantes lo valoraron correctamente. De acuerdo a los resultados obtenidos, el estudiante del primer módulo tiene dificultades para adaptarse a los cambios, para desarrollar ideas creativas y encontrar soluciones únicas para resolver problemas.

El $18 \%$ de los estudiantes manifestaron no indagar sobre el nivel de satisfacción de las personas con las que se relacionan, bien sea a nivel personal o laboral. Este análisis evidencia que los estudiantes tienen poca capacidad para valorar y combinar las capacidades de sus colaboradores hasta consolidarlos como equipos de excelencia. 


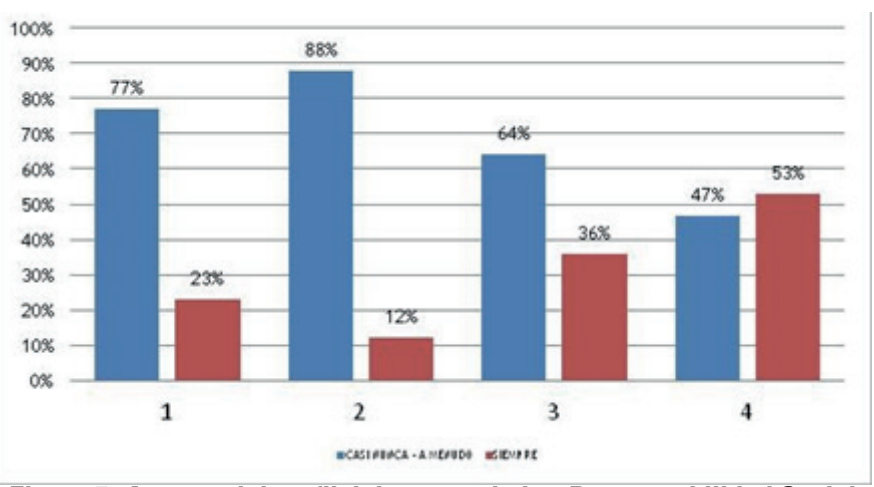

Figura 5. Aspecto del perfil del emprendedor: Responsabilidad Social (estudiantes de primer módulo de cátedra)

El $31 \%$ de los estudiantes valoró correctamente el aspecto del perfil de Responsabilidad Social. Del total de los estudiantes encuestados, solo el $12 \%$ estimó que al desarrollar una actividad o proyecto "El fin no justifica los medios", el $23 \%$ considera importante el impacto de sus acciones en el medioambiente y las personas, y el $36 \%$ el cumplimiento de la normatividad relacionada en el desarrollo de un proyecto.

En estos resultados solo uno de los cinco aspectos, estuvo valorado correctamente por más del $50 \%$ de los estudiantes.

\subsection{Competencias emprendedoras de los estudiantes que han cursado el Tercer Módulo de la Cátedra de Formación Empresarial}

A continuación, los resultados de la encuesta a una muestra de 260 estudiantes que cursan el tercer módulo de la cátedra formación empresarial de los programas de Administración de Empresas, Comercio y Negocios Internacionales, Contaduría Pública, Derecho, Enfermería, Fisioterapia, Ingeniería de Sistemas, Ingeniería Industrial, Psicología y Trabajo Social. Al momento de realizar el análisis con el software SPSS, este validó 259 . 


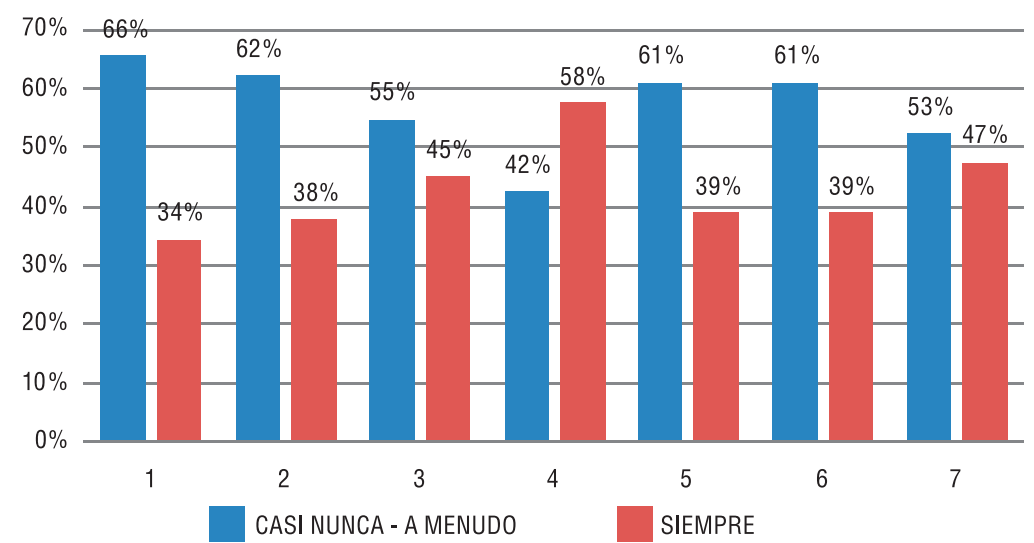

Figura 6. Aspecto del perfil del emprendedor: Pensamiento Sistémico (estudiantes de tercer módulo de cátedra)

Fuente: Elaboración propia

De manera general el aspecto del perfil, Pensamiento Sistémico, sigue teniendo un bajo nivel. En promedio solo el $43 \%$ de los estudiantes valoraron correctamente este aspecto. En la lista de afirmaciones que se relacionan con esta competencia se sigue presentando que las de mayor dificultad para los estudiantes, son las que se relacionan con la capacidad para identificar las diferentes causas de un problema, relacionarlas y plantear escenarios para su resolución.

Con el anterior resultado podemos inferir que los estudiantes no tienen en cuenta las diferentes variables inmersas en el contexto, lo que no les permite plantear soluciones a un problema, teniendo en cuenta las competencias adquiridas en su formación académica. 


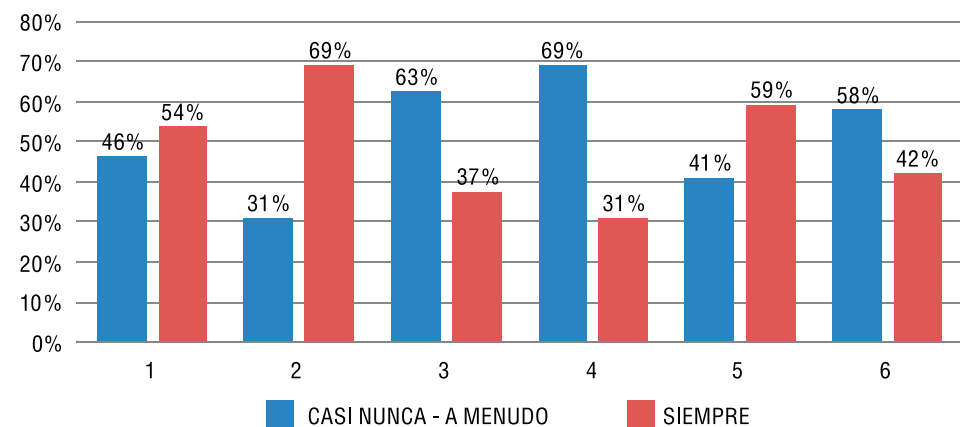

Figura 7. Aspecto del perfil del emprendedor: Identifica y aprovecha oportunidades (estudiantes de tercer módulo de cátedra)

De manera general el aspecto del perfil, Identifica y aprovecha oportunidades, alcanzó un nivel por debajo del $50 \%$. En promedio el $49 \%$ de los estudiantes valoraron correctamente esta competencia. De acuerdo con los resultados por afirmación, entre las que mayor dificultad representaron para los estudiantes, siguen presentándose las que se relacionan con la actitud y capacidad para llevar al plano de la realidad las oportunidades de negocio que han identificado.

Con este resultado podemos observar que los estudiantes de tercer módulo tampoco logran identificar oportunidades, por lo cual no pueden generar iniciativas de negocios que tengan un impacto creativo e innovador.

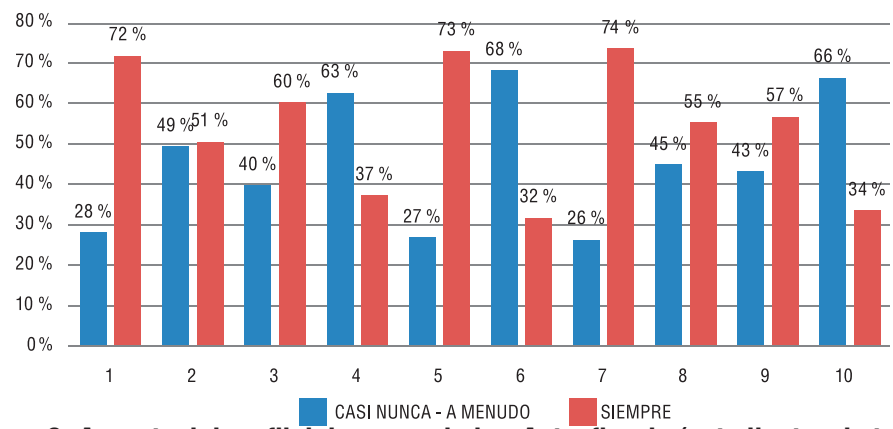

Figura 8. Aspecto del perfil del emprendedor: Autoeficacia (estudiantes de tercer módulo de cátedra)

Fuente: Elaboración propia 
De manera general el aspecto del perfil, Autoeficacia, alcanzó un nivel por encima de $50 \%$. En promedio, el $54 \%$ de los estudiantes valoraron correctamente esta competencia. De acuerdo con los resultados obtenidos, los estudiantes siguen teniendo un concepto positivo sobre sí mismos, ya que se ven como personas que toman sus propias decisiones, asumen las consecuencias y disfrutan de sus triunfos. Asumen retos, reconocen sus fortalezas y debilidades, expresan lo que piensan y creen que el conocimiento, experiencia y habilidad personal ayuda a llevar a cabo con éxito los proyectos.

Del listado de las afirmaciones que componen el aspecto, las que se observan débiles se relacionan con la generación de ideas nuevas en la cotidianidad para demostrar la capacidad personal, y la actitud frente a los problemas y al trabajo bajo presión.

Con este resultado podemos observar que los estudiantes aún mantienen una baja percepción de su efectividad al momento de desarrollar ideas y proyectos.

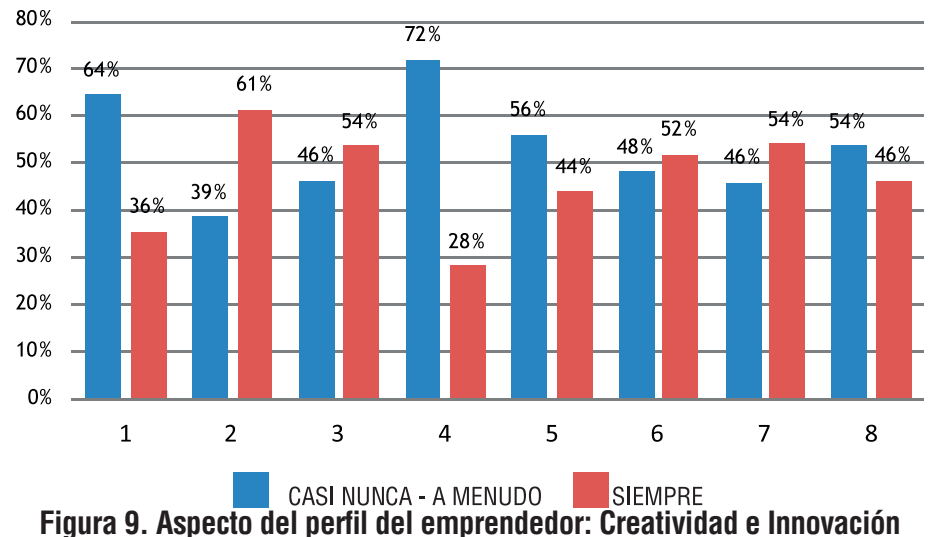

(estudiantes de tercer módulo de cátedra)

Fuente: Elaboración propia

En lo relativo a Creatividad e innovación, el $47 \%$ de los estudiantes 
lo valoraron correctamente. Es destacable mencionar que el $54 \%$ respondió que siempre, cuando se enfrentan a un problema conocido, les gusta encontrar nuevas formas para resolverlo y otro 54 \% también respondió que siempre se adaptan con facilidad a situaciones de cambio; con lo anterior podemos inferir que estos estudiantes cuentan con la capacidad de soñar creativa y realísticamente, y concretar el sueño en una visión proyectiva, en la cual ve oportunidades donde los demás ven problemas.

Con lo anterior se puede inferir que los estudiantes tienen la competencia de creatividad, pero se sigue observando la falta de competencia en Innovación, esto sigue afectando a que se pueda concretar la generación de nuevas ideas.

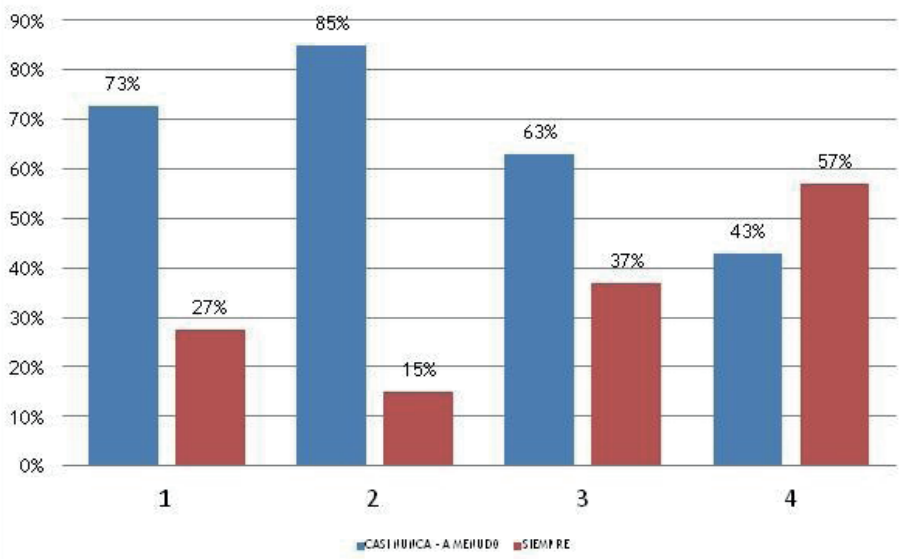

Figura 10. Aspecto del perfil del emprendedor: Responsabilidad Social (estudiantes de tercer módulo de cátedra)

Fuente: Elaboración propia

El $34 \%$ de los estudiantes valoró correctamente el aspecto del perfil de Responsabilidad social. Del total de los estudiantes encuestados, solo el $15 \%$ estimó desarrollar una actividad o proyecto "El fin no justifica los medios"; el $27 \%$ considera importante el impacto de sus acciones en el medioambiente y las personas, y el $37 \%$ el cumplimiento de la normatividad relacionada en el desarrollo de un proyecto. 
Con estos resultados podemos observar que solo uno de los cinco aspectos, estuvo valorado correctamente por más del $50 \%$ de los estudiantes.

\subsection{Diferencias existentes entre los resultados de la medición de las competencias asociadas con el perfil emprendedor de los estudiantes del primer módulo, con la de los estudiantes del tercer módulo de la cátedra de formación empresarial}

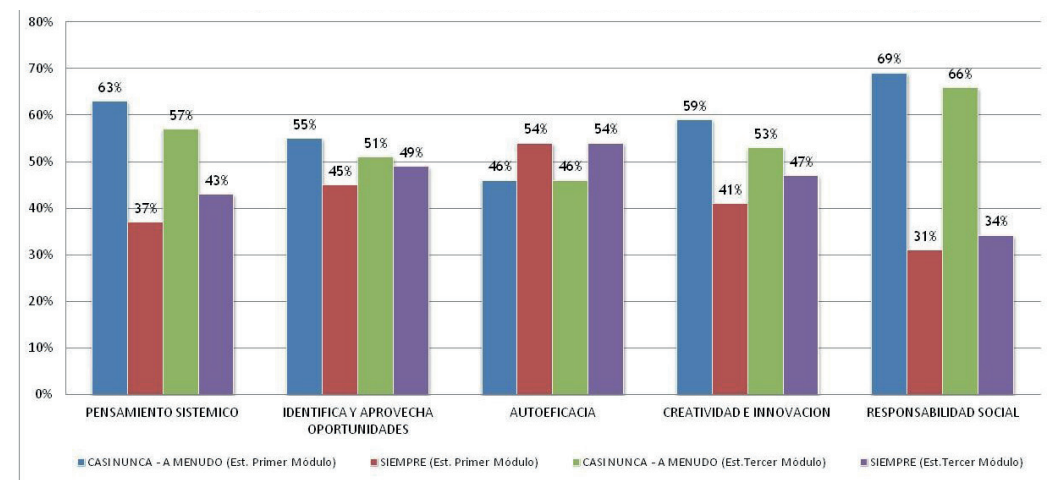

Figura 11. Comparativo entre los resultados de la medición de los aspectos asociados al perfil del emprendedor de los estudiantes de primer y tercer módulo de la cátedra Fuente: Elaboración propia

Como se puede observar en la figura anterior en la que muestran los resultados obtenidos por aspecto del perfil, es evidente que no existen diferencias significativas en ellos. Como comentarios generales, a pesar de que el aspecto denominado Autoeficacia fue el elemento del perfil que obtuvo mejor resultado, no alcanza un nivel aceptable. Se evidenció que la mayor dificultad que tienen los estudiantes está relacionada con la capacidad para resolver problemas y con el nivel de conciencia sobre el impacto de las acciones personales y grupales en la sociedad y el medioambiente, aspecto que indudablemente limita las posibilidades de iniciar y consolidar proyectos emprendedores. 


\section{CONCLUSIONES}

De la revisión realizada alrededor del significado del emprendimiento, se concluyó que se trata de un concepto amplio, que se asocia a la cultura y se materializa en bienestar y desarrollo social. Estos desarrollos, consecuencia de la actividad emprendedora, pueden darse en distintos ámbitos; el empresarial, industrial, político, cultural, religioso, entre muchos otros. Es por ello que se propone modificar la denominación actual de "Cátedra de Formación Empresarial" por "Cátedra de Formación para el Emprendimiento". De esta manera no se limita la actividad emprendedora al ámbito empresarial.

En la literatura especializada el término emprendimiento cuenta con diversidad de acepciones, que en términos generales se refieren a la actitud y la capacidad del ser humano para proyectarse en el futuro, asumir su realidad y solucionar los problemas que enfrenta en la cotidianidad. En esta perspectiva, es un tema que cobra cada vez más importancia en las instituciones de educación superior como una estrategia para impulsar procesos de desarrollo desde la universidad en las distintas áreas de conocimiento en la que se encuentra enmarcada la oferta educativa.

Siendo el emprendimiento un tema que se aborda desde múltiples perspectivas, para el rediseño de la Cátedra se tendrá como fundamento la definición propuesta por los autores, en la que se entiende este como un proceso que parte de la identificación de oportunidades y la decisión de aprovecharlas mediante la realización de un conjunto de acciones sistemáticas, que generan cambios de diverso orden en procura de obtener recompensas que se reflejen en un bienestar social sostenible, concretándose en la constitución de nuevas organizaciones o en el desarrollo de 
× las existentes, a través de la permanente y óptima combinación de los recursos y de las capacidades a su alcance, para reinventarse (innovadoras) y satisfacer necesidades, con sentido ético y responsabilidad social.

Entendido así, podríamos decir que el emprendimiento se concibe como una filosofía de vida, porque implica una manera especial de pensar, de sentir y de actuar, orientada a crear valor tanto para el emprendedor, como para la sociedad en general.

A partir de la definición expuesta anteriormente, se identifican en el sujeto (individuo o grupo de individuos) que realiza la acción emprendedora unos aspectos característicos de su perfil. Estos son: posee pensamiento sistémico, es capaz de identificar oportunidades y aprovecharlas mediante la formulación de un plan que pone en escena de manera creativa, innovadora y responsable. El emprendedor es entonces el sujeto que impulsa una sucesión de cambios de diversa índole, que producen recompensas para él, y para la sociedad, bienestar sostenible. Visto así, se define un perfil del emprendedor, que para el caso que nos ocupa se constituye en el perfil de egreso del estudiante que curse completamente la Cátedra, que en adelante se denominará Cátedra de Formación para el Emprendimiento.

\section{REFERENCIAS BIBLIOGRÁFICAS}

Aitken, H. G. J. (1965). Explorations in enterprise. Cambridge, Mass: Harvard University Press.

Anzola, S., Farías, R. (2011). Un breve acercamiento al estado del arte del emprendimiento latinoamericano. En R. Varela (Ed.). Desarrollo, Innovación y Cultura Empresarial Volumen I Entrepreneurship (pp.187-215). Cali, Colombia: Universidad Icesi-Centro de Desarrollo del Espíritu Empresarial.

Baptista, P., Hernández, R. \& Fernández, C. (2008). Metodo- 
logía de la investigación. 4ta ed. México: McGraw-Hill Interamericana.

Baty, G. (1981). Entrepreneurship in the eighties. Virginia: Reston Publishing.

Baumol, W. J. (1968). Entrepreneurship in economic theory. The American Economic Review, 58(2), 64-71.

Belshaw, C. S. (1955). The cultural milieu of the entrepreneur. Explorations in Entrepreneurial History, 7, 146-163.

Brereton, P. R. (1974). The qualification for entrepreneurship. Journal of Small Business Management, 12(4), 1-3.

Bruyat, C. \& Julien, P. A. (2001). Defining the field of research in entrepreneurship. Journal of Business Venturing, 16(2), 39-56. Bruyat, C. \& Julien, P. A. (2001). Defining the field of research in entrepreneurship. Journal of Business Venturing, 16(2), 17-27.

Bygrave, W. D. \& Zacharakis, A. (Eds.) (2004). The Portable MBA in Entrepreneurship. Wiley: 2nd. Ed.

Cantillon, R. (1755). Essai sur la nature du commerce en général, London: Fetcher Gyler. Also: Edited with an English translation by Henry Higgs, London: MacMillan (1931). The manuscript was probably written around 1720 and was published after Cantillon was murdered in 1734. It is believed that he himself wrote the French and English versions.

Carland, J. W., Hoy, F., Boulton W. R. \& Carland, J. A. C. (1984). Differentiating entrepreneurs from small business owners: a conceptualization. Academy of Management Review, 9(2), 354-359.

Casson, M. (1982). The entrepreneur: an economic theory. Oxford: Martin Robertson.

Castillo, A. (1999). Estado del Arte en la Enseñanza del Emprendimiento. Chile: Intec.

Cochran, T. C. (1968). Entrepreneurship in Sills, D. L. (Ed.) International Encyclopedia of the Social Sciences, London and New York: The MacMillan Co. \& The Free Press, 5, 87-91.

Cole, A. H. (1942). Entrepreneurship as an Area of Research, The Tasks of Economic History. Supplement to Journal of Economic History, 2, 118-126.

Collins, O., D. G. Moore \& D. B. Unwalla (1964). 'The enterprising man', MSU Business Studies, Bureau of Business and 
Economic Research, Graduate School of Business Administration, Michigan State University, East Lansing, Michigan.

Congreso de la República de Colombia. Ley 1014 de 2006 de fomento a la cultura del emprendimiento [en línea]. Edición Diario Oficial No. 46.164. Bogotá, Colombia: Prensa presidencia de la República, 26 de enero de 2006 [citado en 10 de marzo de 2010]. Artículo 2 numeral C.

Comisión Europea (2003). Comunicación de la Comisión al Consejo y al Parlamento Europeo. Pensar a pequeña escala dentro de una Europa ampliada.

Chandler, A. D. Jr (1962). Strategy and structure: chapters in the history of the american industrial enterprise. Cambridge, Mass. and London, England: The MIT Press.

Dana, L. P. (1995). Entrepreneurship in a remote Sub-Arctic community: Nome, Alaska. Entrepreneurship: Theory and Practice, 20(1), 55-72. Reprinted in Norris Krueger (Ed.) Entrepreneurship: Critical Perspectives on Business and Management, Volume IV, London: Routledge, 2002: 255-275.

Drucker, P. F. (1985). Innovation and entrepreneurship: practice and principles. London: Heinemann.

Ely, R. \& Hess, R. H. (1893). Outline of economics. New York: MacMillan.

Fayolle, A. (2008). Entrepreneurship and new value creation. The dynamic of the entrepreneurial process. London, UK: Cambridge University Press.

Ferrás, X. (2010). Innovación 6.0 El fin de la estrategia. Barcelona: Plataforma.

Filion, J. L. (2011). La definición de empresario: Reflexiones sobre un tema complejo y multidimensional. En R. Varela (Ed.). Desarrollo, innovación y cultura empresarial volumen I Entrepreneurship. pp.115-130. Santiago de Cali: Universidad IceslCentro de Desarrollo del Espíritu Empresarial.

Filion, L. J. (1991). Vision and relations: elements for an entrepreneurial metamodel. International Small Business Journal, 9(2), 26-40.

Filion, L. J. (2004). Operators and visionaries: differences in the entrepreneurial and managerial systems of two types of entrepreneurs'. International Journal of Entrepreneurship and Small Business, 1(1/2), 35-55. 
Formichella, M. (2004). El concepto de emprendimiento y su relación con la educación, el empleo y el desarrollo local (monografía). Buenos Aires: Tres Arroyos.

García, L. (2008). Condicionantes del emprendimiento en Colombia. El Cuaderno. Escuela de Ciencias Estratégicas, 2(4), 167-185.

Global Entrepreneurship Monitor (2008). Introducción. Reporte anual Colombia, p.12.

Global Entrepreneurship Monitor (2010). Introducción. Reporte anual Colombia, p.17.

Guzmán, A. \& Trujillo, M. (2008). Emprendimiento social-revisión de Literatura. Estudios Gerenciales, 24(109), 105-125.

Hagen, E. (1960). The entrepreneurs as rebel against traditional society. Human Organization, 19(4), 185-187.

Handy, Ch. (1995). Managung the dream portland. Oregon: Productivity Press.

Hernández Sampieri, R., Fernandez Collado, C., Baptista Lucio, P. (2006). Metodología de la Investigación. McGraw-Hill.

Hernández Sampieri, R., Fernández-Collado, C., Baptista Lucio, P. (2008). Metodología de la investigación. México: McGraw-Hill Interamericana.

Hitt, M. A., Ireland, R. D. \& Hoskisson, R. E. (2008). Administración Estratégica. Competitividad y Globalización Conceptos y Casos (Séptima ed.). México: Cenage Learning.

Hornaday, J. A. \& J. Aboud (1971). Characteristics of successful entrepreneurs. Personnel Psychology, 24(2), 141-153.

Jones, G. R. \& George, J. M. (2010). Administración Contemporánea. México: McGraw-Hill.

Julien, P. A. (1989). The entrepreneur and economic theory. International Small Business Journal, 7(3), 29-39.

Julien, P. A. (Ed.) (1998). The state of the art in small business and entrepreneurship. Aldershot, UK and Brookfield, US: Ashgate. Kantis, H., Angelelli, P. \& Moori, V. (2004). Desarrollo emprendedor. Banco Interamericano de Desarrollo (Primera edición). Kerlinger, F. (1979). Investigación del comportamiento y técnicas metodológicas. 2 edición. México D.F.: Editorial interamericana. Kets De Vries, M. F. R. (1977). The entrepreneurial personality: A person at the cross-roads. Journal of Management Studies, 14(1), 34-47. 
Kets De Vries, M. F. R. (1985). The dark side of entrepreneurship. Harvard Business Review, 160-167.

Kirzner, I. (1983). Perception, opportunity and profit: studies in the theory of entrepreneurship (1st ed. 1979), Chicago: University of Chicago Press.

Knight, F. H. (1921). Risk, Uncertainty and Profit. Boston and New York: Houghton Mifflin. Also: Chicago: University of Chicago Press.

Komives, J. L. (1974). What are entrepreneurs made of Chemtech. Dec.: 716-721.

Leibenstein, H. (1968). Entrepreneurship and development. American Economic Review, 58(2), 72-83.

Libro verde de la comisión empresarial europea. Bruselas, 21/1/2003. Documento basado en COM (2003)27, versión final.

Longenecker, J. G. \& Schoen, J.E. (1975). The Essence of entrepreneurship. Journal of Small Business Management, 13(3), 26-32.

Lynn, R. (1969). Personality characteristics of a group of entrepreneurs. Occupational Psychology, 43, 151-152.

Llisterri, J. J. (2004). Introducción. En H. Kantis, (Ed.). (con P. Angelelli y K. V., Moori). Desarrollo emprendedor América Latina y la experiencia internacional. Recuperado de http:// www.fundes.org/uploaded/content/publicacione/1572456652. pdf

Mancuso, J. R. (1979). Who is the entrepreneur. Business Graduate, 9(2), 32-33.

McClelland, D. C. (1961). The achieving society, Princeton, N.J.: Van Nostrand (See also the New Introduction to this book: New York: Irvington Publishers, 1976).

Mendoza, J. (2013). Gestión de cadenas productivas. Pensamiento Americano, 2(2), 51-56.

Meredith, G. G., Nelson, R. E. \& Neck, P. A. (1982). The practice of entrepreneurship. Geneva: International Labour Organization (ILO).

Mintzberg, H. (1973). The nature of managerial work. New York: Harper and Row. 
Mintzberg, H. (1988). La estructuración de las organizaciones. (ed. org. 1978). Barcelona: Ariel, Economía.

Moffat, D. W. (1983). Economics Dictionary, 2nd ed. New York: Elsevier.

Mendoza, J. (2006). Innovación por lo alto. Imaginación y acción en la empresa. Santa Fe de Bogotá: Asesores del 2000.

Morales, G. S. (2008). El emprendedor académico y la decisión de crear spin-off: un análisis del caso español (Tesis Doctoral). España: Universitat de Valencia.

O'Connor, J. \& McDermontt, I. (1998). Introducción al pensamiento sistémico. Barcelona: Urano.

Palmer, M. (1971). The application of psychological testing to entrepreneurial potential. California Management Review, 13(3), 32-38.

Pearce, D. W. (1981). The MacMillan Dictionary of Modern Economics. London: The MacMillan Press.

Padua, J. (1987). Técnicas de investigación aplicadas a las ciencias sociales. México D.F.: Editorial Fondo de Cultura Económica.

Pereira, F. (2007). La evolución del espiritu empresarial como campo del conocimiento. Hacia una visión sistémica y humanística. Cuaderno de Administración.

Pinchot, G. (1985). Intrapreneuring. New York: Harper \& Row.

Pinilla, M. (2007). Protocolo del programa Empresa y Medio Ambiente adscrito al Departamento de Extensión y Proyección Social de la Universidad Simón Bolívar. Barranquilla, Colombia: [s.n] Sistema de información académica y administrativa -SIAA- de la Universidad Simón Bolívar. Resolución rectoral No. 030 de 2009.

Ponti, F. \& Ferrás, X. (2008). Pasión por innovar, un modelo novedoso que incentiva la creatividad empresarial. Bogotá: Norma.

Renart Cava, J. B. (2003). Creatividad aplicada a la empresa. Barcelona: Gestión 2000.

Reuters Ltd. (1982). Reuter's Glossary of Economic and Financial. Terms, London: Heinemann.

Rodríguez, C. J. (1998). Autoeficacia y educación. Nueva época, 2, 4(18), 45-53. 
Rosenberg, J. M. (1983). Dictionary of business and management. 2nd. ed., Wiley.

Salvador Ferrer, C. M. (2009). Ecuaciones estructurales como modelos predictivos de la autoeficacia emprendedora en una muestra de jóvenes mexicanos y españoles. Apuntes de Psicología, 27(1), 65-78.

Say, J. B. (1815). Cathéchisme d'économie politique, Maison Mame (1972), also translation: Catechism of political economy: on familiar conversations on the manner in which wealth is produced, distributed and consumed by society. London: Sherwood (1816).

Say, J. B. (1996). Cours d'économie politique et autres essais, Paris: GF-Flammarion (Selection of main writings).

Senge, P. M. (1990). La Quinta Disciplina. Editorial Granica Española.

Schumpeter, J. A. (1936). The theory of economic development: an inquiry into profits, capital credit, interest, and business cycle. Cambridge: Harvard University Press.

Schumpeter, J. A. (1947). The creative response in economic history. Journal of Economic History, 7, 149-159.

Schwartz, R. (1982). The entrepreneur: an artist masquerading as a businessman. International Management, 21-32.

Shane, S. \& Venkataraman, S. (2000). The promise of entrepreneurship as a field of research. Academy of Management Review, 25(1), 217-226.

Shapero, A. (1975). The displaced uncomfortable entrepreneur. Psychology Today, 7(11), 83-89.

Smith, N. R. (1967). The entrepreneur and his firm: the relationship between type of man and type of company. Bureau of Business Research, East Lansing, Michigan: Michigan State University.

Stevenson, H. H. \& Gumpert, D. E. (1985). The heart of entrepreneurship. Harvard Business Review, 85-94.

Storey, D. (1982). The new firm. New York: Praeger.

Timmons, J. A. (1989). The entrepreneurial mind. Andover, Mass.: Brick House Publishing.

Timmons, J. A. \& Spinelli, S. (2004). New venture creation. 6th Ed. Irwin/McGraw-Hill. 
Toca, C. (2010). Consideraciones para la formación en emprendimiento: explorando nuevos ámbitos y posibilidades. Estudios Gerenciales, 26(117), 41-60.

Varela, R. (2011). Educación empresarial basada en competencias empresariales. En R. Varela (Ed.). Desarrollo, innovación y cultura empresarial volumen 2 Entrepreneurship. pp. 78-120. Santiago de Cali: Universidad Icesi-Centro de Desarrollo del Espíritu Empresarial.

Vesper, K. H. (1990). New venture strategies. 2nd ed. Englewood Cliffs, N.J.: Prentice Hall.

Weber, M. (1947). The theory of social and economic organization. New York: Free Press.

Wilken, P. H. (1979). Entrepreneurship: a comparative and historical study. Norwood, New Jersey: Ablex Publications.

Zaleznik, A. \& Kets De Vries, M. F. R. (1976). What makes entrepreneurs entrepreneurial. Business and Society Review, 17, 18-23.

Varela, R. (2008). Innovación empresarial arte y ciencias en la creación de empresas. Bogotá, D.C.: Prentice Hall.

Varela, R. \& Bedoya, O. (2006). Desarrollo de empresario basado en competencia empresarial: el caso de jóvenes con empresa. Panamá: Tercera Edición.

Zuluaga, C. (2010). Emprendimiento e Historia Empresarial. Apuntes para un diálogo interdisciplinario en América Latina. Trabajo presentado en el IV Congreso Internacional de la Asociación Mexicana de Historia Económica, México, D.F., resumen. Recuperado de: http://www.economia.unam.mx/ cladhe/registro/ponencias/340_abstract

\section{BIBLIOGRAFÍA CONSULTADA}

Baptista, P., Hernández, R. \& Fernández, C. (2008). Metodología de la investigación. 4ta ed. México: McGraw-Hill Interamericana.

Castillo, A. (1999). Estado del Arte en la Enseñanza del Emprendimiento. Chile: Intec.

Formichella, M. (2004). El concepto de emprendimiento y su relación con la educación, el empleo y el desarrollo local (monografía). Buenos Aires: Tres Arroyos. 
García, L. (2008). Condicionantes del emprendimiento en Colombia. El Cuaderno. Escuela de Ciencias Estratégicas, 2(4), 167-185.

Global Entrepreneurship Monitor (2010). Introducción. Reporte anual Colombia, p.17.

Kantis, H., Angelelli, P. \& Moori, V. (2004). Desarrollo emprendedor. (Primera edición). Banco Interamericano de Desarrollo. Kerlinger, F. (1979). Investigación del comportamiento y técnicas metodológicas. 2 edición. México D.F.: Editorial interamericana. Libro verde de la comisión empresarial europea (2003). Bruselas, 21/1/2003. Documento basado en COM, 27, versión final.

Llisterri, J. J. (2004). Introducción. En H. Kantis, (Ed.). (con P. Angelelli y K. V., Moori). Desarrollo emprendedor América Latina y la experiencia internacional. Recuperado de http:// www.fundes.org/uploaded/content/publicacione/1572456652. pdf

Morales, G. S. (2008). El emprendedor académico y la decisión de crear spin-off: un análisis del caso español (Tesis Doctoral). España: Universitat de Valencia.

Padua, J. (1987). Técnicas de investigación aplicadas a las ciencias sociales. México D.F.: Editorial Fondo de Cultura Económica.

Pinilla, M. (2007). Protocolo del programa Empresa y Medio Ambiente adscrito al Departamento de Extensión y Proyección Social de la Universidad Simón Bolívar. Barranquilla, Colombia: [s.n] Sistema de información académica y administrativa -SIAA- de la Universidad Simón Bolívar. Resolución rectoral No. 030 de 2009.

Renart Cava, J. B. (2003). Creatividad aplicada a la empresa. Barcelona: Gestión 2000.

Rodríguez, C. J. (1998). Autoeficacia y educación. Nueva época, 2, 4(18), 45-53.

Salvador Ferrer, C. M. (2009). Ecuaciones estructurales como modelos predictivos de la autoeficacia emprendedora en una muestra de jóvenes mexicanos y españoles. Apuntes de Psicología, 27(1), 65-78.

Varela, R. (2011). Educación empresarial basada en competencias 
empresariales. En R. Varela (Ed.). Desarrollo, innovación y cultura empresarial volumen 2 Entrepreneurship. pp.78-120. Santiago de Cali: Universidad Icesi-Centro de Desarrollo del Espíritu Empresarial.

Zuluaga, C. (2010). Emprendimiento e Historia Empresarial. Apuntes para un diálogo interdisciplinario en América Latina. Trabajo presentado en el IV Congreso Internacional de la Asociación Mexicana de Historia Económica. México, D.F., resumen. Recuperado de: http://www.economia.unam.mx/ cladhe/registro/ponencias/340_abstract tificación del perfil emprendedor para el desarrollo del emprendimiento. En E. Olivero Vega, K. Barrios Hernández, C. Acosta-Prado, N. Núñez Bravo, C. Miranda Medina, R. Prada Ospina, ... C. Osorio Torres, E. Olivero Vega, K. Barrios Hernández, \& J. C. Acosta-Prado (Comp.), Perspectivas Empresariales e Inclusivas del Emprendimiento (pp.47-91). Barranquilla: Ediciones Universidad Simón Bolívar. 


\title{
INFLUENCIA DEL LIDERAZGO SOBRE EL EMPRENDIMIENTO INNOVADOR EN NUEVAS EMPRESAS DE BASE TECNOLOGICA. \\ UN ESTUDIO DE CASOS BASADO EN EL ENFOQUE DE GESTIÓN DEL CONOCIMIENTO
}

\begin{abstract}
Influence of leadership on innovative entrepreneurship in new technology based firm. A case study based on the knowledge management approach
\end{abstract}

JULIO CÉSAR ACOSTA-PRADO - RICARDO PRADA OSPINA

DUVÁN EMILIO RAMÍREZ OSPINA

\section{RESUMEN}

En este estudio se analiza la relación entre liderazgo y emprendimiento innovador, desde un enfoque de gestión de conocimiento. La metodología aplicada es de carácter cualitativa, basada en el estudio de caso de diez Nuevas Empresas de Base Tecnológica (NEBT), en fase de desarrollo. Los resultados del estudio muestran cómo las habilidades de los líderes emprendedores influyen positivamente en el reconocimiento y explotación de oportunidades de negocio y que, a su vez, permiten guiar a los miembros de las empresas hacia una eficiente gestión del conocimiento que favorece el desarrollo de innovaciones.

Palabras clave: liderazgo, emprendimiento, gestión del conocimiento, nuevas empresas de base tecnológica.

\section{ABSTRACT}

This article analyzes the relationship between leadership and innovative entrepreneurship, from a knowledge management approach. The methodology is qualitative in based on case studies of ten New Technology-Based Firms (NTBFs), in development phase. The study results show how the skills of entrepreneurial leaders positively influence the recognition and exploitation of business opportunities and, in turn, guide members to firms towards an efficient knowledge management that favors the development of innovations.

Key words: leadership, entrepreneurship, knowledge management, new technology-based firms. 


\section{INTRODUCCIÓN}

Suelen señalarse de manera constante los cambios económicos y sociales como una de las principales causas que justifican la creación y desarrollo de Nuevas Empresas de Base Tecnológica (NEBT). No es de extrañar, por tanto, que la mayoría de los análisis sobre estas empresas han llamado la atención no solo de emprendedores, sino también de su capacidad para incorporar tecnologías de vanguardia, como consecuencia de la gestión eficiente orientada a la innovación como negocio y la forma de dirigir y gestionar las personas y su conocimiento, es decir, liderazgo innovador.

Frente a este contexto económico, social y laboral de cambios rápidos, profundos, complejos, discontinuos, y altamente impredecibles, las formas tradicionales de gestionar y dirigir personas y sus capacidades se revelan insuficientes e insatisfactorias. En este sentido, el líder y emprendedor innovador constituye una respuesta que necesariamente converge y se enriquece con base en la gestión del conocimiento ante los nuevos desafíos. Esta necesidad sitúa al líder y emprendedor innovador en la posición donde debe estar: en el mismo centro de la estrategia de personas y la forma en que se crea conocimiento en la organización (Nonaka, 2000).

Este estudio aborda la relación entre liderazgo y emprendimiento innovador, desde un enfoque de gestión del conocimiento, que favorece la capacidad y voluntad de las personas para crear y compartir conocimiento en la organización, mediante procesos eficientes de gestión en NEBT, situación que conlleva al reconocimiento de una oportunidad de negocios (Ardichvili, Cardozo \& Ray, 2003; Baron, 2006) y, a su vez, la explotación de dicha oportunidad (Mcpherson, Jones \& Zhang, 2004), entendida esta como la materialización organizacional de la iniciativa empre- 
sarial, y en la que los recursos y capacidades de la empresa creada influyen en su viabilidad económica, técnica y financiera (García \& García, 2007).

Dicho esto, se plantea un estudio de caso de carácter cualitativo con base en 10 NEBT, en fase de desarrollo. El estudio se realizó en el Parque Científico de Madrid (PCM), España, durante el año 2009. La metodología de análisis aplicada es de carácter cualitativo, basado en estudio de casos. Los resultados obtenidos muestran la necesidad de identificar y conocer la dotación de recursos y capacidades existentes en estas empresas, a partir del liderazgo y emprendimiento innovador, que favorece, no solo su gestión eficiente, sino también la identificación, asimilación y creación de nuevos conocimientos críticos y relevantes para generar resultados innovadores.

\section{FUNDAMENTOS TEÓRICOS: LIDERAZGOY EMPRENDIMIENTO INNOVADOR}

Liderazgo y emprendimiento son dos conceptos que frecuentemente se han relacionado entre sí, entre otras cosas porque se desarrolla una capacidad de ver oportunidades donde la mayor parte de las personas no ve nada, situación que se traduce en muchos casos en un plan de negocio que se lleva a cabo una vez tramitada la puesta en marcha del mismo (Sarasvathy, 2001; Park, 2005). El reconocimiento de la oportunidad y el desarrollo posterior de una innovación en el mercado constituye un factor clave en las etapas generales del proceso de creación de empresa y la forma en que el emprendedor debe explotar sus cualidades en cada una de esas etapas (Morse \& Mitchell, 2006), tales como, la experiencia en la creación de nuevos negocios, la experiencia en gestión de personas y sus capacidades y conocimientos (Sarasvathy, 2001), además de las redes sociales en 
las que participa y los tipos de enlaces con dichas redes (Baron, 2006), entre otras.

Si bien es cierto que una de las cualidades más importantes de los líderes emprendedores es persuadir a las personas de que las ideas que tienen pueden lograr resultados de éxito (Covey, 1989), es decir, que sea capaz de convencer a un buen número de personas de que lo que dice es lo válido, los líderes emprendedores presentan características comunes. La primera es la capacidad de acompañamiento. Un líder emprendedor es capaz de descubrir las capacidades de sus colaboradores y utilizar estas en el momento que sea necesario para la organización. El líder emprendedor también es consciente de cuáles son sus fortalezas y sabe aprovecharlas de la mejor manera para obtener beneficio para su organización. No obstante, identificar y seleccionar las oportunidades correctas para la creación de nuevos negocios es casi la más importante cualidad de un líder emprendedor con éxito (Ruiz, Bojica, Albacete \& Fuentes, 2009).

Lo anterior se confirma cuando el líder emprendedor consigue de las personas una capacidad de empuje y una actitud proactiva, que permita canalizar todas las energías creativas hacia la consecución de un proyecto común (Norton, 1998).

En ese orden de ideas, el líder emprendedor que demanda la empresa actual, deberá ser capaz de reconocer la oportunidad de negocio (Baron, 2006; Baron \& Ensley, 2006), teniendo en cuenta que los procesos de globalización económica y de apertura comercial han incidido en la competencia y en la velocidad de la producción, así como en el interés y gusto del consumidor (Gómez, 2008). Además, como ya se ha señalado, el líder emprendedor debe tener una rápida capacidad de respuesta frente a las condiciones del entorno, y la eficiente 
gestión y dotación de recursos disponibles. Al respecto, Katz (1974) identificó tres tipos de habilidades. Primera, habilidades técnicas: entendidas como la capacidad de usar herramientas, o procedimientos técnicos en un campo especializado; estas representan el aspecto distintivo del desempeño del trabajo operativo. Segunda, habilidades humanas: se refiere a la capacidad de interactuar con personas, trabajar con ellas, comprenderlas, motivarlas y formar equipos de trabajo. Tercera, habilidades conceptuales: se refieren a la capacidad de pensar en modelos, marcos de referencia y relaciones, como planes a largo plazo. No obstante, la descripción de ciertas habilidades no es suficiente para caracterizar el proceso humano y social que acompaña la actividad emprendedora.

Este planteamiento contempla no solo la existencia de habilidades para el reconocimiento y explotación de oportunidades de negocio, sino también la distinción de ciertos rasgos de personalidad (Ardichvili, Cardozo \& Ray, 2003) que, combinados con las circunstancias personales, dan lugar a la formación de nuevas empresas (Park, 2005). Dicho esto, los rasgos distintivos que se identifican del líder emprendedor, con excepción de las características demográficas como sexo, edad, nacionalidad, etc., son la creatividad (Shane, 2003), el optimismo (Krueger \& Brazeal, 1994; Ardichvili, Cardozo \& Ray, 2003), la propensión a asumir riesgos (Stewart \& Roth, 2001), el conocimiento previo de campo o sector de actividad (Shane, 2003; Ardichvili, Cardozo \& Ray, 2003) y las redes sociales (Singh, 2000). Sin embargo, como ya se ha mencionado, el líder emprendedor no es independiente de su contexto organizacional social (Jack \& Anderson, 2002), pues para el reconocimiento de una oportunidad es necesario conocer su trayectoria, su interacción y experiencias con el entorno, sus éxitos y fracasos anteriores, su experiencia funcional, su formación (Zahra, Korni \& Yu, 2005) y sus conocimientos relacio- 
\& nados con aficiones personales (Ardichvili, Cardozo \& Ray, 2003). Estas habilidades que desarrollan los líderes emprendedores de forma idiosincrásica, favorecen un mejor y efectivo reconocimiento de la oportunidad, cuando los conocimientos y experiencias previas permiten identificar el valor de la nueva información (Baron, 2006).

El líder emprendedor innovador que se propone caracterizar en este artículo, es aquel que es capaz de reconocer oportunidades de negocio de base tecnológica como contexto de estudio, que incorporan unas circunstancias peculiares y de relevancia, debido a la complejidad y dinamicidad de este tipo de sectores, calificados como netamente emprendedores (Park, 2005). Sin duda, se entiende que el líder emprendedor de este sector está sometido a un proceso de cambio continuo, motivado principalmente por el uso, actualización y desarrollo en las nuevas tecnologías, así como por las interrelaciones que tienen lugar entre el emprendedor y el entorno, con el cómo y por qué surge y se desarrolla el reconocimiento de la oportunidad que se materializa en una empresa de base tecnológica y que da lugar a una innovación.

Tal y como se ha indicado, la población objeto de estudio son las NEBT localizadas en el PCM de la Comunidad de Madrid. El término "nuevas empresas de base tecnológica" (NEBT) identifica un negocio independiente, que son micro o pequeñas empresas, creadas por un grupo de emprendedores, basadas en la explotación de un invento o innovación tecnológica, que implica unos riesgos tecnológicos sustanciales (Little, 1977; Butchart, 1987; Shearman \& Burrel, 1988) y que, emplean a una alta proporción de trabajadores cualificados, que a partir de una eficiente gestión de sus capacidades y conocimientos, deberán aportar un valor relevante con capacidad para generar importantes sinergias en 
las que sustentar un proyecto empresarial de base tecnológica, diferenciado e innovador.

\subsection{Gestión del conocimiento e innovación}

Una vez identificada la relación existente entre liderazgo y emprendimiento innovador, se aborda el concepto de gestión del conocimiento con el objetivo de estructurar su influencia en la innovación.

Gestionar el conocimiento significa dirigir los procesos de creación, desarrollo, difusión y explotación del conocimiento con la intención de generar ventajas competitivas sostenibles. Se configura, pues, la organización como un conjunto de recursos y capacidades, en la que lo más importante es administrar su inteligencia y saber dirigir y gestionar sus aplicaciones. En este ámbito, cabe plantear que, tanto la organización como el individuo, presentan similitudes en cuanto a conocimientos, dada la interacción dentro de la propia colectividad. Resulta difícil aislar al individuo de la organización en la creación de conocimientos, pues, como apunta Spender (1996), este no resultará útil y eficiente hasta que no esté integrado en la organización y adquiera las rutinas de conocimiento colectivo.

En el ámbito académico existen diversas posiciones para argumentar qué se entiende por gestión del conocimiento. Una de las más destacadas es la de Honeycutt (2001), destacando la importancia de las personas en la organización y su capacidad de generar conocimiento, conforme a una serie de factores condicionantes de la empresa, se trata de ofrecer la información a los trabajadores del conocimiento, relacionando la cultura, los procesos de la empresa y la tecnología para obtener el éxito de las empresas y del personal. 
Según Bueno (1998), la gestión del conocimiento, es el conjunto de procesos que permiten utilizarlo como factor clave para añadir y generar valor. Para Garvin (1998), la gestión del conocimiento obtiene y comparte bienes intelectuales, con el objetivo de conseguir resultados óptimos en términos de productividad y capacidad de innovación de las empresas. Es un proceso que genera, recoge, asimila y aprovecha el conocimiento, con el fin de crear una empresa más inteligente y competitiva.

Beijerse (1999) señala que la gestión del conocimiento es obtener los propositos de la empresa a través de la motivación dirigida por la estrategia, permitiendo a los empleados desarrollar, estimular y utilizar sus capacidades para interpretar datos e información. Este autor destaca la importancia del conocimiento tácito para la consecución de los objetivos; es decir, la aplicación, uso, gestión y potenciación de los recursos y capacidades basadas en conocimientos no codificados en ningún soporte concreto.

Tissen, Andriessen \& Lekanne Deprez (2000), plantean una propuesta de clasificación de la gestión del conocimiento que permite estructurar jerárquicamente las funciones que desempeñan los responsables de la gestión del conocimiento en dos niveles. Así, en primer lugar, se define la 'gestión estratégica del conocimiento', que toma la base de conocimientos como referencia fundamental en el proceso de dirección estratégica de la empresa. En segundo lugar, la 'gestión funcional del conocimiento', consiste en hacer fluir la información en la organización según las necesidades impuestas por la estrategia empresarial. En este caso es necesario desarrollar una serie de técnicas de gestión funcional del conocimiento, con el propósito de conectar a las personas con el sistema que se utiliza para la distribución y transferencia de conocimiento. 
Para facilitar la comprensión y el por qué de esta división conceptual, los autores consideran que es necesario identificar el conocimiento relevante para la organización, establecer mecanismos orientados a captar y crear el conocimiento, buscar fórmulas sencillas de explicitar, estructurar y almacenar el conocimiento, buscar una adecuada interpretación y aplicación del conocimiento transmitido y, por último, reutilizar y renovar dicho conocimiento en todos los ámbitos de la organización. De esta forma se identificará perfectamente el ciclo de la gestión del conocimiento.

A partir de estas reflexiones, podemos decir que la gestión del conocimiento presenta diversas facetas íntimamente relacionadas: la identificación de requerimientos de conocimiento, la captura de conocimiento externo, la asimilación y la utilización de los conocimientos, la creación de una cultura adecuada, etc. Cada una de ellas exige un profundo conocimiento de las bases en las que se fundamenta y un dominio de las técnicas y metodologías que permitan diseñar las soluciones que aportan valor a la empresa.

Sin embargo, todo proceso de innovación lleva asociado el concepto de experimentación y un cierto grado de riesgo de fracaso, si no se logran los resultados previstos. No siempre se dan condiciones favorables en las empresas para formular, desarrollar e implantar un sistema de gestión del conocimiento. Por ello, hay que prever aspectos como la dificultad de otorgar un valor a los trabajadores con fuerte contenido intelectual, o la reticencia a abandonar la idea extendida de que el conocimiento es fundamental para el desarrollo de ventajas competitivas y, por tanto, lo mejor es retenerlo.

Así pues, la misión de la gestión del conocimiento es crear un 
ambiente en el que el conocimiento y la información disponibles en una organización sean accesibles y puedan ser utilizados para estimular la innovación y mejorar la toma de decisiones. La clave estaría en crear una cultura en la que ambos elementos se valoren, se compartan, se gestionen y se usen eficientemente. Esto exige a las organizaciones redefinirse permanentemente, generar cambios duraderos y significativos en su relación con el entorno.

Añadir valor a través del conocimiento es también construir el compromiso en torno a una visión compartida y a un propósito común, aumentar la comunicación y conseguir que las personas formen parte de la estrategia de negocio, afianzar los valores compartidos y modelar la cultura organizacional.

En definitiva, la gestión del conocimiento es, pues, un proceso que pretende asegurar el desarrollo y aplicación de todo tipo de conocimiento en una empresa, con objeto de mejorar su capacidad de resolución de problemas y así contribuir a la sostenibilidad de sus ventajas competitivas (Andreu \& Sieber, 1999).

Dicho esto, las razones que motivaron a definir el estudio en NEBT desde un enfoque de gestión del conocimiento son las siguientes:

1. La relevancia del conocimiento como activo fundamental para el reconocimiento y explotación de oportunidades, así como los rasgos personales distintivos de los líderes emprendedores en la materialización de la idea de negocio en una NEBT.

2. Dada la emergencia del concepto líder emprendedor innovador, se han buscado empresas intensivas en conocimiento, con alto porcentaje de cualificación entre 
sus miembros, lo cual ha facilitado el esfuerzo cognitivo que han tenido que hacer estos para entender el proyecto empresarial y la consecución de resultados superiores.

3. Se han seleccionado empresas en fase de desarrollo, que no confundan el concepto de líder emprendedor innovador con otros relacionados, cosa que podría ocurrir en empresas ya maduras de sectores intensivos en conocimiento.

4. Las empresas participantes pertenecen a diferentes sectores de actividad (biotecnología, agroalimentación, ingeniería y tecnologías de información), lo cual ha permitido tratar esta variable como ceterisparibus y centrar la atención en los elementos que comparten como NEBT.

5. Debido a la falta de estudios empíricos previos se ha considerado oportuno centrar la investigación en un área geográfica reducida, Comunidad de Madrid, específicamente el PCM.

6. Finalmente, este tipo de empresas fue elegido partiendo de una línea de investigación ya existente que realiza diversos estudios que pretenden ayudar al proceso de desarrollo y consolidación de las NEBT localizadas en la Comunidad de Madrid.

Partiendo de los fundamentos teóricos expuestos, el objetivo de este estudio es analizar la relación entre el liderazgo y emprendimiento innovador, desde un enfoque de gestión del conocimiento, en el desarrollo de innovaciones de las NEBT del PCM, localizadas en la Comunidad de Madrid, España. 


\section{METODOLOGÍA}

La metodología diseñada para llevar a cabo el estudio de caso, y con ello la consecución del objetivo de la investigación, ha sido de carácter cualitativa. Se ha seleccionado esta metodología con base en los fundamentos teóricos, la población objeto de estudio y la escasez de estudios previos que analicen la relación propuesta en NEBT. El interrogante que ha guiado el estudio de caso ha sido cómo influye el liderazgo y emprendimiento innovador, desde un enfoque de gestión de conocimiento, en el desarrollo de innovaciones de las NEBT.

El estudio se ha diseñado siguiendo las recomendaciones de Eisenhardt (1989) y Yin (1984), es decir, la pregunta de investigación planteada ha sido del tipo "cómo"; centrada en el contexto de las diez NEBT del PCM.

Se aseguró que la recopilación de los datos y su análisis cumplen con los test de validez de construcción, fiabilidad, validez interna y validez externa (Eisenhardt, 1989; Sarabia, 1999; Yin, 1984) de la siguiente manera: utilizando múltiples fuentes de evidencia empírica; un protocolo para el estudio y un caso piloto para refinar los procedimientos de recogida de datos y el contenido de los mismos, haciendo que los informantes fueran objeto de los procedimientos. A su vez, que todas las NEBT compartiesen características comunes para realizar el análisis, utilizando como técnica de análisis de datos el denominado pattern-matching, relevante para el análisis de casos explicativos donde los vínculos causales se establecen en forma de narración, y para comparar de manera iterativa los acontecimientos comprobados con las proposiciones teóricas, utilizando tablas como técnica específica de tratamiento de datos, para ordenarlos, realizar comparaciones entre los acontecimientos observados, y para establecer relaciones entre los datos y las proposiciones derivadas de los fundamentos teóricos. 
Como técnica principal de recogida de datos fue utilizada la entrevista, y como fuentes de información complementarias la observación y fuentes secundarias. Las entrevistas fueron focalizadas, individuales y tomaron la forma de conversación informal (Merton, Kiske \& Kendal, 1956). Las preguntas fueron extraídas de los fundamentos teóricos ya expuestos, del objetivo de investigación y de la interrogante que ha guiado el estudio. Todas las entrevistas se llevaron a cabo entre noviembre y diciembre de 2009, con un informante por empresa, y fueron un promotor o socio fundador y/o director general, con una duración media de treinta minutos cada una.

Antes de realizar las entrevistas se firmó un acuerdo de confidencialidad para preservar la identidad de las empresas, ya que el estudio forma parte de un proyecto de investigación denominado "Diagnóstico estratégico de activos intangibles", aplicado a NEBT en fase de desarrollo (hasta 3 años de edad), que operan en sectores de tecnología alta, media-alta (ingeniería, biotecnología, agroalimentación y tecnologías de la información y las comunicaciones). Para este estudio se identifican y valoran las siguientes variables: actitudes personales, conocimiento científico y capacidades, y habilidades de los miembros de las diez NEBT objeto de análisis. Además, estas empresas se encuentran inmersas en un proceso social de reflexión y de construcción de la estrategia de innovación. Por esta razón las NEBT han sido identificadas con letras. En la Tabla 1 se describe la ficha técnica del estudio.

Tabla 1. Ficha técnica del estudio de casos

\begin{tabular}{|c|c|c|c|}
\hline NEBT & SECTOR DE ACTIVIDAD & $\begin{array}{c}\text { N}^{\circ} \text { DE } \\
\text { EMPLEADOS }\end{array}$ & NIVEL DE RESPONSABILIDAD \\
\hline A & Biotecnología & 9 & Socio Fundador \\
\hline B & Biotecnología & 7 & Socio Fundador \\
\hline C & Biotecnología & 14 & Director General \\
\hline
\end{tabular}




\begin{tabular}{|c|c|c|c|}
\hline NEBT & SECTOR DE ACTIVIDAD & $\begin{array}{c}N^{\circ} \text { DE } \\
\text { EMPLEADOS }\end{array}$ & NIVEL DE RESPONSABILIDAD \\
\hline D & Ingeniería & 26 & Socio Fundador \\
\hline E & Ingeniería & 5 & Socio Fundador \\
\hline $\mathrm{F}$ & Agroalimentación & 9 & Socio Fundador \\
\hline G & Agroalimentación & 7 & Socio Fundador \\
\hline $\mathrm{H}$ & Tecnologías de información & 8 & Socio Fundador \\
\hline । & Tecnologías de información & 15 & Director General \\
\hline J & Tecnologías de información & 21 & Director General \\
\hline
\end{tabular}

Fuente: Elaboración propia.

La estructura de las entrevistas se desarrolló en dos fases. En la primera, los informantes describieron su trabajo en la empresa y después identificaron las características propias de la empresa como: el sector de actividad, historia, estructura, misión y relaciones con su entorno. La segunda fase se centró en la identificación y valoración de aspectos específicos relacionados con las actitudes personales, conocimiento científico y capacidades y habilidades de los miembros de las empresas. Para extraer de las conversaciones y discursos los datos de análisis, se grabaron todas las entrevistas y se transcribieron íntegramente después de su realización (Eisenhardt, 1989; Yin, 1984).

Como técnicas complementarias para la obtención de datos a tiempo real, se utilizó la observación y las fuentes secundarias. En cuanto a la observación, se tomaron notas de las impresiones sobre las actividades y conversaciones de los miembros de las NEBT. En lo referente a las fuentes secundarias, estas han incluido: páginas web de las NEBT participantes en el estudio; página web del PCM; la Memoria 2007 y 2008 del PCM; artículos y notas de prensa sobre las empresas analizadas, así como documentos internos e informes confidenciales proporcio- 
nados por los entrevistados como informes de capital intelectual y esquemas sobre la estrategia de la empresa.

Tabla 2: Resumen de los datos extraídos de las entrevistas

\begin{tabular}{|c|c|c|c|c|c|c|c|c|c|c|}
\hline $\begin{array}{c}\text { MEDIDAS DE INPUT } \\
\text { \% de personas implica- } \\
\text { das en actividades de } \\
\text { mejora }\end{array}$ & 100 & 100 & 100 & 100 & 100 & 100 & 100 & 100 & 100 & 100 \\
\hline $\begin{array}{c}\text { \% personal en promo- } \\
\text { ción/desarrollo profe- } \\
\text { sional }\end{array}$ & 90 & 90 & 80 & 70 & 90 & 70 & 100 & 80 & 90 & 70 \\
\hline $\begin{array}{c}\text { \% de proyectos de } \\
\text { investigación }\end{array}$ & 100 & 100 & 90 & 100 & 100 & 80 & 90 & 90 & 100 & 100 \\
\hline $\begin{array}{c}\% \text { de personal con } \\
\text { estudios de especiali- } \\
\text { zación y postgrado }\end{array}$ & 100 & 100 & 100 & 100 & 100 & 100 & 100 & 100 & 100 & 100 \\
\hline $\begin{array}{c}N^{\circ} \text { de años de antigüe- } \\
\text { dad media en el sector } \\
\text { I+D }\end{array}$ & 6 & 12 & 8 & 9 & 8 & 10 & 7 & 9 & 4 & 6 \\
\hline $\begin{array}{c}\% \text { de personas con } \\
\text { experiencia profesional } \\
\text { internacional }\end{array}$ & 70 & 80 & 50 & 60 & 50 & 80 & 30 & 40 & 60 & 50 \\
\hline $\begin{array}{c}N^{0} \text { de años de expe- } \\
\text { riencia empresarial }\end{array}$ & 3 & $\mathrm{X}$ & 6 & 8 & 4 & 6 & $\mathrm{X}$ & $\mathrm{X}$ & 3 & $\mathrm{X}$ \\
\hline $\begin{array}{c}\mathrm{N}^{\circ} \text { de personas con } \\
\text { experiencia empren- } \\
\text { dedora }\end{array}$ & 1 & $\mathrm{X}$ & 2 & 2 & 1 & 1 & $\mathrm{X}$ & $\mathrm{X}$ & 1 & $\mathrm{X}$ \\
\hline $\begin{array}{c}\mathrm{N}^{0} \text { de personas dedi- } \\
\text { cadas a la gestión del } \\
\text { negocio }\end{array}$ & 1 & 1 & 2 & 2 & 1 & 1 & 1 & 2 & 2 & 1 \\
\hline $\begin{array}{c}N^{0} \text { de competencias de } \\
\text { gestión identificadas }\end{array}$ & 3 & 3 & 4 & 4 & 4 & 3 & 3 & 4 & 3 & 3 \\
\hline $\begin{array}{c}N^{\circ} \text { de personas dedica- } \\
\text { das a la comunicación } \\
\text { interna }\end{array}$ & 1 & 1 & 1 & 2 & 1 & 2 & 2 & 1 & 1 & 2 \\
\hline $\begin{array}{c}N^{\circ} \text { de grupos de inves- } \\
\text { tigación interno }\end{array}$ & 1 & 2 & 3 & 3 & 2 & 2 & 2 & 1 & 1 & 2 \\
\hline
\end{tabular}

Fuente: Elaboración propia.

\section{RESULTADOS}

La Tabla 2 muestra los datos obtenidos de las entrevistas de las 
diez NEBT del PCM. Estos corresponden a las medidas de input que guiaron las entrevistas y que se han materializado en los resultados que se describen a continuación:

Actitudes personales: Estas hacen referencia al conocimiento que las personas tienen sobre las cosas para lograr un buen desempeño; con base en este criterio se identificaron dos medidas de input; primera, personas implicadas en actividades de mejora, que la totalidad de las NEBT identifican con un porcentaje igual a $100 \%$; segunda, personal en promoción/ desarrollo profesional, identificado por las empresas $\mathrm{D}, \mathrm{F}, \mathrm{J}$, con $70 \%$; C, H, con $80 \%$; A, B, E, I, con $90 \%$; y, G con $100 \%$.

Conocimiento científico: Se entiende como la capacidad de la empresa de adquirir nuevas competencias y conocimientos, con la finalidad de responder a las dinámicas de cambio y desarrollo organizacional. Con base en ese criterio se han identificado tres medidas de input; primera, participación y desarrollo de proyectos de investigación activos, se identificó con 80 \% la empresa $F$; con $90 \%$ las empresas C, G, H; y, con $100 \%$ las empresas A, $B, D, E, I$, J; segunda, personal con estudios de especialización y postgrado, identificado con $100 \%$ por todas las empresas, y, tercera, antigüedad media en el sector de I+D en años, con una antigüedad de los socios promotores de 4 años la empresa I; con 6 años las empresas A, J; con 7 años la empresa G; con 8 años las empresas $C$, E; con 9 años las empresa $D, H$; con 10 años la empresa $F$, y con 12 años la empresa $B$.

Capacidades y habilidades: Estas se refieren al tipo de conocimiento relacionado con la forma de hacer las cosas, es decir, el 'saber hacer'. En concreto se consideran capacidades y habilidades que la persona desarrolla básicamente como fruto de la experiencia y de la práctica; este criterio se compone de siete medidas de input. 
Primera, personas con experiencia profesional internacional, extrayendo los siguientes datos, con $30 \%$ la empresa G; con $40 \%$ la empresa $\mathrm{H}$; con $50 \%$ las empresas C, E, J; con $60 \%$ las empresas $\mathrm{D}$, I; con $70 \%$ la empresa $\mathrm{A}$; $\mathrm{y}$, con $80 \%$ las empresas $B, F$.

Segunda, años de experiencia empresarial promedio. En esta medida se identificó que los socios promotores de las empresas $B, G, H, J$, no contaban con experiencia previa empresarial en el momento de iniciar el proyecto empresarial; con 3 años las empresas A, I; con 4 años la empresa $E$; con 6 años las empresas $C, F ; y$, con 8 años la empresa D.

Tercera, número de personas con experiencia emprendedora; se identificó, al igual que en la medida anterior, que los socios fundadores de las empresas $\mathrm{B}, \mathrm{G}, \mathrm{H}, \mathrm{J}$, no contaban con experiencia emprendedora; con 1 persona las empresas A, E, F, I; y con 2 personas las empresas C, D.

Cuarta, número de personas dedicadas a la gestión del negocio. Se hallaron los siguientes datos: con una persona las empresas A, B, E, F, G, J; y, con 2 personas las empresas C, D, H, I. En ambos casos (1 o 2 personas), la gestión del negocio es asumida por los socios fundadores.

Quinta, número de competencias de gestión identificadas. Se identificaron 3 competencias en las empresas A, B, F, G, I, J; y 4 competencias en las empresas C, D, E, H.

Sexta, número de personas dedicadas a la comunicación interna, las empresas $\mathrm{A}, \mathrm{B}, \mathrm{C}, \mathrm{E}, \mathrm{H}, \mathrm{I}$, disponen de 1 persona para realizar esta actividad; $y$, las empresas $D, F, G, J$, disponen de 2 personas. En ambos casos se entiende que el uso de herramientas de comunicación se hace con soporte en tecnologías de 
información y métodos tradicionales, como reuniones, reportes diarios y semanales, entre otros.

Finalmente, la séptima medida, referente a número de grupos de investigación internos, se identificó en las empresas $A, H, I, 1$ grupo de investigación; 2 grupos en las empresas B, E, F, G, J; y 3 grupos en las empresas C, D.

\section{CONCLUSIONES}

De los resultados obtenidos en el estudio se desprende que la relación liderazgo y emprendimiento innovador influye de forma positiva en el desarrollo de innovaciones en las NEBT. Concretamente, se reconocen las NEBT analizadas como sistemas de aprendizaje capaces de reducir la brecha entre los conocimientos existentes en la organización y los que son necesarios para responder eficientemente a las exigencias percibidas del entorno. Todo ello dependerá de la interpretación que los líderes emprendedores hagan de la realidad y de su potencial para reconocer y explotar oportunidades de negocio. En otras palabras, la capacidad de reconocer la oportunidad de un líder emprendedor está relacionada con el grado de innovación de una NEBT, pues es resultante de un ciclo continuo de articulación y codificación de conocimientos que se relacionan y se refuerzan mutuamente, capacitando al sistema para crear, sostener y generalizar conocimientos con impacto, es decir, innovación.

La habilidad de identificar oportunidades emprendedoras, es uno de los atributos con los que el emprendedor debe contar. Desde esta perspectiva, el estudio de caso muestra cómo los líderes emprendedores orientados a la innovación deben estar inmersos en un proceso continuo de aprendizaje, entendido este como un proceso social por el que se crea nuevo conocimiento a través 
de la transformación de la experiencia, al combinar los conocimientos previos con sus percepciones, cogniciones y experiencia (Kolb, 1984). De esta forma, el aprendizaje se configura como un factor clave en las NEBT y que, a su vez, permite comprender el proceso de reconocimiento de la oportunidad, a partir de las relaciones establecidas con diversas redes y enlaces durante todo el proceso. Esta situación permitirá recaudar y evaluar nueva información, tanto de tipo formal como informal, para generar conocimiento útil.

Sin duda, un elemento diferencial en la orientación hacia innovación en las NEBT está en reconocer la complejidad y amplitud de conocimientos necesarios y, por tanto, la idoneidad o imperativo alrededor de la construcción de un marco relacional potente, donde los flujos de información y conocimiento sean de calidad (Raju, 2006).

Conforme a los resultados obtenidos, se pretende ofrecer algunas guías de acción, en general, dirigidas a mantener, tanto a los líderes emprendedores como sus empresas, en un estado de mejora continuada en el desarrollo de su capacidad de aprendizaje y, por ende, de su innovación. Estas sugerencias, como el desarrollo teórico, están sujetas a revisión, por tratarse de empresas en constantes cambios.

Es más, el esfuerzo organizacional, en su conjunto, debe ser estructurado contando con un esquema empresarial dotado de funciones y responsabilidades definidas, procesos formalizados, protección de los resultados, etc., asegurando las dinámicas de gestión en todas las áreas funcionales.

La identificación de experiencias empresariales o emprendedoras previas, además de la existencia de perfiles especiali- 
zados para la gestión, favorece en las NEBT la existencia de una estructura organizacional definida, la formalización de procesos y el esfuerzo en la mejora continua, que se materializa en innovaciones. Todos ellos, aspectos que permiten dilucidar el grado de madurez de la empresa, y, por ende, la superación del voluntarismo y posible caos de las primeras fases. Es más, se logra diferenciar si la orientación hacia la innovación como negocio es real o se quiere hacer un negocio con un resultado concreto de los conocimientos acumulados durante las etapas pre-empresa.

Siempre conviene analizar las características del mercado que se pretende atacar y el soporte derivado de las redes y alianzas. Todo ello se complementa con el ámbito social en el que se valoran activos tan significativos hoy en día como la notoriedad, imagen y reputación, que no fueron incluidos en las medidas de input, pero sí fueron analizados en las fuentes de información complementarias, por tratarse de activos necesarios en el desarrollo del negocio.

El resultado del estudio ha favorecido la articulación de prioridades en la gestión para hacerla más completa, eficiente y profesional, ajustando las variables -actitudes personales, conocimiento científico y capacidades y habilidades- a aquellas que el negocio demanda. Además, los resultados se presentan como una herramienta de comunicación importante, dado que aflora una realidad de valor que generalmente se encuentra escasamente definida, y que en procesos donde se pretende la valoración por terceros, resulta un requerimiento crítico para mejorar el atractivo de la organización.

Sin duda, la visualización de factores clave como: actitudes personales, conocimiento científico y capacidades y habilidades, sitúan a los líderes emprendedores y la forma de gestionar los conocimientos y capacidades de los miembros de las NEBT en el 
eje central de todas las etapas del proyecto empresarial, pues se configuran en agentes de cambios y responsables de la consecución de los objetivos propuestos. De acuerdo a los resultados del estudio, depende de los líderes emprendedores definir, guiar y mantener el espíritu empresarial, conforme a sus experiencias previas, asunción de riesgos, proactividad y acompañamiento, para saber identificar oportunidades de éxito, que permitirá crear valor a la empresa, y en consecuencia, su sostenibilidad en el mercado.

Desde esta perspectiva, el conjunto de las NEBT se configura como un colectivo especial. Los códigos de conducta, la percepción del tiempo y los perfiles que la conforman, son aspectos especialmente críticos a la hora de realizar el tratamiento de datos, y, más aún, en el momento de construir recomendaciones.

\section{REFERENCIAS BIBLIOGRÁFICAS}

Andreu, R. \& Sieber, S. (1999). La gestión integral del conocimiento y del aprendizaje. Economía Industrial, 326, 63-72.

Ardichvili, A., Cardozo, R. \& Ray, S. (2003). A theory of entrepreneurial opportunity identification and development. Journal of Business Venturing, 18, 105-123.

Baron, R. A. (2006). Opportunity recognition and patter recognition. How entrepreneur 'connect the dots' to identify new business opportunities. Academy of Management Perspectives, 20(1), 104-119.

Baron, R. A. \& Ensley, M. D. (2006). Opportunity recognition as the detection of meaningful patterns: evidence from comparisons of novice and experienced entrepreneur. Management Science, 52(9), 1331-1344.

Beijerse, R. (1999). Questions in Knowledge Management: Defining and Conceptualising a Phenomenon. Journal of Knowledge Management, 3, 94-109. 
Bueno, E. (1998). El Capital Intangible como Clave Estratégica en la Competencia Actual. Boletín de Estudios Económicos, 164, 207-229.

Butchart, R. (1987). A new UK definition of high technology industries. Economy Trends, 400 (Febrero), 82-88.

Covey, S. R. (1989). The 7 Habits of Highly Effective People. New York: Simon and Schuster.

Eisenhardt, K. M. (1989). Building theories from case study research. Academy of Management Review, 14, 532-550.

García, A. M. \& García, M. G. (2007). Reconocimiento de la oportunidad y emprendeduría de base tecnológica. XVII Jornadas Hispano Lusas de Gestión Científica, 1276-1293.

Garvin, D. (1998). Building a Learning Organizations. Harvard Business Review, 78-91. Boston.

Gómez, R. A. (2008). El liderazgo empresarial para la innovación tecnológica en las micro, pequeñas y medianas empresas. Pensamiento \& Gestión, 24, 157-194.

Honeycutt, J. (2001). Así es la dirección del conocimiento. Madrid: Microsoft-McGraw-Hill.

Jack, S. L. y Anderson, A. R. (2002). The effects of embeddedness of the entrepreneurial process. Journal of Business Venturing, 17, 467-487.

Katz, R. L. (1974). Skills of an Effective Administrator. Harvard Business Review, 52, 90-102.

Kolb, D. A. (1984). Experiential learning: experience as the source of learning and development. New Jersey: Prentice Hall.

Krueger, N. J. y Brazeal, D. H. (1994). Entrepreneurial potential and potential entrepreneurs. Entrepreneurship Theory and Practice, 19, 91-104.

Little, A. D. (1977). New Technology-Based Firms in the United Kingdom and the Federal Republic of Germany. London: Wilton House.

Macpherson, A., Jones, O. \& Zhang, M. (2004). Evolution or revolution? Dynamic capabilities in a knowledge-dependent firm, R \& D. Management, 34(2), 161-176.

Merton, M. Q., Fiske, M. \& Kendall, P. L. (1956). The focused interview. Glencoe, II, Free Press.

Morse, E. A. \& Mitchell, R. K. (2006). Case in entrepreneurship. United Kingdom, London: Sage Publications Inc. 
Nonaka, I. (2000). La empresa creadora de conocimiento. En Gestión del conocimiento. Harvard Business Review. España: Ediciones Deusto S.A.

Norton, P. (1998). Compitiendo en el siglo XXI. Cómo innovar con éxito. España: Ediciones Gestión 2000.

Park, J. S. (2005). Opportunity recognition and product innovation in entrepreneurial hi-tech star-ups. A new perspective and supporting case study. Technovation, 25, 739-752.

Raju, P. U. L. (2006). Creating business value through people. International Journal of Learning and Intellectual Capital, 3(4), 357-366.

Ruiz, M., Bojica, A. M., Albacete, C. A. \& Fuentes, M. M. (2009). ¿Cómo identifican las oportunidades de negocio los emprendedores? Una aproximación descriptiva al caso andaluz. Gestión Joven, 3, 1-13.

Sarabia, F. J. (1999). Metodología para la investigación en marketing y dirección de empresas. Madrid: Pirámide.

Sarasvathy, S. D. (2001). Causation y effectuation: Toward and theoretical shift from economic inevitability to entrepreneurial contingency. Academy of Management Review, 26(2), 243-264.

Shane, S. (2003). A general theory of entrepreneurship. Cheltenham, Edward Elgar.

Shearman, C. \& Burrell, G. (1988). New technology-based firms and the emergence of new industries: some employment implications. New Technology, Work and Employment, 3(2), 87-99.

Singh, R. P. (2001). Entrepreneurial opportunity recognition through social networks. New York: Garland.

Spender, J. C. (1996). Making knowledge the basic of a dynamic theory of the firm. Strategic Management Journal, 17, 45-62.

Stewart, W. H. \& Roth, P. L. (2001). Risk propensity difference between entrepreneurs and manager: A meta-analytic review. Journal of Applied Psychology, 86(1), 145-153.

Tissen, R., Andriessen, D. \& Lekanne Deprez, F. (2000). El valor del conocimiento para aumentar el rendimiento en las empresas. Madrid: Prentice Hall.

Yin, R. K. (1984). Case Study Research: Design and Methods. 


\section{California: Sage Publications.}

Zahra, S. A., Korri, J. S. \& Yu, J. (2005). Cognition and international entrepreneurship: implications for research on international opportunity recognition and exploitation. International Business Review, 14(2), 129-146.

\section{BIBLIOGRAFÍA CONSULTADA}

Parque Científico de Madrid (2007). Memoria anual. España: Fundación Parque Científico de Madrid.

Parque Científico de Madrid (2008). Memoria anual. España: Fundación Parque Científico de Madrid.

Shrivastava, P. (1983). Atipology of organizational learning systems. Journal of Management Science, 20, 2-24. 


\title{
EMPRENDER DESPUÉS DE UNA DISCAPACIDAD
}

\author{
Undertake ofter a disability
}

\author{
NARLEDIS NÚÑEZEZ BRAVO - LILIBETH SÁNCHEZ GÜETTE - \\ VANESSA SOTELO BERRÍO - CARLOS MIRANDA MEDINA \\ CARLOS OSORIO TORRES
}

\section{RESUMEN}

La discapacidad es un concepto que evoluciona y que resulta de la interacción entre las personas con deficiencias y las barreras debidas a la actitud y al entorno que evitan su participación plena y efectiva en la sociedad, en igualdad de condiciones con los demás. Se desarrolla un estudio de caso en el cual, a través de las experiencias significativas de vida de un sujeto, se pretenden describir los factores sociales e individuales que lo llevan a afrontar las dificultades y sobresalir en la sociedad en la que se desempeña, venciendo barreras y/o obstáculos para lograr el emprendimiento y empresarismo utilizando la entrevista abierta bajo un abordaje cualitativo y un diseño metodológico de estudio de caso como estrategia de investigación comprensiva, abordando las categorías de emprendimiento y discapacidad. En los resultados obtenidos se observan los factores y/o motivaciones que llevan a una persona con discapacidad a iniciar y proponerse ser emprendedoras están principalmente la fe en Dios, la perseverancia, las redes sociales y familiares. Así mismo se encontró como característica principal, la percepción y análisis de la realidad desde una óptica emprendedora, identificando las oportunidades que lo han llevado a sobresalir en la sociedad a pesar de su condición de salud.

Palabras clave: discapacidad, inclusión social, resiliencia, familia y emprendimiento.

\section{ABSTRACT}

Disability is an evolving concept that results from the interaction between people with disabilities and the barriers due to attitude and environment that prevent their full and effective participation in society, on an equal basis with others. It develops a case study in which through the significant experiences of a subject's life, they are intended to describe the social and individual factors that leads him to face the difficulties and excel in the society in which he works, overcoming barriers and/or obstacles to achieve entrepreneurship and entrepreneurship. Using the open interview under a qualitative approach and a 
methodological design of case study as a comprehensive research strategy, addressing the categories of entrepreneurship and disability. In the obtained results it is observed as far as the factors and/or motivations that lead to a person with disability to initiate and to propose to be entrepreneurs are mainly; faith in God, perseverance, social and family networks. Likewise, the main characteristic was the perception and analysis of reality from an entrepreneurial point of view, identifying the opportunities that have led him to excel in society despite his health condition.

Key words: disability, social inclusion, resilience, family and entrepreneurship.

\section{INTRODUCCIÓN}

Existen múltiples definiciones de emprendimiento, así como numerosas disciplinas en las que se aborda el tema. Se define un emprendedor social como una persona que presenta soluciones innovadoras a los problemas más graves dentro de sus comunidades (Fundación Ashoka, 2012). Generalmente, el emprendimiento surge como un proyecto personal al cual es necesario introducir esfuerzo para desarrollarlo y muchas veces suele implicar el sorteo de obstáculos y dificultades para lograr obtener el éxito deseado.

En el caso de las personas con discapacidad, estos obstáculos y dificultades se acrecientan, debido a que no solo deben enfrentar los problemas propios de un emprendedor, sino que además se ven enfrentados a "barreras sociales y mentales", muy a pesar de que el 11,6 \% de personas con discapacidad son autónomos y capaces de realizar cualquier tipo de actividad (Instituto Nacional de Estadística, 2014). Según la Clasificación Internacional del Funcionamiento (CIF), la discapacidad abarca las deficiencias, limitaciones en la actividad y las restricciones en la participación, y deja de utilizarse el término discapacidad solo para las consecuencias de una enfermedad (Organización Mundial de la Salud, 2001).

A lo largo de la vida se pueden presentar situaciones que 
interrumpen de forma brusca el curso normal de la historia de las personas. Estas pueden ser de tipo evolutivo o de tipo circunstancial. La primera se refiere a aquellas que aparecen con el paso del tiempo y como consecuencia del transcurrir de las etapas vitales; las últimas se presentan de formas accidentales, sobrevenidas e inesperadas. Del modo en que se superen estas crisis dependerá el restablecimiento saludable del equilibrio emocional y la continuación de una vida satisfactoria o, por el contrario, que se produzca un deterioro que no permita avanzar y genere estancamiento a partir de esa circunstancia (Fernández, 2010).

Para una persona sin discapacidad, que sufre un accidente o enfermedad que le produce ciertas limitaciones y restricciones, es complicado retomar su vida en todos los contextos y sobre todo el laboral. Diversos factores van a influir en cómo se perciben las situaciones críticas y cómo las incorpora a la vida para continuarla de la forma más satisfactoria posible; en ello intervienen variables personales, familiares, sociales, del propio hecho en sí mismo y las estrategias desarrolladas para la superación del evento traumático.

Estas variables desarrollan procesos resilientes que contribuyen a la readaptación de la nueva realidad que se presenta para la persona con discapacidad, generando procesos de ajustes con la sociedad. Es así como Bea Gómez (2010) propone que la resiliencia es:

La capacidad de las personas para sobreponerse a períodos de dolor emocional y situaciones adversas. Cuando la persona que sufre alguna de estas condiciones es capaz de sobreponerse se afirma que esta tiene una resiliencia adecuada, y resulta con fortalezas luego de superarla. (p.14)

A través del análisis de experiencias significativas de vida de un sujeto, se pretende describir los factores personales, familiares, 
sociales e individuales, y las estrategias de afrontamiento para superar las dificultades y sobresalir en la sociedad en la que se desenvuelve, logrando el emprendimiento y empresarismo; venciendo la discapacidad física, alterando su capacidad de locomoción y como consecuencia, la utilización de silla de ruedas como ayuda técnica.

Es necesario lograr que las personas con discapacidad alcancen el máximo de desarrollo, que sean mirados en sus potencialidades y no se les encasille en su deficiencia; lograr un cambio cultural con espacios para todos y todas. Para conseguir este cambio se requiere visibilizar experiencias exitosas como estas, que permitan valorar el aporte que las personas con discapacidad hacen a la sociedad, estimulando una mirada social inclusiva.

Con base en lo anterior, algunas personas con discapacidad se han propuesto romper estas barreras de inequidad y exclusión social que les impide su desempeño laboral, y recibir un salario adecuado y digno, y han logrado ser emprendedoras, incluso empleadoras superando el estado temporal de trastorno generado en su crisis, desarrollando capacidades para abordar sus situaciones particulares, utilizando métodos innovadores para la solución del problema, obteniendo resultados positivos en sus actividades cotidianas de adaptación laboral y transformación de la realidad, logrando ser emprendedores.

\section{FUNDAMENTACIÓN TEÓRICA}

Según el informe mundial sobre discapacidad realizado por la Organización Mundial de la Salud (OMS) y presentado en el 2011, se estima que más de mil millones de personas viven con discapacidad, esto representa el $15 \%$ de la población mundial, cifras superiores a las estimadas por la OMS en el año 1970. Su 
aumento es debido al envejecimiento de la población, pues las personas adultas mayores tienen un mayor riesgo de discapacidad; de igual forma el incremento de enfermedades cardiovasculares, metabólicas y trastornos del desarrollo han generado este panorama.

Según la OMS, discapacidad es un término general que abarca las deficiencias, las limitaciones de la actividad y las restricciones de la participación. Las deficiencias son problemas que afectan a una estructura o función corporal; las limitaciones de la actividad son dificultades para ejecutar acciones o tareas, y las restricciones de la participación son problemas para participar en situaciones vitales. Por consiguiente, la discapacidad es un fenómeno complejo que refleja una interacción entre las características del organismo humano y las características de la sociedad en la que vive.

El 22 de mayo de 2001, en la 54a Asamblea de la OMS, se aprueba la nueva versión de la clasificación con el nombre definitivo de "Clasificación Internacional del Funcionamiento, la Discapacidad y la Salud", con las siglas CIF. En el propio título de la nueva Clasificación se encuentra una declaración de intenciones (OMS, 2001). Ya no se enuncian tres niveles de consecuencias de la enfermedad, sino que se habla de funcionamiento (como término genérico para designar todas las funciones y estructuras corporales, la capacidad de desarrollar actividades y la posibilidad de participación social del ser humano), discapacidad (de igual manera, como término genérico que recoge las deficiencias en las funciones y estructuras corporales, las limitaciones en la capacidad de llevar a cabo actividades y las restricciones en la participación social del ser humano), y salud (como el elemento clave que relaciona a los dos anteriores). En sus primeras líneas, la CIF enuncia su objetivo principal: "brindar un lenguaje unificado y estandarizado, y un marco conceptual para la descripción de la salud y los estados relacionados con la salud". 
La CIF, desde los comienzos de su elaboración, se pronuncia por un enfoque biopsicosocial y ecológico, superando la perspectiva biomédica imperante hasta el momento. Particularmente, este dato queda evidente con la inclusión de un apartado dedicado a los factores contextuales, como se puede observar en la Figura 1.

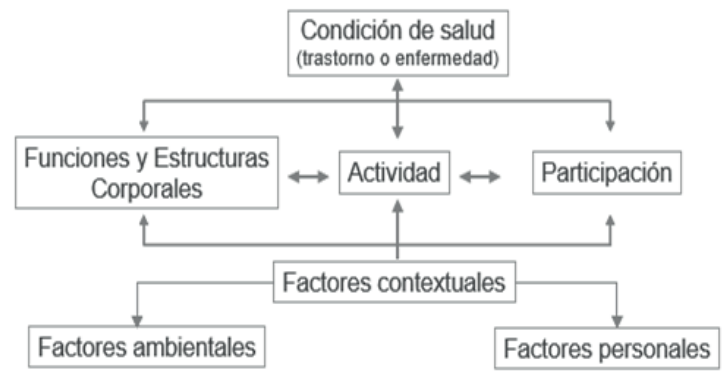

Figura 1. Interacciones entre los componentes de la CIF

Fuente: Organización Mundial de la Salud, OMS. (2001). Clasificación internacional del funcionamiento, de la discapacidad y de la salud: CIF. p.21.

La complejidad de la Clasificación ha aumentado con respecto a la versión original de 1980. Se incorporan nuevos términos y conceptos (ver Figura 2).

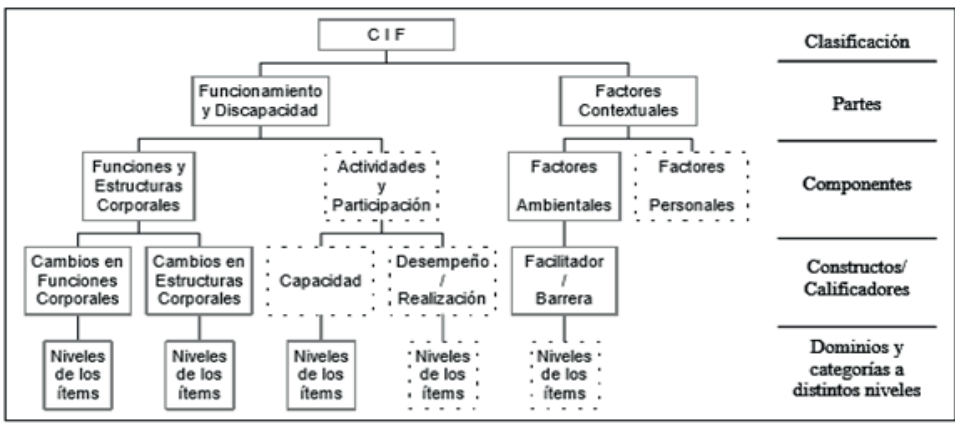

Figura 2. Incorporación de nuevos términos y conceptos en las interacciones entre los componentes de la CIF

Fuente: Organización Mundial de la Salud, OMS. (2001). Clasificación internacional del funcionamiento, de la discapacidad y de la salud: CIF. p.22.

La CIF está compuesta por cuatro escalas (funciones corporales, estructuras corporales, actividades y participación, y factores 
contextuales). Es fundamentalmente útil para la valoración y descripción de condiciones de salud y, por lo tanto, de la forma negativa de salud. Consecuentemente en el contexto de la salud: "Funciones corporales son las funciones fisiológicas de los sistemas corporales (incluyendo las funciones psicológicas)". "Estructuras corporales son las partes anatómicas del cuerpo, tales como los órganos, las extremidades y sus componentes". "Deficiencias son los problemas en las funciones o estructuras corporales, tales como una desviación o una pérdida". "Actividad es el desempeño/realización de una tarea o acción por parte de un individuo". "Limitaciones en la Actividad son dificultades que un individuo puede tener en el desempeño/realización de actividades".

"Participación es el acto de involucrarse en una situación vital". "Restricciones en la Participación son problemas que el individuo puede experimentar al involucrarse en situaciones vitales". "Factores Ambientales constituyen el ambiente físico, social y actitudinal en el que una persona vive y conduce su vida". La salud en forma positiva vendrá descrita por las funciones y estructuras corporales, la actividad y la participación. La salud en forma negativa lo será por las deficiencias, las limitaciones en la actividad y las restricciones en la participación. Mientras tanto, los factores ambientales actuarán de forma positiva si su presencia supone un facilitador para superar la deficiencia, las limitaciones en la actividad o las restricciones en la participación, y serán negativos en tanto que supongan una barrera u obstáculo que entorpezca o agrave cualquiera de los componentes anteriores.

En la CIF, la Discapacidad "engloba las deficiencias, las limitaciones en la actividad y las restricciones en la participación." Se utiliza Condición de Salud para referirse al efecto, debido a las 
$\approx$ enfermedades o trastornos, que padece un individuo y es la llave de paso entre el funcionamiento y la discapacidad. Debemos diferenciar este concepto del de "salud", que, en la CIF, es el genérico que hace referencia tanto a aspectos negativos como positivos. En su línea de positividad, la CIF recoge la codificación del funcionamiento humano, línea base sobre la que se ha generado una terminología considerada "positiva" para describir la salud. Pero la verdadera utilidad de la CIF la encontramos en el uso de los "calificadores" que proporciona para describir los "estados relacionados con la salud".

Uno de los factores contextuales a los cuales debe enfrentarse una persona con discapacidad, es que los gobiernos, durante el diseño de las políticas y normas, no siempre tienen en cuenta las necesidades de la persona, o, por el contrario, a pesar que las políticas existen estas no se cumplen dentro del aspecto educativo, laboral y sanitario. En el aspecto económico las personas con discapacidad tienen más probabilidad de estar desempleadas y generalmente ganan menos cuando trabajan; la tasa de empleo es menor para hombres y mujeres con discapacidad, situándose en $53 \%$ y $20 \%$ respectivamente, y entre hombres y mujeres sin discapacidad está representado en un $65 \%$ y un $30 \%$ (OMS, 2011).

Es importante abordar los obstáculos en materia de desempleo para estas personas, y las leyes contra la discriminación se convierten en el punto de partida para promover la inclusión laboral de las personas con discapacidad. En países donde la legislación exige a los empleadores que realicen adaptaciones razonables, que permitan facilitar el acceso a los procedimientos de selección y contratación, se ha adaptado el entorno del trabajo, modificando los horarios laborales y proporcionando tecnologías auxiliares; estas adaptaciones podrían disminuir 
la discriminación en el empleo, mejorar el acceso al lugar de trabajo y modificar las percepciones acerca de las aptitudes de las personas con discapacidad para ser productivos (OMS, 2011).

Un estudio realizado por Valdés (2012), cuyo interés fue identificar las representaciones sociales del trabajo de jóvenes en situación de discapacidad intelectual, se desarrolló bajo un modelo social de la discapacidad, vinculándose a conceptos como inteligencia dialógica, ciudad educadora y pedagogía crítica. Los jóvenes participantes en el estudio presentaban un nivel leve de discapacidad intelectual, y se encontraban vinculados a una empresa a través de una pasantía laboral y recibían apoyo de un centro de educación especial. En dicho estudio se encontraron los siguientes aspectos. En primera instancia, acceder en términos procesuales a las representaciones sociales del trabajo en situación de discapacidad intelectual, permite destacar el valor que estas tienen en cuanto a adquisiciones determinadas por la posibilidad de compartir contextos laborales con distintos trabajadores, hacen parte de diálogos en los que participan directamente, aspecto que puede ser interpretado como inclusión dialógica, es decir, a partir de las experiencias en donde jóvenes, que aunque cargan con el estigma de lo patológico, construyen significados en torno a procesos de aprendizaje en el trabajo, contribuyendo a cambiar aspectos de la realidad social que les son adversos.

Por otra parte, en cuanto a las actitudes positivas que conforman las representaciones que tienen los jóvenes participantes acerca del trabajo, resulta relevante que, perteneciendo estos al nivel socioeconómico bajo, se orienta en función de una visión habilitadora del mismo, permitiendo un crecimiento personal orientado hacia el futuro relacionando el trabajo como un proyecto de vida.

Esto, además de confirmar la importancia de preparar a estos 
jóvenes para adaptarse a un medio laboral cambiante, permite analizar que, a pesar de las limitaciones conceptuales y dificultades en la conducta adaptativa, los jóvenes en situación de discapacidad intelectual son capaces de construir interpretaciones al ser parte del contexto laboral, donde disponen de un flujo de información en la relación con otros trabajadores y una cultura en torno al trabajo.

Por otra parte, según el informe presentado por la Organización Internacional del Trabajo (O'Reilly, 2007), se ha venido analizado el concepto de empleo por cuenta propia, subvencionado para personas con discapacidad grave. Específicamente en Estados Unidos observaron cómo el empleo por cuenta propia puede ayudar a aumentar la satisfacción individual de las personas con discapacidad; sin embargo, también reconocen que es importante contar con mucho apoyo en todas las fases de la creación y dirección de una empresa.

En Letonia apoyan la incorporación al mercado de trabajo de las personas con discapacidad a través de un programa denominado "lucha contra la exclusión social", que incluye medidas como el desarrollo del espíritu empresarial y el empleo por cuenta propia. En Suecia, una persona con discapacidad, con una idea empresarial sólida, puede recibir una subvención para crear una empresa.

Con base en lo anteriormente enunciado, es de vital importancia incentivar el emprendimiento, permitiendo de esta manera que se incrementen los índices de independencia y empleabilidad en las personas con discapacidad.

Según Jaramillo (2008):

El emprendimiento es una capacidad de los seres humanos para salir adelante de una manera novedosa y con ideas renovadas, ser emprendedor requiere de habilidades no solo de 
manera individual, sino también colectiva, una de las razones por las cuales este término se ha vuelto importante en las últimas décadas es debido a la manera como se han manejado las situaciones económicas y cómo estas han sido superadas con nuevas ideas. (p.1)

La palabra emprendimiento viene del francés entrepreneur, que significa pionero; se refiere a la capacidad de una persona de realizar un esfuerzo adicional para alcanzar una estrategia o meta. Es también utilizada para las personas que inician una nueva empresa o proyecto. Una persona emprendedora es capaz de aprovechar situaciones de insatisfacción, los momentos de rutina, de poco crecimiento personal y laboral para desencadenar situaciones de satisfacciones y nuevo logros (Jaramillo, 2008).

Un estudio realizado por la Organización Iberoamericana de Seguridad Social (2012) reconoce lo siguiente:

La población con discapacidad ha fomentado iniciativas a partir de instituciones competentes en materia de promoción de empleo y del fomento empresarial desarrollando programas para la promoción y el financiamiento de proyectos empresariales de trabajadores con discapacidad, que contemplan la condición de créditos en condiciones favorables, el asesoramiento para la puesta en marcha de los emprendimientos, pagos reducidos en las cuotas de seguridad social y otros apoyos. Una fórmula utilizada en algunos países es la posibilidad de capacitar las personas con discapacidad en materia de emprendimiento. (p.40).

En Brasil, el Banco Nacional de Desarrollo Económico y Social (BNDES), a través de programa de apoyo a la inversión social de las Empresas (PAIS), proporciona recursos para financiar la creación de empresas por parte de las personas con discapacidad; unos de los aspectos financiados son: la obra civil, 
\& adecuación física de las instalaciones, equipos especiales, ayudas técnicas, equipos, materiales de enseñanza, maquinaria y herramientas especiales, capacitación del personal y asesoramiento técnico para la realización de proyectos empresariales (OISS, 2012, p.40).

Varios países han desarrollado diferentes estrategias para promover el autoempleo y el emprendimiento en las personas con discapacidad, a través de capacitaciones para este grupo de personas en destrezas empresariales con el fin de consolidar proyectores productivos tales como:

Chile creó el programa YO emprendo del Fondo de solidaridad e inversión Social (FOSIS) en una convocatoria Nacional de proyecto de micro emprendimiento. Costa Rica creó el Programa Nacional de Apoyo a la Microempresa (PRONAMYPE). En Ecuador, de acuerdo con el artículo 55 de la Ley Orgánica de Discapacidades, las entidades públicas crediticias mantienen líneas de crédito preferentes para emprendimientos individuales, asociativos y/o familiares de las personas con discapacidad. En Honduras, se gestiona un Fondo Rotario para ofrecer apoyo a micro-emprendimientos de las personas con discapacidad. En México se creó el Fondo Nacional de Apoyos para Empresas de Solidaridad (FONAES). En Nicaragua el Ministerio del Trabajo desarrolla programas de apoyo al autoempleo, a través de los cuales dota a los beneficiarios, de equipos y herramientas de trabajo.

En Panamá la Secretaría Nacional de Discapacidad (SENADIS) desarrolla el Proyecto de Inclusión Socioeconómica de las personas con discapacidad y sus familias, Fami-Empresas. En Paraguay el Ministerio de Justicia y Trabajo en este sentido, a través de la Dirección General de Empleo y el Sistema Nacional 
de Formación y Capacitación Laboral (SINAFOCAL). En la República Dominicana, el Consejo Nacional sobre Discapacidad (CONADIS) desarrolla un Programa Especial de Créditos, en colaboración con el Consejo Nacional de Promoción y Apoyo a la Micro, Pequeña y Mediana Empresa (PROMIPYME). En España, el programa de promoción del empleo autónomo contempla subvenciones de hasta un máximo de 10.000 euros para desempleados con discapacidad que se establezcan como trabajadores autónomos o por cuenta propia. OISS: Organización Iberoamericana de Seguridad Social. Medidas para la promoción del empleo de personas con discapacidad en iberoamerica.

Inicialmente en Colombia, la Ley 361 de 7 de febrero de 1997, establece mecanismos de integración de las personas con limitación y dicta otras disposiciones; contempla, en su artículo 34, la promoción del autoempleo y la creación de empresas por parte de las personas con discapacidad.

Un estudio explorativo, realizado en España, y cuyo interés es conocer la realidad de las iniciativas emprendedoras sociales promovidas por las entidades no lucrativas dedicadas a la discapacidad, realizado en la comunidad en Castilla, reconoce que el fenómeno del emprendimiento social ha venido ganando protagonismo en la literatura académica. Los resultados demuestran que, a pesar de los esfuerzos realizados por estas instituciones, su principal problema es la falta de recursos para mantenerlas, por tanto, se sugirió que tomara la figura de federaciones con la finalidad de ser más eficientes en la gestión de los recursos, y así brindar el apoyo a las personas con discapacidad en temas como innovación y creación de empresas, con el fin de que estos se ajusten con el perfil competitivo de la sociedad (Cruz, Gómez, Pérez, Trevilla \& Estrada, 2008).

Con la óptica de la perspectiva psicosocial se han estudiado 
$\approx$ propuestas de intervención desde el bienestar subjetivo, habilidades sociales y capacidad emprendedora en mujeres con discapacidad intelectual. Los resultados identificaron que, al tener un alto nivel de autoconcepto y habilidades sociales, demuestran tener mayores capacidades para el desarrollo de su propio negocio, sin embargo necesitan el apoyo de entidades que orienten este proceso (Poblete \& Jiménez, 2013).

Otro estudio analiza las actitudes emprendedoras en personas con discapacidad, estableciendo la creación de empresas como aquel fenómeno deseable para una sociedad por los beneficios que aporta, especialmente creando empleo y oportunidades empresariales. Este hecho es muy importante para las personas con discapacidad, porque esta es una de sus principales vías de inserción profesional. Los resultados muestran que las personas con discapacidad presentan actitudes desfavorables hacia la creación de empresas, y la justifican de similar manera, pues ocurre igual con los individuos que no presentan discapacidad. No obstante, parecen surgir datos que sugieren que la conducta de la persona con discapacidad obedece a particularidades propias, como la búsqueda de seguridad laboral y las barreras emocionales y de autoconfianza (Alonso, 2014).

\section{METODOLOGÍA}

Tipo de Investigación. Se empleó un abordaje cualitativo. Salamanca (2000, citado por Vanegas \& Giménez, 2011) asegura que la investigación cualitativa explora la profundidad, la riqueza y la complejidad inherente del fenómeno. Destaca que este tipo de investigación está basada en el paradigma naturalista, puesto que reconoce la existencia de diversas realidades y no una realidad única y objetiva, buscando comprender la complejidad y significado de la existencia humana, centrándose en la persona como ser complejo. 
En este sentido, Durán (2000, citado por Vanegas \& Giménez, 2011) afirma que dentro del marco de la integralidad u holístico, la investigación cualitativa busca explorar a profundidad la riqueza y la complejidad inherente a los fenómenos en contexto, tal como ocurren naturalmente.

Diseño Metodológico. Estudio de caso con la entrevista como fuente de evidencia.

De acuerdo con DePoy \& Gitlin en 1994 y Yin en 1994 (Citados por Barrios, 2005):

El diseño de estudio de caso es apropiado cuando: (a) Existe un interés por examinar a un fenómeno en su contexto de la vida real; (b) Cuando las fronteras entre el fenómeno y el contexto no son evidentes; (c) El estudio intenta desarrollar o apoyar una teoría; (d) Existe una necesidad de explorar un fenómeno en profundidad pero los investigadores no pueden llevar a cabo una investigación a gran escala. Yin (1994) ha indicado que «el estudio de caso como una estrategia de investigación comprende una forma de metodología holística que abarca un diseño lógico que incorpora enfoques específicos para recolectar los datos y para ser analizados-. En ese sentido, el estudio de caso no es solamente una táctica para la recolección de datos, ni simplemente un rasgo de diseño, sino una estrategia de investigación comprensiva». Asimismo, ha señalado que el diseño de un estudio de caso puede ser constituido por múltiples unidades de análisis (p.116).

Se hizo una búsqueda de personas con discapacidad que cumplieran con las características de ser emprendedoras, logrando contactar a la persona con quien se realizaría la investigación, conociendo que cumplía con las características requeridas, quien accedió a ser parte de la investigación: Sujeto emprendedor con discapacidad física, a quien se le aplicó una entrevista abierta: Joven de 33 años de edad, con lesión en la 
$\approx$ columna vertebral a nivel cervical. Creador de una fundación con gran impacto.

Burns \& Groven (2004) afirman que el objeto de la investigación cualitativa es revelar la subjetividad, por lo que el muestreo se centra más en las experiencias, los acontecimientos y situaciones que en la cantidad de personas participantes.

Se realizó una entrevista abierta como técnica directa para la recolección de información, que permitiera una indagación sobre la vida de la persona clave. Se desarrollaron unas preguntas orientadoras que generaron una amplia gama de información y que el grupo investigador consideró suficientes para iniciar el proceso de análisis.

\section{RESULTADOS}

Historia de vida de la persona clave con discapacidad.

Joven de 33 años de edad, publicista de la Universidad Jorge Tadeo Lozano, quien trabajó varios años en Sancho BBDO.

En el 2004 se encontraba celebrando el matrimonio de su hermana en las Islas del Rosario de Colombia, se lanzó al mar, calculó mal y tuvo un golpe contra un banco de arena, quedando inmediatamente cuadripléjico. Al momento de los hechos, alguien que iba en la lancha lo vio, se lanzó al mar y lo auxilió, él estaba a pocos minutos de broncoaspirar y sin posibilidad de movimiento; tuvo lesión de columna en las vértebras IV y V cervical, lo cual le generó una parálisis irreversible con limitaciones sensoriales severas y con prescripción de aditamento médico (silla de ruedas). Fue una situación difícil de aceptar y asimilar, pero no se resignó a su suerte, aceptó su 
condición y empezó una nueva vida, dándole inicio a su proceso de rehabilitación en Colombia, luego viajó a Estados Unidos donde continuó su proceso. Durante ese tiempo transcurrido se apasionó por el rugby en silla de ruedas, le pareció algo increíble para las personas en situación de discapacidad. Regresa nuevamente a Colombia e inicia un movimiento en pro de la defensa de los derechos humanos.

Junto a su padre, un reconocido arquitecto, urbanista y diseñador industrial capitalino, decide diseñar y construir un Centro Comercial en la ciudad de Bogotá, con el fin de convertirlo en una reivindicación de los derechos laborales de las personas con discapacidad; luego, junto a un equipo de doctores, diseñadores, constructores y pacientes, que lideraba el joven, empiezan a soñar con un centro de rehabilitación especializado para personas con lesiones medulares, y nació una fundación sin ánimo de lucro, que ayuda a las personas desde que sufren el accidente hasta que son inscritos en ambientes laborales.

El 29 de diciembre del 2006 inició el proyecto que promueve la vinculación de personas con algún tipo de discapacidad al ámbito laboral, con una entidad sin ánimo de lucro que tiene como misión ofrecer rehabilitación integral, desde fisioterapia hasta sostenimiento laboral, a personas con algún tipo de discapacidad; es un grupo social empresarial que, desde las cinco empresas que lo conforman, todas sin ánimo de lucro, desarrolla modelos de inclusión social para las poblaciones vulnerables del país, mediante programas y proyectos de impactos sostenibles, medibles y cuantificables, que inciden en las condiciones sociales que propician su vulnerabilidad, mejorando así su calidad de vida, desde enfoques de equidad, acceso a los derechos y eficiencia ambiental, social y financiera. Tiene actua- 
$\approx$ ciones en áreas como: salud, capital social, comunicaciones, construcciones y deportes.

Inicia el plan piloto del proyecto en el Centro Comercial. Contrataron hombres y mujeres con algún tipo de discapacidad para desempeñarse en labores de vigilancia, sala de cine, restaurantes, parqueaderos, información y almacenes de ropa, lo cual generó buena acogida a nivel mundial.

Hoy día la Fundación presta atención integral a más de 150 personas, a través de convenios con el Grupo Sánitas Internacional, Famisanar, Colmédica, Bolívar, Ottobock, Aliansalud y Compensar, a su vez, programas de inclusión social y proyectos productivos, impactando a más de 3.500 familias en Casanare, Valle del Cauca, Huila, Funza y Bogotá, con el apoyo de los gobiernos locales, la Asociación Tejido Humano, Alcaldía Mayor de Bogotá-Secretaria Distrital de Desarrollo Económico, el Instituto para la Economía Social-IPES, USAID, CHF; inclusión laboral a más de 60 personas con discapacidad auditiva en Mc Donalds, 40 personas con discapacidad física en Colombia, Perú y Argentina con la multinacional de seguridad Securitas, y 40 personas con discapacidad en IQ Electronics, Teledatos y Human Capital; creación de los Centros Poeta en Bogotá y Villanueva-Casanare con el apoyo de Trust for the Americas, entidad cooperante de la OEA y Microsoft, donde se han capacitado más de 1.000 personas en temas relacionados con el paquete Office de Microsoft y el mundo laboral.

Otra de sus áreas es el diseño gráfico, en la cual ha realizado diseño de cartillas de derechos e inclusión, deporte paralímpico, promoción de salud, vivienda saludable para la Gobernación del Casanare, Huila y Fundación Saldarriaga Concha; diseño de 
más de 400 imágenes corporativas para unidades productivas en Casanare, Huila y Bogotá; ha generado desarrollos audiovisuales tales como: video institucional del proyecto "Implementación de mecanismos para el mejoramiento de las condiciones de la vida de la población con discapacidad (1.050 personas) en el departamento de Casanare", comercial para TV "Ayudar está en tus manos" para Tejido Humano, video animado de publicidad interna "Aprendiendo a Reciclar con los Piraquive" para Constructora Bolívar, video promocional "Rumble in Cartagena" para la Convención de Ottawa, video y campaña de "Segregator Project" en Colombia, Argentina y Japón, video de "Máximus Americas" para QudRugby, video "Somos más" para Acción Social de la Presidencia de la República, video y campaña "Remángate" para sensibilización en contra del uso de las Minas Antipersona.

Desarrollos web tales como: Leveleleven (www.level11pt. com), la ONG Tiempo de Juego (www.tiempodejuego.org), el proyecto Sport Power de USAID y OIM (www.sportpower.org), el panamericano de rugby en silla de ruedas (www.bogota2011. org), Maximus Project (www.maximusproject.org), Parcharte (www.parcharte.org); más de 200 viviendas intervenidas con los programas de accesibilidad y vivienda saludable en Casanare y Huila, desarrollo de construcciones comunitarias (canchas de fútbol, salas de lecturas, etc.) en diferentes regiones como Ciudad Bolívar, Palomino, Momil, Islas del Rosario, Parque Tayrona y Morichal, transformando espacios de delincuencia en centros de convivencia ciudadana con el apoyo de la Policía Nacional y Cemex, asesoría en accesibilidad y adecuación del edificio de la Gobernación del Valle del Cauca, asesoría al Banco de Bogotá para la construcción de oficinas accesibles, programas de recreación y deporte, impactando a más de 1.500 personas 
en Casanare, Huila y Bogotá, con el apoyo de los gobiernos locales, OIM y USAID, creación de más de 5 clubes de deporte paralímpico, como rugby en silla de ruedas, atletismo, fútbol para ciegos, volleyball sentado, realización del Panamericano de Rugby en Silla de Ruedas con la participación de más de 100 atletas y de los países de Estados Unidos, Canadá, Brasil, Argentina, México y Colombia, Maximus Project para la implementación y desarrollo del Rugby en silla de ruedas en Uruguay, Paraguay, Chile, Bolivia, Perú y Ecuador con el apoyo de USAID.

El joven, consciente de la situación que vive el país y de la violencia generada por grupos al margen de la ley, y de todas las consecuencias que ha dejado la situación, lidera una campaña que es apoyada por la Vicepresidencia de la República, con el propósito de romper la indiferencia de los ciudadanos en torno a las minas antipersona, que desde 1990 han truncado la vida y la integridad de más de 9.000 colombianos, 8.000 de ellos niños y niñas; "Remangate", campaña que arrancó con una fuerte promoción en las redes sociales. De acuerdo con él, en 2011 se alcanzaron más de 102.000 visitas al video oficial montado en Youtube en menos de un mes. "Lo más sorprendente fue notar que no solo los colombianos vieron el video; gran porcentaje de esas visitas vinieron de personas interesadas en todo el mundo".

"Esta idea la vamos a exportar", señaló, y efectivamente así fue: En 2012 la campaña se convirtió en internacional, con la participación de importantes personajes públicos como: Iker Casillas, arquero del Real Madrid, Carlos el 'Pibe' Valderrama y Ban Ki Moon, participaron en ella. 


\section{Análisis de persona clave con discapacidad en relación con el emprendimiento.}

Tabla 1. Factores sociales e individuales, motivaciones para ser emprendedor.

- Apoyo de la familia, contexto familiar nuclear como elemento protector.

- La fe en Dios.

- El autoconcepto.

- $\quad$ Percepción de la realidad.

- $\quad$ Redes de amigos que conocen la enfermedad y se convierten en elementos que brindan apoyo para superar la crisis.

- $\quad$ Plantear metas a futuro que le posibilitan la autosuperación.

Fuente: Elaboración propia

En la Tabla 1 se determinó que los factores y/o motivaciones que llevan a una persona con discapacidad a iniciar y proponerse ser emprendedores son principalmente: la fe en Dios, la familia y la perseverancia.

Minuchin y Fishman (1984) plantean que los elementos característicos de la familia son, brindar un espacio para crecer, recibir auxilio y elaborar pautas de interacción que constituyen la estructura familiar, que rige el funcionamiento de los miembros, define su gama de conductas y facilita su interacción recíproca, estos presentan la estructura familiar como la característica fundamental que define a la familia, y resaltan el hecho de que aquella se constituye en el ente regulador del funcionamiento de todos sus miembros.

Son elementos motivacionales claves en esta persona, los compromisos adquiridos por los sujetos debido al valor que le dan a los esfuerzos realizados por la familia. La posibilidad de aceptar la condición de salud le llevó a generar productividad con los elementos que le ofrece el medio, las redes de apoyo que se generaron con personas fueron fundamentales para superar la crisis. 
Erick Erikson (1956) afirma que el concepto de la crisis no solamente contiene un potencial patológico, sino que también es una oportunidad de crecimiento y desarrollo. Si bien, es cierto que la crisis representa un riesgo, también implica una oportunidad, posibilitando incorporar estrategias de afrontamiento y de autoconocimiento personal.

En este orden de ideas, se resaltan como parte fundamental en la recuperación y afrontamiento los factores personales de resiliencia, y el apoyo social como interpersonal que se reciba.

Tabla 2. Características de la persona con discapacidad para lograr ser emprendedora

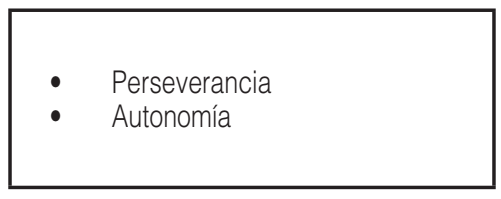

Fuente: Elaboración propia

De acuerdo con la Tabla 2, se puede observar que una característica importante que debe tener una persona con discapacidad para lograr ser emprendedora, es tener las ganas y deseos de salir adelante. En un estudio realizado por la Universidad de Cuenca en el año 2010 se identificó que la mayor causa para que una persona con discapacidad no logre llegar a emprender es la falta de aceptación de su discapacidad en su propia condición. Un gran conglomerado no reconoce que tiene discapacidad, cualquiera que sea el tipo o el grado de esta, y no es tan fácil que tome la decisión de emprender así sea hábil, es justamente ahí, en el ámbito de la toma de decisión, en el que las personas con discapacidad están luchando por tener una presencia más efectiva, y en donde también se debe apoyar y animar a que se arriesgue con los emprendimientos que tenga (Esquivel, 2010). 
Tabla 3. Barreras y/o limitaciones que afrontan las personas con discapacidad

\section{Sujeto 1}

- Dependencia física.

- Deficiencias y limitaciones en las actividades de la vida diaria.

- Pérdida de fuerza muscular.

- Falta de oportunidades laborales y educativas.

- Violación del derecho a la educación.

- Paradigmas mentales errados.

- Difícil acceso al transporte publico.

- Barreras arquitectónicas.

Fuente: Elaboración propia

La Tabla 3 muestra que las personas con discapacidad se ven enfrentadas a numerosas barreras que les impiden una verdadera inclusión social: inequidad, falta de oportunidad, exclusión social, escepticismo a la diversidad, barreras físicas, culturales y económicas, entre otras. Cada día una prueba más difícil de superar. Una ciudad que no fue pensada desde su arquitectura y transporte público para ellos, un sistema educativo que los excluye, un mercado laboral que no se ajusta a sus posibilidades, un Estado que no genera las políticas públicas necesarias para acompañarlos y una sociedad que les da la espalda.

Según Antonio Jiménez Lara (2007), Miguel Ángel Verdugo (2009), Ricardo Canal Bedia (2001), y Agustín Huete García (2010), los principales obstáculos para la vida independiente y la plena igualdad no radican en las diferencias de competencia o de capacidad de las personas, sino en la existencia o no de entornos familiares y sociales solidarios, dispuestos a prestar los apoyos necesarios para satisfacer las necesidades de todos los miembros de la comunidad. Existen modelos segregadores o sobreprotectores, que imposibilitan el goce de una vida plena, además las barreras físicas, psicológicas y sociales impiden la participación plena y activa de las personas con discapacidad en los diferentes contextos.

Si bien es cierto que existen serias dificultades en relación a las 
barreras físicas, son quizás las barreras actitudinales las que generan mayor exclusión, ya que existen diferentes escenarios en donde las personas con discapacidad encuentran dificultades que les impiden disfrutar plenamente de sus derechos y autonomía en igualdad de condiciones, pero tambien los obstáculos presentes en la actitud de las demás personas con respecto a su condición de discapacidad, los estereotipos, prejuicios y las prácticas nocivas y excluyentes.

\section{CONCLUSIONES}

De acuerdo a la información obtenida en la entrevista y al análisis derivado, se exponen las siguientes conclusiones:

Respecto al análisis de los factores y/o motivaciones que llevan a una persona con discapacidad a iniciar y proponerse ser emprendedores, se encontró que a nivel individual el mismo hecho de estar con vida es una oportunidad para superarse (aquí se relaciona el factor de la fe en Dios) y sacar adelante a sus familias, las cuales jugaron un papel importante brindándoles el apoyo necesario para encontrar el impulso para redirigir sus metas, esfuerzos y expectativas.

A nivel social surgen otras motivaciones concernientes a la lucha por los derechos de las personas que como ellos se encuentran en condición de discapacidad, rompiendo barreras y esquemas primordialmente de tipo mental y cultural en la sociedad, con miras a lograr una verdadera transformación, frente a la problemática de la discapacidad.

En cuanto a las características que debe tener una persona con discapacidad para lograr ser emprendedora, se destaca el inconformismo frente a su entorno, el sentirse en condiciones de exclusión social, y principalmente las ganas y deseos de salir adelante y responder ante su familia. Esto se constituye como el 
motor para vencer barreras mentales que nacen en el interior de la personas con discapacidad, tales como la falta de aceptación de su estado, por lo que, hallando su identidad en medio de su condición, facilita la toma de decisión de emprender.

En el análisis de las barreras y/o limitaciones, muestra que es la dependencia física, debido a la dificultad que representa no poder realizar sus actividades diarias igual que las personas sin condición de discapacidad y, por otra parte, la falta de oportunidades ofrecidas por el Estado y los diferentes actores de la sociedad, o el difícil acceso que hay, la discriminación. Esta situación crea la necesidad de que los gobiernos generen espacios y políticas que respondan, de manera más efectiva e inclusiva, a estas problemáticas que acompañan este tema permitiendo a las personas con discapacidad y sus familiares tener acceso a bienes, programas y servicios en igualdad de condiciones.

Se evidencia que la primera y más significativa barrera a derribar es la inequidad, lo cual, como lo plantean las Naciones Unidas, implica transformaciones en el entorno físico y cultural.

Finalmente, es de resaltar la labor emprendedora de la persona en estudio, que se convierte en ejemplo claro de cómo la cátedra del emprendimiento puede actuar como una herramienta de gran utilidad, en la generación de oportunidades y nuevas perspectivas para las personas en condición de discapacidad.

\section{REFERENCIAS BIBLIOGRÁFICAS}

Alonso, M. F. (2014). Discapacidad y actitudes emprendedoras: un estudio exploratorio (Tesis de pregrado). Universidad de León, León, España. Recuperado de: http://buleria.unileon. es/xmlui/bitstream/handle/10612/3730/71554466V_GADE_ julio14.pdf? sequence $=1$ 
Barrios, A. (2005). Autoconcepto y características familiares de niños resilientes con discapacidad: El caso de una población del Caribe colombiano. Investigación y desarrollo, 13(1), 108-127. Recuperado de file:///C:/Users/Trabajo/ Downloads/1065-2574-1-PB.pdf

Burns, N. \& Groven, S. (2004). Introducción a la investigación cualitativa. En: N. Burns, S. K. Grove, Investigación en Enfermería, 3aㅡ Ed. 384-430. Génova: Elsevier España S.A.

Canal, R. (2001). Referencia Conjunta y Autismo. En A. Riviere y J. Martos. (Eds.). Autismo: Comprensión y explicación actual. Madrid: APNA.

Cruz, M., Gómez, J., Pérez, M., Trevilla, C. \& Estrada, V. (2008). Las entidades no lucrativas dedicadas a la discapacidad como emprendedores sociales: Un análisis de su capacidad de generar empleo en Castilla y León. Revista Española del tercer sector, 8(1), 69-88. Recuperado de:hptt:/// Dialnet-LasEntidadesNoLucrativasDedicadasALaDiscapacidadCo-2649013\%20(1).pdf

Esquivel, P. (2010). Cultura emprendedora en las personas con discapacidad. (Tesis de Maestría). Universidad de Cuenca, Cuenca, Ecuador.

Erikson, E. H. (1956). The problem of ego identity. Journal of American Psychoanalysis, 4, 56-121.

Fernández-Berrocal,P.(2010). Inteligenciaemocionalparamédicos del siglo XXI. El Médico. 1112, 22-25. Recuperado de: http:// www.academia.edu/4695342/Fernandez-Berrocal_P._2010_. _Inteligencia_Emocional_para_medicos_del_siglo_XXI.

Fundación ASHOKA (2012). What is a Social Entrepreneur? Recuperado de: https://www.ashoka.org/social_entrepreneur Gómez, B. (2010). Resiliencia individual y familiar. Recuperado de http://www.avntf-evntf.com/imagenes/biblioteca/G\%C3\%B3 mez,\%20B.\%20Trab.\%203\%C2\%BA\%20BI\%2009-10.pdf

Gómez, J. (2010). Discapacidad en Colombia: Reto para la Inclusión en Capital Humano. Bogotá: Fundación Saldarriaga Concha. Recuperado de http://www.colombialider.org/ wp-content/uploads/2011/03/discapacidad-en-colombia-reto-para-la-inclusion-en-capital-humano.pdf

Hernández, R., Fernández, C. y Baptista, M. P. (2010). Metodología de la Investigación (5a Ed.). México: McGraw-Hill Educación. 
Huete A. \& Sola, A. (2010). Los jóvenes con discapacidad en España. Informe de situación 2010. Madrid: Cinca.

Instituto Nacional de Estadística España INE (2014). España en Cifras 2014. Disponible en: http://www.ine.es/prodyser/espa cifras/2014/files/assets/common/downloads/publication.pdf Jaramillo, L. (2008). Emprendimiento: Concepto básico en competencias. Revista Lumen, 7(1), 1-6. Recuperado de. https:// guayacan.uninorte.edu.co/divisiones/iese/lumen/ediciones/7/ articulos/emprendimiento.pdf

Jiménez Lara, A. (2007). Conceptos y tipologías de la discapacidad. Documentos y normativas de clasificación más relevantes. En Tratado sobre discapacidad R. de Lorenzo García y L.C. Pérez Bueno. Madrid: Thomson- Aranzadi.

Minuchin, S. \& Fishman, H. C. (1984). Técnicas de terapia familiar. Barcelona: Paidós.

ONU (2006). Convención sobre los Derechos de las Personas con Discapacidad. Asamblea General. 76ª sesión plenaria. New York: Organización de las Naciones Unidas.

O'Reilly, A. (2007). El derecho al trabajo decente de la personas con discapacidades (Segundo Informe). Ginebra: Organización Internacional del Trabajo. Recuperado de. http://www. ilo.org/wcmsp5/groups/public/@ dgreports/@ dcomm/@ publ/ documents/publication/wcms_091966.pdf

Organización Iberoamericana de Seguridad Social, OISS (2012). Medidas para la promoción del empleo de personas con discapacidad en Iberoamérica. OISS. Recuperado de: http://www.oiss.org/IMG/pdf/Oiss_Estudio_sobre_medidas_ promocion_de_empleo.pdf

Organización Mundial de la Salud, OMS (2001). Clasificación internacional del funcionamiento, de la discapacidad y de la salud. CIF. IMSERSO. Madrid: OMS. Recuperado de http:// www.imserso.es/InterPresent2/groups/imserso/documents/ binario/435cif.pdf

Organización Mundial de la Salud, OMS (2011). Informe mundial sobre la discapacidad. Malta: OMS-Banco Mundial. Recuperado de: http://www.who.int/disabilities/world_report/ 2011/accessible_es.pdf?ua=1

Poblete, Y. \& Jiménez, A. (2013). Propuesta de intervención 
psicosocial en autodeterminación, habilidades sociales y capacidad emprendedora: contribución desde la psicología a la integración de mujeres microempresarias con discapacidad intelectual. Psychologia, 7(2), 55-67.

Valdés, M. (2012). Representaciones sociales del trabajo de jóvenes en situación de discapacidad intelectual: Una aproximación dialógica. Revista de Psicología, 21(1), 34-56. Recuperado de http://www.elhuron.uchile.cl/index.php/RDP/ article/viewFile/19982/21135

Vanegas, Y. M. \& Giménez, J. (2011). Futuros profesores de matemáticas y ciudadanía. Actas de la XIII Conferencia Interamericana de Educación Matemática. Brasil: Programa de Posgrado en Educación Matemática y Tecnológica Universidad Federal de Pernambuco.

Verdugo, M. A., Córdoba, L., Restrepo, A., Cardona, J. \& Peña, P. (2009). Adults with intellectual disability and psychiatric disorders in Cali, Colombia. Psycho-social factors. Journal of Policy and Practice in Intellectual Disabilities, 6(3), 173-79.

Núñez Bravo, N., Sánchez Güette, L., Sotelo Berrio, V., Miranda Medina, C., \& Osorio Torres, C. (2017). Emprender después de una discapacidad. En E. Olivero Vega, K. Barrios Hernández, C. Acosta-Prado, N. Núñez Bravo, C. Miranda Medina, R. Prada Ospina, ... C. Osorio Torres, E. Olivero Vega, K. Barrios Hernández, \& J. C. Acosta-Prado (Comp.), Perspectivas Empresariales e Inclusivas del Emprendimiento (pp.117-144). Barranquilla: Ediciones Universidad Simón Bolívar. 


\section{EMPRENDIMIENTO SOCIAL. MECANISMO INTEGRADOR DE LAS EMPRESAS MIXTAS PETROLERAS \\ Social enterprise. Integrated mechanism of mixed oil companies \\ FÉLIX FRANCO SEGOVIA - RONALD PRIETO PULIDO ANNHERYS PAZ MARCANO - DONIPHANE MESLIER}

\section{RESUMEN}

El emprendimiento social busca generar un cambio en las comunidades, con acciones que creen valor al bienestar del colectivo, teniendo el emprendedor que explorar oportunidades que coadyuven a la calidad de vida. En razón de ello, el propósito de esta investigación es analizar el emprendimiento social como mecanismo integrador de las empresas mixtas petroleras al desarrollo de las comunidades venezolanas. Metodológicamente, fue un enfoque epistemológico positivista, de tipología descriptiva; diseño no experimental, transaccional y de campo. Población, (30) gerentes de las empresas mixtas petroleras en las áreas de recursos humanos y desarrollo social. La técnica de recolección de datos, la encuesta, e instrumento, un cuestionario de 15 ítems con escala de estimación múltiples, sometido a la validez de contenido por 10 expertos; la confiabilidad se comprobó con la fórmula de alpha cronbach resultando $r=0,99$ fiabilidad. Para la interpretación de los datos se utilizó la estadística descriptiva. A manera de conclusión, las empresas objeto de estudio ejercen el emprendimiento social para integrar las comunidades adyacentes, en iniciativas sociales para apoyar las acciones destinadas al bienestar del colectivo desde las políticas públicas y una cultura responsable, que garantiza el valor agregado al desarrollo, con ayuda de los grupos de interés.

Palabras clave: emprendimiento social, empresas mixtas petroleras, desarrollo de las comunidades. JEL: L2, L26, H, HO.

\section{ABSTRACT}

The social entrepreneurship seeks to generate a change in the communities, with actions that create value to the well-being of the collective, having the entrepreneur to explore opportunities that contribute to the quality of life. For this reason, the purpose of this research was to analyze social entrepreneurship as an integrating mechanism of mixed oil companies to the development of the Venezuelan communities. Methodologically, it was 
a positivist epistemological approach, descriptive typology; Non-experimental, transactional and field design. Population (30) managers of mixed oil companies in the areas of human resources and social development. The data collection technique of the survey and instrument a questionnaire of 15 items with multiple scale of estimation, subject to the validity of content by 10 experts; Reliability was checked using the alpha cronbach formula resulting in $r=0.99$ reliability. The descriptive statistics were used for the interpretation of the data. As a conclusion, the companies under study exercise social entrepreneurship to integrate the adjacent communities, social initiatives to support actions aimed at the welfare of the collective from public policies and a responsible culture, which guarantees added value to development, with the help of interest groups.

Key words: social entrepreneurship, joint ventures, development of communities.

\section{INTRODUCCIÓN}

En la actualidad, las transformaciones y cambios registrados en los diversos sectores de la economía venezolana han conducido al mercado empresarial al establecimiento de actividades dirigidas, no solo a satisfacer los requerimientos de sus clientes, y alcanzar los indicadores económicos financieros para permanecer estables en el mercado donde oferta sus bienes y servicios, sino también aportar ideas que despierten el interés del colectivo social, para explorar las oportunidades que favorezcan el desarrollo de las comunidades, por lo que sus acciones deben focalizarse en la aplicación de tendencias donde participen de manera voluntaria los grupos de interés, creando reciprocidad, a fin de conocer las necesidades del entorno y establecer respuestas a las realidades que se viven en ella.

Si bien es cierto en las últimas décadas los procesos empresariales han sido marcados por los avances de tendencias como la comunicación, tecnología, nuevos modelos de trabajo, haciendo de la globalización de los mercados un medio de participación e integración de la gente para garantizar la proyección en los espacios nacionales e internacionales, ha dejado rezagada la gestión social, como un medio que agrega valor al desarrollo 
de las comunidades. Es así como las empresas del sistema productivo venezolano, donde no se excluyen las mixtas petroleras, constantemente llevan a cabo actividades donde está asentada su actividad tanto administrativa como operativa, propia de su economía energética, para conocer las realidades del entorno y proponer iniciativas para solventar los problemas que pudiesen deteriorar la calidad de vida de las comunidades adyacentes.

Por esta razón, ha promovido la práctica de tendencias sociales, como un modo que coadyuve a la recuperación de la sostenibilidad comunitaria, es decir, no solo es generar bienes y servicios para convertirse en fuente de proyección económica en la construcción de una sociedad estable, sino al igual proponer desde su gestión integradora empresa-sociedad ideas que fomenten el emprendimiento social como mecanismo que estudie oportunidades para garantizar el bienestar de todos representando una alternativa que agrega valor al cambio social a favor del desarrollo de las comunidades.

Ante esta realidad, se puede hacer mención del trabajo desarrollado por Silberstein \& Galli (2016) acerca de cuál es el vínculo entre el emprendimiento social y el desarrollo sostenible, y cómo los emprendedores sociales contribuyen a la inclusión social y a la erradicación de la pobreza. En él se trataron aspectos en los cuales se explica que hoy hay diversos tipos de catástrofes: climáticas, económicas, sociales y ecológicas; representando los principales desafíos que tiene por delante un mundo con un crecimiento relevante de tecnologías de punta y capacidades de producción, pero débil en su ingeniería social.

Los resultados de la investigación pudieron discernir que en los últimos años el emprendimiento social se ha constituido en una 
de las áreas más innovadoras de reflexión y acción sobre las implicaciones sociales de la actividad económica, surgiendo un consenso creciente sobre la importancia del papel de los emprendedores sociales, donde no se trata solo de introducir valores éticos en la práctica empresarial, sino de situar la producción de objetivos sociales de justicia, solidaridad y sostenibilidad en el corazón mismo del emprendimiento.

Es de esta manera como se puede inferir que las empresas objeto de estudio, a razón de los aspectos expuestos, han redimensionado la gestión de sus actividades centradas en el alcance de valores económicos para mantener su participación en el mercado energético, para incorporar en su función las acciones sociales, siendo el emprendimiento social una oportunidad hacia el desarrollo del entorno. En líneas generales, las referidas empresas son responsables por la gestión u omisión de sus funciones en el sector productivo donde ejercen la exploración, producción y transformación de productos; por tanto, a pesar de que su objetivo principal es la productividad de bienes y servicios basada en capital natural, hoy día son gestores de una participación integral de su gente con las comunidades, trabajando con el objetivo de sustentar la calidad de vida de la gente.

Bajo esta concepción, las organizaciones mixtas petroleras deben establecer directrices, con el objeto de guiar sus acciones sociales de forma transparente y participativa con el talento de su gente e integración de las personas de las comunidades de su entorno, como estrategia para captar ideas que generen el emprendimiento social, facilitando el establecimiento de oportunidades que muestren respuestas a sus necesidades bajo una concepción corresponsable, despertando el interés hacia la calidad de vida sostenible del ser humano, desde la experiencia de ideas comunitarias acordes a su contexto, es decir, fomentar 
cambios sociales para activar la dinámica del desarrollo de las comunidades venezolanas. En razón de los aspectos planteados, se establece como objetivo analizar el emprendimiento social como mecanismo integrador de las empresas mixtas petroleras al desarrollo de las comunidades venezolanas.

\section{FUNDAMENTACIÓN TEÓRICA}

En el mundo empresarial los cambios y transformaciones, producto de la dinámica global, estimulan la generación de emprendimientos e innovaciones en sus estructuras, tratando de mantenerse competitivos en el mercado, en un entorno cada vez más complejo. Es por ello que Vásquez \& Dávila (2008) afirman que el emprendimiento ha sido estudiado desde la economía, la psicología, la sociología y la antropología. En un principio, la economía se encargó de estudiarlo buscando su relación con el desarrollo desde un punto de vista puramente económico. Posteriormente, la psicología, la sociología y la antropología desarrollaron aportes que se encargaron del estudio del fenómeno desde un punto de vista social.

Al interior de las escuelas de negocios este tema ha cobrado interés, desde la década de los ochenta, debido a la relación con la creación y dirección de empresas, entre otras razones. El emprendimiento involucra diferentes acepciones, como el emprendimiento social, sobre el cual existen relativamente pocos acuerdos.

Desde el trabajo seminal de Cantillón (1755) hasta el trabajo realizado por Shane \& Venkataraman (2000), se ha relacionado el emprendimiento con el descubrimiento de oportunidades rentables. Estos últimos autores toman la definición de oportunidad de Casson (1982) y declaran que "las oportunidades de 
emprendimiento son aquellas situaciones en las que nuevos bienes, servicios, materias primas y métodos de organización, pueden ser vendidos e introducidos a un precio mayor que sus costos de producción" (Shane \& Venkataraman, 2000, p. 220).

Por su parte, el emprendimiento social es un campo que recientemente ha empezado a llamar poderosamente la atención del mundo académico. Leadbeater (1997), uno de los autores más citados por su trabajo seminal "The rise of social entrepreneurship", enfatizó en su obra la creciente necesidad de desarrollar, de manera innovadora, nuevas formas de capital social que fomenten la erradicación de la pobreza y la solución de los problemas sociales.

Para Roberts \& Woods (2005, p.49) "el emprendimiento social es la construcción, evaluación y persecución de oportunidades para el cambio social transformativo llevado a cabo por individuos visionarios, apasionadamente dedicados". Por su parte, Austin \& Chu (2006, p.2), definen emprendimiento social como "una actividad innovadora, de creación de valor social, que ocurre al interior y a través de los sectores sin ánimo de lucro, de negocios y gubernamental".

\subsection{Consideraciones teóricas sobre emprendimiento social}

Al hablar de emprendimiento social es necesario revisar la construcción realizada por Martin \& Osberg (2007). Para ellos, el emprendimiento social sigue tres componentes:

(1) la identificación de un equilibrio estable pero intrínsecamente injusto que causa exclusión, marginalización, o sufrimiento a un segmento de la humanidad que carece de medios financieros o influencia política para alcanzar un beneficio transformador por su cuenta; (2) la identificación de una oportunidad en este equilibrio injusto, desarrollando una proposición de valor social y llevando a utilizar inspiración, 
creatividad, acción directa, coraje y fortaleza, desafiando de ese modo la hegemonía del estado estable; y (3) la creación de un equilibrio estable y nuevo que libera el potencial coartado o alivia el sufrimiento del grupo objetivo, y a través de la imitación y la creación de un ecosistema estable alrededor del nuevo equilibrio, asegura un mejor futuro para el grupo objetivo y la sociedad como un todo. (Martin \& Osberg, 2007, p.35)

Para Arce (2012), el emprendimiento son los motores que impulsan la existencia de expectativas y la necesidad o huida hacia adelante, en momentos de confusión económica como la actual, donde los emprendedores sociales tienen una oportunidad para convertirse en una verdadera opción en el país, crear conciencia y generar empleos en varios ámbitos. Es por ello, que el emprendimiento ha cobrado interés spara las escuelas de negocios desde la década de los ochenta, debido a la relación con la creación y dirección de empresas.

De acuerdo a los criterios de Reis \& Clohesy (2011, p.116) "El emprendimiento social es influenciado por el deseo del cambio social, de sostenibilidad de la organización y los servicios sociales que presta.' Por su parte, el emprendimiento social (Choi \& Majumdar, 2014) reside en adaptar las estrategias empresariales con el objetivo de contribuir al bienestar social. De esta forma, se entiende el emprendimiento social como la creación de nuevos productos, servicios y conductas empresariales que, además de satisfacer las necesidades que demanda la sociedad, supone una transformación social sostenible (Dacin, Dacin \& Matear, 2010).

Según Gatica, Larenas, Koljatic y Miranda (2012), el emprendimiento social es el proceso y la oportunidad de crear valor para la sociedad, generando un cambio o impacto en la comunidad, 
ya sea mediante la creación de productos y servicios, o mediante nuevos modelos de negocios o nuevas organizaciones. Estas actividades son impulsadas a partir de las acciones de un individuo, de un colectivo o de diversas organizaciones que se desenvuelven en un contexto determinado. En líneas generales, el emprendimiento social comprende las oportunidades que agregan valor al desarrollo de las comunidades a través de iniciativas que ayudan a propender una mejor calidad de vida, por el bienestar común de todos.

Melian \& Campos (2010) esbozan que el emprendedurismo social tiene tres objetivos: económico, social y sociopolítico. El primero, acerca del objetivo económico, asegura que esta actividad sea lo suficientemente sólida, proporcione retornos de inversión que le permitan ser viable financieramente; el segundo, el objetivo social va a ser la inclusión laboral de sectores con alto riesgo de exclusión (trabajo para privados de libertad) o la prestación de servicios a un colectivo de riesgo de exclusión, que les permita financiar sus propios negocios (los micropréstamos con bajos intereses a sectores pobres de Muhammad Yunus); $y$, finalmente, el objetivo socio-político, que asegura que se cumplan estos dos objetivos mediante un proceso que contenga la inclusión social, como la participación de todos los agentes en la empresa.

Elkingston \& Hartigan (2008), manifiesta que la actividad emprendedora debe ser determinada con un propósito social arraigado; los emprendedores sociales y medioambientales trabajan con empresas, desde las puras benéficas hasta las puramente comerciales. Dentro de este marco, se explica que el emprendimiento social en los últimos años se ha convertido en una tendencia en el entorno de las organizaciones, representando una estrategia de apoyo para superar las demandas sociales y económicas de los grupos más vulnerables, razón por 
la que el emprendimiento, puede definirse como una actividad impulsada a partir de las acciones de un individuo, colectivo o diversas organizaciones que se desenvuelven en un contexto determinado hacia la obtención de un logro y aportar al bienestar del colectivo; asimismo al desarrollo de las comunidades.

\subsection{Dimensiones del emprendimiento social}

En este aparte se explican las dimensiones del emprendimiento social, siendo un punto de partida para establecer los criterios que sustentan el compromiso que agrega valor al desarrollo de las comunidades, y una práctica que responde a las necesidades de la sociedad, o bien los vacíos del mercado, con propuestas innovadoras y creativas para generar financiamientos sostenibles, a fin de solventar los problemas acuciantes de la sociedad, con la cooperación entre los sectores públicos, privados y de organizaciones sin fines de lucro.

Las dimensiones del emprendimiento social suelen ser diversas; a efectos de esta investigación se toman en cuenta: iniciativa social, capital social, políticas públicas, cultura organizacional, desarrollo social. En atención a ello, Praszkier \& Nowax (2012) manifiestan que estas dimensiones son una alternativa para lograr cambios en las condiciones de vida, aportando significativamente beneficios colectivos. Estas permiten la búsqueda de modos innovadores para solucionar las necesidades y problemas que entienden al emprendedor como un agente de cambio social, teniendo en cuenta que entre los elementos de la dimensión del emprendimiento social se muestran los siguientes:

- Iniciativa social

Según De la Cuesta \& Valor (2003) en las iniciativas sociales se encuentran ejes temáticos que demuestran el compromiso 
$\propto$

\section{- Capital social}

Jaramillo (2003) expone que son un conjunto de normas, confianzas, valores, actitudes y redes entre personas e instituciones en una sociedad, que definen el grado de asociatividad entre los diferentes actores sociales, facilitando las acciones colectivas y de cooperación; señala el autor que el capital social tiene varias dimensiones, entre ellas una individual, las cuales contemplan el grado de integración a su entorno a partir de las relaciones con las personas, familias, empresas; una dimensión sectorial, la acción de personas, familias o empresas en su sector o entorno ampliado, su interrelación y su relación con los poderes públicos, relacionada con las redes comunitarias, gremios, asociaciones, entre otros. Finalmente, la dimensión colectiva o nacional tiene que ver con la sociedad en su conjunto.

Por otro lado, Klisksberg (2003) manifiesta que el capital social es muestra de la riqueza y fortaleza del tejido social de una sociedad que permite tener beneficios para las personas, y la sociedad en su conjunto; en tal caso puede considerarse como una red, cuyos nodos son los individuos instituciones, y cuya utilización genera rendimiento. Desde los preceptos planteados por Novacousky (2003), el capital social puede dividirse en individual 
(acceso a la información y activos, voz y participación), comunitarios (mejora del emprendimiento colectivo, acceso de bienes y servicios colectivos) y societal (incremento de emprendimientos, estimula la creatividad y mitiga riesgos de fractura social).

En virtud de los aspectos planteados, los autores coinciden que el capital social constituye una de las dimensiones contextualizadas en la gestión de las empresas, tanto en su interior como de manera externa, mediante normas, valores, actitudes, redes entre personas e instituciones asentadas en la sociedad, siendo el sustento que engrana la asociatividad entre los grupos de interés bajo la práctica de acciones colectivas.

- Políticas públicas

En tal sentido, genera beneficios a las sociedades enmarcándose legalmente en la producción de ventajas. Subirats, Knoepfel, Larrue \& Varone (2008) manifiestan que debe ser vista como un conjunto de acciones tomadas por varios actores, tanto públicos como privados, hacia la solución de problemas claramente identificados.

Alcántara (2005) enfatiza que las políticas públicas se consideran como determinados flujos del régimen político hacia la sociedad, siendo concebidas como productos del sistema político. Por ello se infiere que no deben entenderse como partes exógenas, sino medios constitutivos de acciones, o de los resultados de las actuaciones de los elementos formalmente institucionalizados del sistema político adscrito al ámbito del Estado.

Pallares \& Casellas (2006) destaca que las políticas públicas son el conjunto de actividades de las instituciones de gobierno, actuando directamente o a través de agentes, dirigidas a tener 
una influencia determinada sobre la vida de los ciudadanos. Considerando las inferencias de los autores citados, las políticas públicas vienen a ser vínculos de los instrumentos que se emplean en la gestión de naturaleza gubernamental, donde se desprende la elaboración de ellas. Estos instrumentos son: las normas jurídicas, los servicios, los recursos financieros y la persuasión.

\section{- Cultura organizacional}

Siliceo, Casares y Gonzáles (2006) Se refieren a la cultura empresarial como la verdadera fuerza vital de una organización para el logro de sus objetivos económicos, sociales, entre otros. Comprende el reflejo emitido como médula empresarial, estando presente en la funcionalidad de las actividades llevadas a cabo por los colaboradores, acompañado de las estrategias para lograr los objetivos, donde su actuar son las huellas de identidad responsable, siendo el corazón que otorga vida propia. Además, está acompañada de los propósitos estratégicos de forma transparente, siendo el factor dinamizador del desenvolvimiento en la sociedad, por tanto, las raíces construyen su personalidad y el lenguaje particular.

Señalan Werther \& Davis (2009) que la gente asume con facilidad su cultura, ya que le generá seguridad y una posición en cualquier entorno donde se encuentre; de esta forma se le atribuye como la conducta convencional de una sociedad influyente en sus acciones. En este sentido, fija comportamientos éticos, ejerciendo identidad e interacción entre los colaboradores, siendo ejemplo de transformación que otorga competitividad.

En líneas generales, los autores aseveran que la cultura organizacional, es el eje que dinamiza la razón de ella, basada en los 
valores, principios y creencias que la distinguen, entre otras, de su entorno, creando así el sustento de la investigación (Silíceo, et al, 2006) al destacar que es la fuerza vital de una organización, la cual aporta el logro de los objetivos económicos, sociales, culturales, espirituales, para una gestión exitosa, ejerciendo identidad e interacción entre los colaboradores.

\section{- Desarrollo social}

Para Mokate \& Saavedra (2008) el desarrollo social es un proceso dinámico, multidimensional, que conduce a mejoras sostenibles en el bienestar de los individuos, familias, comunidades y sociedades, en un contexto de justicia y equidad. Agregan los autores, que promueve la reducción de la desigualdad, reduce la pobreza, fortale tanto el Estado democrático como una ciudadanía plena, incluyente y responsable.

Sen (2000) nos dice que el desarrollo social obliga a los gerentes sociales a repensar lo que se va a entender como desarrollo y como logros sociales, que serán priorizados, con base en los desafíos particulares de cada sociedad y la visión con respecto al tipo de sociedad que se busca promover; por consiguiente, son acciones que generan valor para la sociedad, conduciéndolas hacia un mejor convivir en el entorno.

Las dimensiones del emprendimiento social facilitan la incorporación de elementos que sirven de sustento para la construcción de comunidades, apoyado en iniciativas que ayudan al desarrollo local mediante políticas públicas, capital social, desarrollo social y cultura responsable. En líneas generales, el emprendimiento social, se visualiza como las oportunidades para conocer las necesidades y dar respuesta a la sociedad mediante ideas creativas e innovadoras. 


\section{MÉTODO}

El presente capítulo se esboza desde el quehacer del método científico, con el desarrollo de actividades investigativas para indagar el tema de estudio, estableciendo criterios analítico-reflexivos para proporcionar respuesta al objetivo planteado. Sobre la base de esta investigación se orienta al enfoque positivista, también denominado como pragmático, donde la interpretación y análisis de la información compilada de los encuestados se hizo bajo el lenguaje numérico, empleando la estadística descriptiva. En referencia al método, se utilizó el deductivo, Guanipa (2010) menciona que el enfoque positivista permite la observación de los hechos sociales con una visión objetiva de la labor científica, determinada por una metodología basada en los números, derivada de la recolección de datos mediante la aplicación de cuestionarios tanto válidos como confiables.

En cuanto al tipo de investigación se suscribe como descriptiva, recopilando hechos característicos de la variable en escenarios (Hurtado, 2008). El estudio descriptivo sugiere exponer detalladamente sus características, de modo tal que los resultados se puedan obtener partiendo, del fenómeno estudiado y el propósito perseguido por el investigador. Del mismo modo para Hernández, Fernández \& Baptista (2014) la investigación descriptiva busca especificar propiedades, características y rasgos importantes de cualquier fenómeno analizado, describiendo tendencias de un grupo o población, partiendo de perfiles de personas, grupos, comunidades, procesos u objetos, o cualquier otro fenómeno sometido a análisis.

En relación al diseño, el estudio se asume como no experimental, transaccional de campo, donde no se manipula la información si no se alcanza de fuentes reales en un tiempo pautado por los investigadores. Para Hernández, et al (2014), el diseño no 
experimental no manipula deliberadamente variables, es decir, esta no hace intencionalmente las variables independientes, sino que está destinada a observar los fenómenos tal y como se dan en su contexto natural, para después interpretarlo. Por consiguiente, para Tamayo \& Tamayo (2010), un diseño de campo, los datos se recogen directamente de la realidad, por lo cual se les denomina primarios.

Para el desarrollo del estudio, la población fue de 30 sujetos de la gerencia de recursos humanos y desarrollo social de las empresas mixtas petroleras en Venezuela, por ser los encargados de atender las necesidades de la gestión social, producto de sus características finitas y accesibles. No se recurrió a la aplicación de cálculo muestral; se estudió a través de los criterios de censo poblacional (Hernández, et al., 2014). La población es el conjunto de todos los casos que concuerdan con determinadas especificaciones, partiendo de características de contenido, de lugar y el tiempo. Refiere Méndez (2006) que un censo estudia todos los elementos involucrados en la población, siendo aconsejable aplicarla cuando esta es finita, asimismo requiere información inmediata sobre el estudio.

Con respecto a los datos que sirvieron de insumo sobre la variable emprendimiento social, fue la técnica de observación por encuesta, definida por Méndez (2006) como un instrumento de observación formado por una serie de preguntas formuladas, cuyas respuestas son anotadas por el encuestador; esta técnica permite el conocimiento de las motivaciones, actitudes y opiniones de los individuos en relación con su objeto de investigación.

En lo perteneciente al registro de la información, se formalizó el cuestionario estructurado por 15 ítems con alternativas de 
respuestas múltiples, entre ellas: siempre, casi siempre, a veces, casi nunca y nunca (Hernández, Fernández \& Baptista, 2014). Los instrumentos de medición son recursos que utiliza el investigador para registrar información o datos sobre las variables que tiene en mente, teniendo como función de medición establecer una correspondencia entre el mundo real con el mundo conceptual, siendo el cuestionario el instrumento más utilizado para recolectar datos, un conjunto de preguntas respecto de una o más variables a medir.

Vale acotar que el referido instrumento de recolección de datos acerca de la variable emprendimiento fue previamente validado por 10 expertos, y calculada la confiabilidad por la fórmula de alfa cronbach, reflejando un resultado de 0,99 de fiabilidad Hernández, et al., (2014) definen la validez como el grado donde un instrumento mide la variable que busca mientras la confiabilidad de un instrumento es el grado en que un instrumento produce resultados consistentes y coherentes; es decir, su aplicación repetida al mismo individuo u objeto produce resultados iguales, oscilando entre 0 y 1 . Infieren los autores que un instrumento de medición puede ser confiable, pero no válido, por tanto debe demostrar que este cumple con ambos requisitos.

En relación a la interpretación de los resultados de la información emitida por la población encuestada, se obtuvo de la aplicación del programa SPSS, donde se cuantificó, organizó, registró y tabularon los datos, permitiendo, posteriormente, analizar e interpretar los resultados emitidos por los sujetos encuestados, empleando a tal efecto técnicas estadísticas, a fin de medir el comportamiento de la dimensión e indicadores que integran la variable objeto de estudio. Para Méndez (2006), las técnicas estadísticas se utilizan para analizar e interpretar la información recopilada del instrumento, siendo la más manejada la distri- 
bución de frecuencias, como medidas de tendencia central, la media aritmética, geométrica, medina y moda; mientras emplea las medidas de dispersión, la varianza, desviación estándar, coeficiente de variación, entre otros.

En virtud de lo expuesto se efectuó un proceso de codificación, el cual consiste en asignar un indicador numérico a las respuestas señaladas por los encuestados en los ítems del cuestionario suministrado para medir la variable, teniendo como propósito convertir los atributivos cualitativos en cuantitativos, y, con ello, registrar e interpretar los datos extraídos de la aplicación a la población objeto. Sobre este caso, la expresión numérica de las respuestas múltiples fue de: siempre 5 , casi siempre 4 , a veces 3 , casi nunca 2 , nunca 1 , para ambos instrumentos.

La codificación para Hernández, et al., (2014) significa asignar a los datos un valor numérico o símbolo que los represente, siendo necesario para asignarlos cuantitativamente. Al igual, Sabino (2008) establece que la codificación es un procedimiento que tiene por objeto agrupar numéricamente los datos que se expresen en forma verbal, para poder operar con ellos como si se tratara simplemente de datos cuantitativos.

Con respecto a la tabulación, Méndez (2006) señala que es el ordenamiento de la información donde, al ser procesada y cuantificada por ítems, asimismo agrupada por variables, permitió la presentación en tablas. Por su parte, Sabino (2008) dice que la tabulación significa hacer tablas, listados de datos que los muestren agrupados y contabilizados, siendo preciso contar cada una de las respuestas que aparecen, distribuyéndolas en categorías o códigos previamente definidos. En cuanto a la organización de los atributos de las opciones de respuestas de los instrumentos de la presente investigación, se vació en tablas, 
con la intención de registrar los datos codificados del cuestionario aplicado a la población, pudiendo determinar el comportamiento de las variables emprendimiento social y responsabilidad social en términos cuantitativos.

Cabe destacar que luego de codificar y tabular los datos registrados en tablas, se aplicó la estadística inferencial, la cual utilizó técnicas especiales para conocer los elementos de un conjunto, a partir de dos dados de un subconjunto; en este sentido, Tamayo \& Tamayo (2010) menciona que el tratamiento estadístico permite llegar a las conclusiones en relación a las hipótesis propuestas.

Cuadro 1. Baremo de interpretación de datos promedios

\begin{tabular}{|c|c|}
\hline RANGOS & CATEGORÍAS \\
\hline $1,00 \geq 1,80$ & Muy baja \\
\hline $1,81 \geq 2,60$ & Baja \\
\hline $2,61 \geq 3,40$ & Moderada \\
\hline $3,41 \geq 4,20$ & Alta \\
\hline $4,21 \geq 5,00$ & Muy alta \\
\hline
\end{tabular}

Fuente: Elaboración propia

\section{RESULTADOS, DISCUSIÓN Y CONCLUSIONES}

En cuanto al objetivo conducente a analizar el emprendimiento social como mecanismo integrador de las empresas mixtas petroleras al desarrollo de las comunidades venezolanas, se tiene que al emplear la técnica estadística análisis de la varianza (ANOVA), se precisa la significancia obtenida por los indicadores de la dimensión en este particular, dimensiones de emprendimiento social, en las cuales se obtuvo un nivel de significancia de 0,000; siendo este valor menor que 0,05 $(0,000<0,05$ nivel de significancia referencial). Se concluye que existen diferencias altamente significativas entre los indicadores comparados, por lo que todos 
no tienen el mismo grado de presencia en la referida dimensión, tal como se muestra en la Tabla 1, donde se ilustran los datos:

Tabla 1. Nivel de significancia.

Dimensiones del emprendimiento social.

Anova de un factor. Puntaje

\begin{tabular}{|c|c|c|c|c|c|}
\hline & $\begin{array}{c}\text { SUMA DE } \\
\text { CUADRADOS }\end{array}$ & GL & MEDIA CUADRÁTICA & F & SIG. \\
\hline Entre grupos & 142.086 & 4 & 35.521 & 83.932 & .000 \\
\hline Dentro de grupos & 61.367 & 145 & .423 & & \\
\hline Total & 203.453 & 149 & & & \\
\hline
\end{tabular}

Fuente: Elaboración propia

La comparación de la prueba de múltiples rangos Post Hoc de Tukey, revela las diferencias entre los diversos indicadores que componen la medición de los datos referentes a la dimensión Dimensiones del emprendimiento social, de la variable Emprendimiento social; al mismo tiempo se destaca la homocedasticidad de las varianzas entre los indicadores, medidos en su comportamiento estadístico (Ver Tabla 2).

Tabla 2. Dimensiones del emprendimiento social. Anova de un factor. Subconjuntos homogéneos. Puntaje

\begin{tabular}{|c|c|c|c|c|}
\multicolumn{2}{c}{ HSD Tukeya } \\
\hline \multirow{2}{*}{ FACTOR } & \multirow{N}{*}{$\mathbf{N}$} & \multicolumn{2}{c|}{ SUBCONJUNTO PARA ALFA = $\mathbf{0 . 0 5}$} \\
\cline { 3 - 5 } & & $\mathbf{1}$ & $\mathbf{2}$ & $\mathbf{3}$ \\
\hline Iniciativa social & 30 & 1.2778 & & \\
\hline Capital social & 30 & & 2.7778 & \\
\hline Políticas públicas & 30 & & 2.9333 & \\
\hline Desarrollo social & 30 & & & 3.7333 \\
\hline Cultura organizacional & 30 & & & 4.0889 \\
\hline Sig. & & 1.000 & .886 & .219 \\
\hline
\end{tabular}

Se visualizan las medias para los grupos en los subconjuntos homogéneos. a. Utiliza el tamaño de la muestra de la media armónica $=30.000$. 
En la Tabla 2 se exponen los resultados sobre los datos de la comparación establecida, donde la prueba de múltiples rangos de Tukey ubicó tres subconjuntos, basados en la similitud y diferencias de comportamiento entre sus medias, correspondiendo el primero de ellos al indicador Iniciativa social, donde este obtuvo la calificación más baja con una media de 1,27 ptos; seguido de los indicadores Capital social, cuya media es 2,77 ptos; Políticas públicas, media 2,93 ptos; Desarrollo social con la media 3,73 ptos; por último, con la media más alta el indicador Cultura organizacional, de media 4.08 ptos.

En los resultados que se muestran en la ilustración de la Tabla 2 , se analizan los datos denotando una diferencia significativa con el indicador Cultura organizacional, donde las respuestas emitidas por los encuestados dieron origen al posicionamiento de los indicadores en la referida Tabla, el cual, a través del tratamiento estadístico, revela el orden de importancia que tiene para la opinión emitida desde la percepción de la población encuestada, indicativo de que en las Dimensiones del emprendimiento social, la Cultura organizacional es el primer indicador considerado como parte importante del emprendimiento social, seguido del Desarrollo social, las Políticas públicas, el Capital social e Iniciativa social.

Las Dimensiones del emprendimiento social, buscan las iniciativas sin fines de lucro, por consiguiente, rescata personas en riesgo social y genera capital social, inclusión social y emancipación; asimismo ejerce la capacidad de contribuir al logro de las metas organizacionales en las empresas objeto de estudio, asumiendo la perspectiva de ajuste estratégico, mediante el desarrollo de acciones valiosas enfocadas en el mejoramiento continuo. 
En lo atinente, al indicador Iniciativa social se situó de acuerdo al baremo de interpretación de datos, entre los promedios de los indicadores, muy baja en el intervalo $(0,99<1,79)$, los indicadores Capital social y Políticas públicas se ubicaron en la categoría de análisis, moderada entre el intervalo establecido $(2.60<3,39)$, mientras Desarrollo social y Cultura organizacional se situaron en la categoría alta con el intervalo $(3,40<4,19)$.

Estos resultados revelan contradicciones con los criterios manifestados por los sujetos informantes, quienes conciben que las dimensiones del emprendimiento social se encuentran en la categoría de análisis moderada; revelan que discrepan parcialmente con el postulado planteado por Praszkier \& Nowax (2012), quienes la definen como la búsqueda de modos innovadores para solucionar las necesidades y problemas que entienden al emprendedor como un agente de cambio social, siendo una alternativa para lograr cambios en las condiciones de vida, aportando significativamente beneficios colectivos.

Los resultados acontecidos permitieron establecer semejanzas con la investigación realizada por Silberstein \& Galli (2016), quienes desarrollaron un artículo acerca del vínculo entre el emprendimiento social y el desarrollo sostenible, y cómo los emprendedores sociales contribuyen a la inclusión social y a la erradicación de la pobreza. En él se trataron aspectos en los cuales se explica que los diversos tipos de catástrofes, climáticas, económicas, sociales y ecológicas representan los principales desafíos que tiene por delante el mundo con un crecimiento relevante de tecnologías de punta, y capacidades de producción, pero débil en su ingeniería social.

Seguidamente, en cuanto al indicador Iniciativa social, los resultados muestran una media muy baja, lo cual difiere con los 
criterios de Seller (2012), quien expresa que la iniciativa social es el fenómeno más importante en la configuración de la sociedad, del bienestar colectivo, ya que apoya la gestión e implementación de las políticas sociales, en la disposición relacional de los sistemas sociales, en los nuevos escenarios de participación ciudadana, en la descentralización de la gestión social; en definitiva, en la vertebración del tejido social.

El resultado para el indicador Capital social maneja una media moderada, medianamente concordante con lo planteado por Klisksberg (2003), para que el capital social es muestra de la riqueza y fortaleza del tejido social de una sociedad que permite tener beneficios para las personas y la sociedad en su conjunto. En tal caso, puede considerarse como una red cuyos nodos son los individuos e instituciones que generan rendimiento; es decir, destaca el capital social como sustento a beneficio de la sociedad en su conjunto.

Para el indicador Políticas públicas, maneja una media moderada que es medianamente concordante con lo planteado por Pallares \& Casellas (2006), quien destaca que ellas son el conjunto de actividades de las instituciones de gobierno, actuando directamente o a través de agentes, dirigidas a tener una influencia determinada sobre la vida de los ciudadanos, representando un conjunto de decisiones y vínculos de los instrumentos que se emplean en la gestión de naturaleza gubernamental, donde se desprende la elaboración de ellas como las normas jurídicas, los servicios, los recursos financieros y la persuasión.

Por otro lado, el indicador Cultura organizacional presenta una media alta, asimismo concuerda con lo planteado por Silíceo et al., (2006) al destacar que es la fuerza vital de una organización, que aporta al logro de los objetivos económicos, sociales, culturales, espirituales para una gestión exitosa, ejerciendo identidad e interacción entre los colaboradores. 
Los resultados para el indicador Desarrollo social manejan una media alta, coincidiendo con los criterios planteados por Mokate \& Saavedra (2008), que se trata de un proceso dinámico, multidimensional, conducente a mejoras sostenibles en el bienestar de la sociedad, en un contexto de justicia y equidad, lo que promueve la reducción de la desigualdad y la pobreza, el fortalecimiento del Estado democrático de una ciudadanía plena, incluyente y responsable.

A manera de conclusión, según los hallazgos alcanzados de la percepción de los encuestados acerca de la dimensión Emprendimiento social, se presenta un gráfico de polígono de frecuencias, que, para el caso concreto del estudio, únicamente expresa las medidas de tendencia central; medias obtenidas, las cuales esbozan el comportamiento de las unidades de análisis por cada uno de los indicadores que integran la medición estadística de la dimensión analizada. En este, se observan los promedios en orden descendente de acuerdo a la preferencia de los sujetos consultados en las empresas mixtas del sector petrolero en Venezuela, específicamente las ubicadas en la zona occidental, como es el Estado Zulia (ver Gráfico 1).

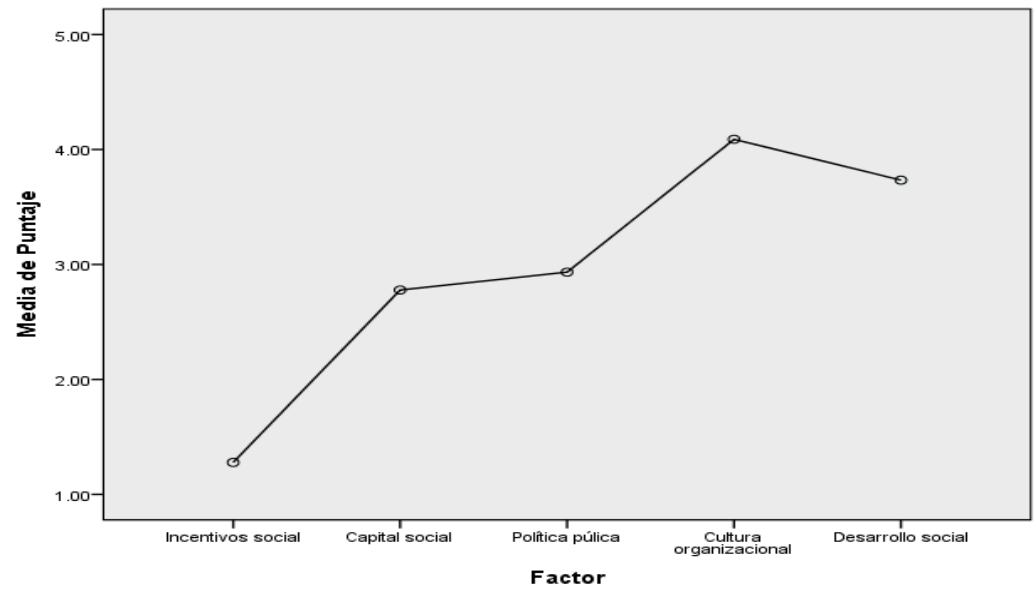

Gráfico 1. Medias para la Dimensión: Dimensiones del emprendimiento social Fuente: Elaboración propia 
Se concluye que el Emprendimiento social es una fuente que dinamiza el desarrollo de las comunidades mediante el aporte de la gestión de las empresas mixtas petroleras venezolanas, siendo agentes que agregan valor a la economía local, a través de iniciativas sociales que contribuyen al bienestar del colectivo, con la práctica de acciones para fortalecer el bienestar del tejido social, con apoyo de diversos grupos de interés e involucrando a los entes públicos, para trabajar a favor de la satisfacción de la sociedad, y al mismo tiempo, provee empleo a todos los sectores de la comunidad.

De tal manera que, el Emprendimiento social comprende una opción que aporta a la solución de los problema de la sociedad, pudiendo balancear la inclusión de los sectores con riesgo de exclusión y generar la viabilidad económica para el desarrollo de las comunidades. Por tanto, de acuerdo a la apreciación de los encuestados las iniciativas sociales se encuentran poco presentes en la gestión de las empresas objeto de estudio, donde se promueven incipientemente ideas que den respuestas a las necesidades de la comunidad; sin embargo, establecen en su presupuesto partidas para atender las inquietudes procedentes del entorno donde se desenvuelven, a fin de aportar en la elección de alternativas que dignifiquen el bienestar comunitario.

De tal manera que se muestran discrepancias en su opinión, ya que plantearon apoyarse en un capital social, con la participación de actores sociales para emprender programas de interés comunitario, el cual facilite fortalecer el bienestar del colectivo mediante actividades asociadas a las políticas públicas de la nación, con una toma decisiones donde concurran entes del gobierno local, con el objeto de desarrollar las acciones comunitarias en conjunto. Además, su actuación coadyuva a la difusión de valores para mostrar su identidad en el entorno, además de propiciar espacios de diálogo para solventar sus necesidades acuciantes. 


\section{REFERENCIAS BIBLIOGRÁFICAS}

Alcántara, A. (2005). Entre Prometeo y Sísifo. Ciencia, tecnología y universidad en México y Argentina. Barcelona: Editorial Pomare.

Arce, P. (2012). ¿Cuáles y cuántas empresas del Sector Financiero en Costa Rica realizan emprendedurismo Social o tienen expectativas de desarrollar emprendimientos sociales y qué esfuerzos han venido realizando para alcanzarlas?. Costa Rica: Universidad Latinoamericana de la Ciencia y Tecnología Facultad de Ciencias Empresariales Maestría en Administración de Empresas Énfasis en Gerencias de Operaciones.

Austin, J. \& Chu, M. (2006). Businessand Low-Income Sectors: Findinga new weapon to attack poverty. Harvard Review of Latin America, 6(1), 3-5.

Casson, M. (1982). The Entrepreneur. An Economic Theory. Oxford: Martin Robertson.

Cantillón, R. (1755). Ensayo sobre la naturaleza del comercio en general. México: Fondo de Cultura Económica.

Corredor, D. (2010). Hacia un modelo de emprendimiento universitario. Apuntes del CENES, 27(43), 275-292.

Choi, N. \& Majumdar, S. (2014). Social entrepreneurship as an essentially contested concept: Opening a new avenue for systematic future research. Journal of Business Venturing, 29(3), 363-376.

Dacin, P. A., Dacin, M. T. \& Matear, M. (2010). Social entrepreneurship: Why we don't need a new theory and how we move forward from here. The Academy of Management Perspectives, 24(3), 37-57.

De la Cuesta, M. \& Valor, C. (2003). Responsabilidad social de la empresa, concepto, medición y desarrollo en España. Madrid: Boletín Económico del ICE

Elkington, J. \& Hartigan, P. (2008). The Power of Unreasonable People: How Social Entrepreneurs Create Markets that Change the World. Boston: Harvard Business Press.

Gatica, S., Larenas, J. P., Koljatic, M. y Miranda, P. (2012). La innovación social en Chile y el rol del Estado en su desarrollo. Santiago: Escuela de Administración, Pontificia Universidad Católica de Chile.

Guanipa, M. (2010). Reflexiones básicas sobre investigación. 
Maracaibo. Primera edición. Venezuela: Editorial de la Universidad Rafael Belloso Chacín.

Guédez, V. (2010). Responsabilidad Social Empresarial. Visiones Complementarias hacia un modelo social. Venezuela: Edición especial 60 años de Venancham.

Hernández, R., Fernández, C. \& Baptista., M. (2014). Metodología de la Investigación. Sexta Edición. México: Editorial McGraw-Hill Interamericana Editores, S.A.

Hurtado, J. (2008). El proyecto de Investigación. Metodología de la investigación Holística. Quinta edición ampliada. Venezuela: Ediciones Quirón. Sypal, Servicios y proyecciones para América Latina.

Jaramillo, F. (2003). El desafío para construir capital social en América Latina. Caracas: Norma Color Caracas, Venezuela.

Kliksberg, B. (2003). Hacia una nueva visión de desarrollo de la política social en América Latina. Seminario Internacional de Capital social, ética y desarrollo. Los desafíos de la gobernabilidad democrática. Publicación cortesía de la Embajada del Reino de Noruega en Venezuela y STATOIL. Caracas, Venezuela: Universidad Metropolitana.

Leadbeater, C. (1997). The rise of the social entrepreneur, London: Nesta.

Leal, A. O., Pardo, M. L. M., Ruiz, J. O. \& Morales, F. E. (2016). Factores explicativos de competitividad empresarial. Capítulo 8, 115-130.

Martin, R. \& Osberg, S. (2007). Social Entrepreneurship: The case for definition. Stanford social innovationreview, 5(1), 28-39.

Melián Navarro, A. \& Campos Climent, V. (2010). Emprendedurismo y economía social como mecanismos de inserción socio laboral en tiempos de crisis. Revesco: Revista de Estudios Cooperativos, (100), 43-67.

Méndez, C. (2006). Metodología diseño y desarrollo del proceso de investigación. Cuarta edición. Colombia. Editorial Limusa.

Mokate, K. \& Saavedra, J. (2008). Gerencia Social: Un enfoque integral para la gestión de políticas y programas. New York: Editorial instituto interamericano para el desarrollo social.

Novacovsky, I. (2003). Capital Social y Etica Aplicada en Proyectos de Desarrollo. En: CAF (2003). Capital Social: Clave para una agenda Integral de desarrollo. Caracas. 
Pallares, M. \& Casellas, A. (2006). Embodying New Economy in Urban Areas: The $22 @$ Barcelona Lab. Urban Studies (en pensa).

Praszkier, R. \& Nowak, A. (2012). La responsabilidad social en el ámbito de la crisis. Memoria académica, 10. Reflexiones, economía y empresa. Editor. Universidad Pontifica. ISBN: 8484685055

Reis, T. \& Clohesy, S. (2011). Unleashing new resources and entrepreneurship for the common good: philanthropic renaissance. New Directions for Philanthropic Fundraising, (32), 109-144.

Roberts, D. \& Woods, C. (2005). Changing the world on a shoestring: Theconcept of social entrepreneurship. University of Auckland Business Review, 7(1), 45-51.

Sabino, C. (2008). El proceso de investigación. Caracas: Editorial Panapo.

Seller, E.(2012). Iniciativa socialytrabajo socialcomunitario.Disponible en: https://rua.ua.es/dspace/bitstream/10045/5712/1/ ALT_09_09.pdf

Sen, A. (2000). Desarrollo y libertad. Primera reimpresión. México: Editorial Terra.

Shane, S. \& Venkataraman, S. (2000). The promise of entrepreneurship as a field of research. Academy of Management Review, 25, 217-226.

Silberstein, D. \& Galli Basualdo, M. (2016). ¿Cuál es el vínculo entre el emprendimiento social y el desarrollo sostenible, y cómo los emprendedores sociales contribuyen a la inclusión social y a la erradicación de la pobreza?. Revista Tecsistecatl, 20, Agosto de 2016. En línea: http://www.eumed.net/rev/ TECSISTECATL/n20/emprendimiento.htmlHandle: http://hdl. handle.net/20.500.11763/tecsistecatl-n20- emprendimiento

Silíceo, A., Casares, D. y González, J. (2000). Liderazgo, Valores y Cultura Organizacional. México. Editorial McGraw-Hill.

Silíceo, A. (2006). Capacitación y desarrollo del personal. Cuarta edición. México: Limusa.

Subirats, J., Knoepfel, P., Larrue, C., Varone, et al. (2008). Análisis y gestión de las políticas públicas. Barcelona: Ariel.

Tamayo \& Tamayo, M. (2010). El Proceso de la Investigación Científica. México D.F.: Editorial Limusa. 
Vásquez, A. G. \& Dávila, M. A. T. (2008). Emprendimiento social revisión de literatura. Estudios Gerenciales, 24(109), 105-125. Werther, W. y Davis, K. (2009). Administración de personal y Recursos Humanos. Sexta edición. México: Editorial McGraw-Hill Interamericana.

\section{BIBLIOGRAFÍA CONSULTADA}

American Economic Association (2017). Descriptores del tema Corredor, D. (2010). Hacia un modelo de emprendimiento universitario. Apuntes del CENES, 27(43), 275-292.

Guédez, V. (2010). Responsabilidad Social Empresarial. Visiones Complementarias hacia un modelo social. Venezuela: Edición especial 60 años de Venancham.

Leal, A. O., Pardo, M. L. M., Ruiz, J. O. \& Morales, F. E. (2016). Factores explicativos de competitividad empresarial. Capítulo 8, 115-130. Núñez Bravo, C. Miranda Medina, R. Prada Ospina, ... C. Osorio Torres, E. Olivero Vega, K. Barrios Hernández, \& J. C. Acosta-Prado (Comp.), Perspectivas Empresariales e Inclusivas del Emprendimiento (pp.145-172). Barranquilla: Ediciones Universidad Simón Bolívar. 


\section{ACERCA DE LOS AUTORES}

\section{ENOHEMIT OLIVERO VEGA}

eolivero@unisimonbolivar.edu.co

Máster en Administración de Empresas e Innovación de la Universidad Simón Bolívar (Colombia); Administradora de Empresas, Universidad Simón Bolívar; Profesora Investigadora adscrita a los grupos: Pensamiento contable y Gestión organizacional de la Universidad Simón Bolívar. Coordinadora Pedagógica del Programa Ondas Atlántico. Sus líneas de investigación se centran en: Capacidades Dinámicas, Emprendimiento e Innovación.

\section{KARELIS BARRIOS HERNÁNDEZ}

kbarrios22@unisimonbolivar.edu.co; karelisbarrios03@gmail.com

Máster en Administración de Empresas e Innovación de la Universidad Simón Bolívar (Colombia); Administradora de Empresas de la Universidad del Atlántico. Profesora Investigadora adscrita a los grupos Gestión de la Innovación y el Emprendimiento y Gestión Organizacional de la Universidad Simón Bolívar. Par académico del Ministerio de Educación Nacional. Sus líneas de investigación se centran en: Capacidades Dinámicas, Emprendimiento, Innovación y Gestión Universitaria.

\section{JULIO CÉSAR ACOSTA-PRADO}

jcap2000@hotmail.com

Post-Doctor en Administración de la Universidad de Sao Paulo; Doctor en Dirección y Organización de Empresas de la Univer- 
× sidad Autónoma de Madrid; Diploma de Estudios Avanzados en Dirección y Organización de Empresas de la Universidad Rey Juan Carlos de Madrid; Máster en Relaciones Internacionales y Comercio Exterior y Máster en Dirección de Recursos Humanos. Licenciado en Ciencias Políticas y de la Administración. Actualmente, Profesor Visitante de Posgrados, Investigador y Consultor Internacional de Empresas en Colombia, España y Brasil. Autor de un significativo número de artículos científicos y capítulos de libros. Evaluador y Miembro de Comités Científicos y Editoriales de Revistas Científicas Nacionales e Internacionales. Sus líneas de investigación se centran en: Gestión del Conocimiento, Capital Intelectual, Capacidades Dinámicas, Aprendizaje Organizacional, Emprendimiento, Gestión Tecnológica e Innovación. Profesor Invitado de la Maestría en Administración e Innovación, Universidad Simón Bolívar.

\section{NARLEDIS NÚÑEZ BRAVO}

nnunez3@unisimonbolivar.edu.co

Magíster en Desarrollo y Gestión de Empresas Sociales; Fisioterapeuta, Universidad Simón Bolívar.

\section{CARLOS MIRANDA MEDINA}

cmiranda@unisimonbolivar.edu.co

Estudiante doctorado en Métodos Alternos de Solución de conflíctos. Universidad Autonóma de Nuevo León, México. Psicólogo, de la Universidad Simón Bolívar.

\section{RICARDO PRADA OSPINA}

rpradao@universidadean.edu.co

PhD en Ciencias Empresariales y PhD en Gestión. Profesor Titular de la Universidad EAN. 


\section{DUVÁN EMILIO RAMÍREZ OSPINA}

merca2@umanizales.edu.co

PhD en Administración. Decano de la Facultad de Ciencias Contables, Económicas y Administrativas de la Universidad de Manizales. Profesor de Posgrados de la Universidad Simón Bolívar.

\section{JOSÉ MARÍA MENDOZA GUERRA}

jmendoza@unisimonbolivar.edu.co

Candidato a Doctor, Universidad Autónoma de Querétaro, México; Máster en Administración de Empresas, Universidad del Norte; Economista, Universidad de Antioquia. Jefe de Departamento de Administración y Contraloría, Universidad del Norte, Universidad Autónoma del Caribe; Rector de la Corporación Educativa del Litoral, Director de la Maestría de Administración de Empresas e Innovación, Profesor en pregrado o postgrado de las siguientes universidades, Universidad de Antioquia, del Norte, EAFIT, Nacional de Medellín, Autónoma de Bucaramanga, del Valle. Autónoma del Caribe, Tecnológica de Bolívar, y Simón Bolívar. Ha escrito los siguientes libros: Las funciones administrativas; Macroadministración: gerencia estratégica; La competitividad en las empresas de Barranquilla; Innovación por lo alto; Decisiones estratégicas y Mundo competitivo.

\section{RONALD PRIETO PULIDO}

rprieto1@unisimonbolivar.edu.co

Doctor en Cs Gerenciales. Magíster en Gerencia Empresarial. Economista. Editor de la Revista Desarrollo Gerencial. Decano Facultad de Administración y Negocios de la Universidad Simón Bolívar (Colombia); Posdoctor en Gerencia de las Organizaciones. Investigador adscrito al grupo de investigación Innovación y Emprendimiento Empresarial (GIDE). 


\section{CARLOS OSORIO TORRES \\ cosorio@unisimonbolivar.edu.co \\ Doctorante en Ciencias de la Educación, Trabajador Social Universidad Simón Bolívar, Especialista en Pedagogía para el Desarrollo del Aprendizaje Autónomo, Especialista en Salud Ocupacional, Magíster en Administración y Supervisión Educativa, Universidad Simón Bolívar.}

\section{LILIBETH SÁNCHEZ GÜETTE}

Isanchez26@unisimonbolivar.edu.co

Fisioterapeuta, Magíster en Desarrollo y Gestión de Empresas Sociales, Universidad Simón Bolívar.

\section{YARELIS LARA RODRÍGUEZ}

ylara@unisimonbolivar.edu.co

Profesional en Negocios y Finanzas Internacionales y Magíster en Administración de Empresas e Innovación, Universidad Simón Bolívar-Directora de Innovación y Emprendimiento de la Universidad Simon Bolivar, Barranquilla-Colombia.

\section{CARLA PALACIO OROZCO}

kpalacio@ unisimonbolivar.edu.co

Máster en Administración de Empresas e Innovación de la Universidad Simón Bolívar (Colombia); Administradora de Empresas, Universidad Simón Bolívar; Asdcrita al departamento de Autoevaluación Institucional de la Universidad Simón Bolívar.

\section{DONIPHANE MESLIER}

dmeslier@unisimonbolivar.edu.co

Magíster en Administración de Empresas y Administración de 
Mercadeo. Profesor de la Facultad de Administración y Negocios; Mentor y asesor en emprendimiento Macondo Lab. Universidad Simón Bolívar. Barranquilla- Colombia

\section{ANNHERYS PAZ MARCANO}

aipaz@uniguajira.edu.co.

Doctora en Ciencias Gerenciales. Docente investigadora Universidad de La Guajira, Universidad de La Guajira, Riohacha, Departamento de La Guajira, Colombia.

\section{VANESSA SOTELO BERRIO}

Fisioterapeuta, Magíster en Desarrollo y Gestión de Empresas Sociales, Universidad Simón Bolívar.

\section{FÉLIX FRANCO SEGOVIA}

Fjfs67@hotmail.com

Petróleos de Venezuela, S A.

Magíster en Gerencia Empresarial. Doctorante de Ciencias Gerenciales. Gerente de Recursos Humanos de la empresa mixta del sector petrolero Petrocabinas, Maracaibo, Venezuela. 
En las organizaciones, la dinámica del mundo actual implica promover el emprendimiento debido a la necesidad que presentan muchas personas por lograr una estabilidad e independencia económica que genere sus propios recursos. Desde

este enfoque, el emprendimiento se presenta como un concepto amplio,

transdisciplinar y experiencial, que se asocia a la cultura y se materializa en bienestar y desarrollo económico y social. Para conseguirlo, los emprendedores deben contar con habilidades y capacidades que les permitan detectar oportunidades en la constitución de empresas con potencial de crecimiento, en condiciones de rápido cambio e incertidumbre de la nueva economía.

A través de este libro se busca divulgar los resultados que comprenden una opción que aporta a la solución de los problemas de la sociedad, logrando balancear la inclusión de los sectores con riesgo de exclusión y generar la viabilidad económica para el desarrollo de las comunidades. Dichas investigaciones fueron realizadas por académicos e investigadores de la Universidad Simón Bolivar, Universidad Externado de Colombia, Universidad de La Guajira, Universidad de Manizales, Universidad EAN, y Universidad Autónoma de Nuevo León, México.

Este libro lo integran cinco capítulos en los que se destacan aspectos asociados al emprendimiento y el emprendedor como sujeto activo en la sociedad, en donde es fundamental la articulación de los diferentes actores que dinamizan y estimulan el espíritu emprendedor, diseñando estrategias o modelos que permiten adaptar el emprendimiento a las especificidades y características propias de cada país aprovechando el conocimiento y la experiencia de los actores involucrados sobre las realidades y vocaciones de los emprendedores y empresarios.

\section{Julio Gésar Agosta-Prado}

